\title{
SIMPLIFIED PROCEDURES FOR SEISMIC ANALYSIS AND DESIGN OF PIERS AND WHARVES IN MARINE OIL AND LNG TERMINALS
}

\author{
by \\ Rakesh K. Goel \\ California Polytechnic State University, San Luis Obispo
}

\author{
Research Conducted for the \\ California State Lands Commission \\ Contract No. C2005-051 \\ and \\ Department of the Navy, Office of Naval Research \\ Award No. N00014-08-1-1209
}
Department of Civil and Environmental Engineering California Polytechnic State University, San Luis Obispo, CA 93407 June 2010

Report No. CP/SEAM-08/01 


\section{EXECUTIVE SUMMARY}

This investigation developed simplified procedures for the seismic analysis and design of pile supported wharves and piers in Marine Oil and LNG Terminals. A simplified coefficient-based approach is proposed for estimating seismic displacement demand for regular structures. This approach is adopted from the performance-based analysis procedure recently approved for buildings in the ASCE/SEI 41-06 standard (ASCE, 2007). A modal pushover analysis (MPA) approach is proposed for irregular structures. The MPA procedure accounts for the higher-mode effects that are important in irregular structures (Chopra and Goel, 2004). The acceptability of piles in terms of displacement ductility limitation, instead of the material strain limitation, is proposed. For this purpose, simplified expressions for estimating displacement ductility capacity of piles are recommended. These expressions are calibrated such that the material strain limits in Title 24, California Code of Regulations, Chapter 31F, informally known as the Marine Oil Terminal Engineering and Maintenance Standards (MOTEMS), would not be exceeded if the displacement ductility demand is kept below the proposed displacement ductility capacity. These simplified procedures can be used as an alternative to the procedures currently specified in the MOTEMS. The simplified procedures can be used for preliminary design or as a quick check on the results from detailed nonlinear analyses. The more sophisticated analysis methodology can still be used for final design.

The following is a summary of the procedures to estimate displacement demands and capacities for pile-supported wharves and piers.

\section{DISPLACEMENT DEMAND}

\section{Regular Structures}

It is proposed that the seismic displacement demand in a regular structure (MOTEMS 2007) be estimated from

$$
\Delta_{d}=C_{1} C_{2} S_{A} \frac{T^{2}}{4 \pi^{2}}
$$

in which $S_{A}$ is the spectral acceleration of the linear-elastic system at vibration period, $T$. The coefficient $C_{1}$ is given by 


$$
C_{1}=\left\{\begin{array}{lr}
1.0 ; & T>1.0 \mathrm{~s} \\
1.0+\frac{R-1}{a T^{2}} ; & 0.2 \mathrm{~s}<T \leq 1.0 \mathrm{~s} \\
1.0+\frac{R-1}{0.04 a} ; & T \leq 0.2 \mathrm{~s}
\end{array}\right.
$$

in which $a$ is a site dependent constant equal to 130 for Site Class A and B, 90 for Site Class C, and 60 for Site Class D, E, and F (definition of Site Class is available in ASCE/SEI 41-06 standard), and $R$ is the ratio of the elastic and yield strength of the system and is defined as

$$
R=\frac{S_{A}}{g} \frac{W}{V_{y}}
$$

where $W$ is the seismic weight of the system, $V_{y}$ is the yield force (or base shear) of the system, and $g$ is the acceleration due to gravity. The coefficient $\mathrm{C}_{2}$ is given by

$$
C_{2}= \begin{cases}1.0 ; & T>0.7 \mathrm{~s} \\ 1+\frac{1}{800}\left(\frac{R-1}{T}\right)^{2} ; & T \leq 0.7 \mathrm{~s}\end{cases}
$$

Use of Equation (1) to compute the displacement demand should be restricted to systems with $R \leq R_{\max }$ where $R_{\max }$ is given by

$$
R_{\max }=\frac{\bar{\Delta}_{d}}{\Delta_{y}}+\frac{\left|\alpha_{e}\right|^{-t}}{4}
$$

in which $\bar{\Delta}_{d}$ is the smaller of the computed displacement demand, $\Delta_{d}$, from Equation (1) or the displacement corresponding to the maximum strength in the pushover curve, $\Delta_{y}$ is the yield displacement of the idealized bilinear force-deformation curve, $t$ is a constant computed from

$$
t=1+0.15 \ln (T)
$$

and $\alpha_{e}$ is the effective post-elastic stiffness ratio computed from

$$
\alpha_{e}=\alpha_{P-\Delta}+\lambda\left(\alpha_{2}-\alpha_{P-\Delta}\right)
$$

where $\lambda$ is a near-field effect factor equal to 0.8 for sites that are subjected to near-field effects 
and 0.2 for sites that are not subjected to near field effects. The near field effects may be considered to exist if the 1 second spectral value, $S_{1}$, at the site for the maximum considered earthquake is equal to or exceeds $0.6 \mathrm{~g}$. The P-Delta stiffness ratio, $\alpha_{P-\Delta}$, and the maximum negative post-elastic stiffness ratio, $\alpha_{2}$, in Equation (7) are estimated from the idealized forcedeformation curve.

\section{Irregular Structures}

A modal pushover analysis (MPA) procedure is proposed to estimate displacement demands in irregular Marine Oil and LNG Terminal structures (MOTEMS 2007). The following is a step-bystep summary of the MPA procedure:

1. Compute the natural frequencies, $\omega_{n}$ and modes, $\phi_{n}$, for linearly elastic vibration of the irregular Marine Oil and LNG Terminal structure.

2. Select a reference point where the displacement, $u_{r n}$, is to be monitored in the selected direction of analysis during the pushover analysis. Ideally, this reference point should be the location on the structure with largest value of $\phi_{r n}$ in the selected direction of analysis.

3. For the nth-mode, develop the pushover curve, $V_{b n}-u_{r n}$, for the nth modal force distribution, $s_{n}^{*}=\mathbf{M} \phi_{n}$, where $\mathbf{M}$ is the mass matrix of the structure, and $\phi_{n}$ is the nth mode shape. The base shear $V_{b n}$ should be monitored in the same direction as the direction of the selected reference point displacement $u_{r n}$.

4. Convert the $V_{b n}-u_{r n}$ pushover curve to the force-displacement, $F_{s n} / L_{n}-D_{n}$, relation for the nth -"mode" inelastic SDF system by utilizing $F_{s n} / L_{n}=V_{b n} / M_{n}^{*}$ and $D_{n}=u_{r n} / \Gamma_{n} \phi_{r n}$ in which $\phi_{r n}$ is the value of $\phi_{n}$ at the reference point in the direction under consideration, $M_{n}^{*}=\left(\phi_{n}^{T} \mathbf{M} \mathbf{\imath}\right)^{2} / \phi_{n}^{T} \mathbf{M} \phi_{n}$ is the effective modal mass, and $\Gamma_{n}=\phi_{n}^{T} \mathbf{M} \mathbf{\imath} / \phi_{n}^{T} \mathbf{M} \phi_{n}$ with $\mathbf{\imath}$ equal to the influence vector. The influence vector $\mathbf{l}$ is a vector of size equal to the total number of degrees of freedom. For analysis in the x-direction, the components of $\mathbf{l}$ corresponding to $\mathrm{X}$ degree-of-freedom are equal to one and remaining components equal to zero. Similarly the 
components of $\mathbf{l}$ corresponding to y-degree-of-freedom are equal to one and remaining components equal to zero for analysis in the y-direction.

5. Idealize the force-displacement, $F_{s n} / L_{n}-D_{n}$, curve as a bilinear curve and compute the yield value $F_{\text {sny }} / L_{n}$.

6. Compute the yield strength reduction factor, $R=S_{A} /\left(F_{\text {sny }} / L_{n}\right)$.

7. Compute the peak deformation $D_{n}=\Delta_{d}$ of the nth-"mode" inelastic SDF system defined by the force-deformation relation developed in Step 4 and damping ratio $\zeta_{n}$, from Equation (1). The elastic vibration period of the system is based on the effective slope of the $F_{s n} / L_{n}-D_{n}$ curve, which for a bilinear curve is given by $T_{n}=2 \pi\left(L_{n} D_{n y} / F_{s n y}\right)^{1 / 2}$.

8. Calculate peak reference point displacement $u_{r n}$ associated with the nth-"mode" inelastic SDF system from $u_{r n}=\Gamma_{n} \phi_{r n} D_{n}$.

9. Push the structure to the reference point displacement equal to $u_{r n}$ and note the values of desired displacement $\delta_{n o}$.

10. Repeat Steps 3 to 9 for all significant modes identified.

11. Combine the peak modal displacement, $\delta_{n o}$, by an appropriate modal combination rule, e.g., CQC, to obtain the peak dynamic response, $\Delta_{o}$.

\section{DISPLACEMENT CAPACITY}

It is proposed that the displacement capacity of piles in Marine Oil and LNG Terminals be estimated from

$$
\Delta_{c}=\mu_{\Delta} \Delta_{y}
$$

where $\Delta_{y}$ is the yield displacement of the pile and $\mu_{\Delta}$ is the displacement ductility capacity of the pile. Following are the recommendations that have been developed for the yield displacement and displacement ductility of piles commonly used in Marine Oil and LNG Terminals. These recommendations have been developed to ensure that the material strains in the pile at its 
displacement capacity remain within the limits specified in the MOTEMS (2007).

The procedure to estimate the displacement capacity is intended to be a simplified procedure for either initial design of piles or for checking results from more complex nonlinear finite element analysis. The recommendations presented in this report are limited to: (1) piles with long freestanding heights (length/diameter $>20$ ) above the mud line; (2) piles with transverse volumetric ratio greater than $0.5 \%$; and (3) piles in which the displacement demand has been estimated utilizing equivalent-fixity approximation. Results from this investigation should be used with caution for parameters or cases outside of those described above.

\section{Piles with Full-Moment- or Pin-Connection to the Deck Slab}

The recommended values of displacement ductility capacity of piles with full-momentconnection or pin-connection to the deck slab are

\begin{tabular}{|c|c|c|c|}
\hline $\begin{array}{c}\text { Design Earthquake } \\
\text { Level }\end{array}$ & Hinge Location & $\begin{array}{c}\text { Reinforced- } \\
\text { Concrete Piles }\end{array}$ & $\begin{array}{c}\text { Hollow-Steel } \\
\text { Piles }\end{array}$ \\
\hline \multirow{2}{*}{ Level 1 } & In-Ground & 1.75 & 1.2 \\
\cline { 2 - 4 } & Pile-Deck & 1.75 & 1.2 \\
\hline \multirow{2}{*}{ Level 2 } & In-Ground & 2.5 & 2.75 \\
\cline { 2 - 4 } & Pile-Deck & 5.0 & 2.75 \\
\hline
\end{tabular}

The yield displacement of the pile may be estimated either from idealized pushover curve developed from the nonlinear static pushover analysis or may be estimated from

$$
\Delta_{y}=\left\{\begin{array}{l}
\frac{M_{y} L^{2}}{6 E I_{e}} \text { for full-moment-connection } \\
\frac{M_{y} L^{2}}{3 E I_{e}} \text { for pin-connection }
\end{array}\right.
$$

in which $M_{y}$ is the section yield moment and $E I_{e}$ is the effective value of $E I$ that can be estimated from the section moment-curvature analysis. Note that $M_{y}$ is not the section moment at first-yield but the effective yield moment estimated from bilinear idealization of the momentcurvature relationship. 


\section{Piles with Dowel-Connection to the Deck Slab}

Simplified formulas are proposed for estimating displacement ductility capacity of piles with dowel-connection, such as hollow-steel piles or prestressed concrete piles connected to the deck slab with dowels. The following is a step-by-step summary of the procedure to implement these formulas to estimate displacement capacity of such piles:

1. Establish the axial load, $P$, on the pile.

2. Estimate the pile length based on equivalent-fixity assumption.

3. Select an appropriate design level - Level 1 or Level 2 - and establish various strain limits for the selected design level.

4. Develop the moment-rotation relationship of the dowel-connection using the procedure described in Chapter 8 of this report.

5. Determine rotational stiffness, $k_{\theta}$, yield moment, $M_{y, \mathrm{C}}$, and yield rotation, $\theta_{y, \mathrm{C}}$ of the dowel-connection from the moment-rotation relationship developed in Step 4.

6. Establish the rotation of the dowel-connection, $\theta_{L}$, and corresponding ductility, $\mu_{\theta}=\theta_{L} / \theta_{y, \mathrm{C}}$, when strain in the outer-most dowel of the connection reaches the strain limit established in Step 3 for the selected design level.

7. Conduct the moment-curvature analysis of the pile section with appropriate axial load and idealize the moment-curvature relationship by a bi-linear curve.

8. Compute the effective, $E I_{e}$, and effective yield moment, $M_{\mathrm{y}, \mathrm{P}}$, from the pile momentcurvature relationship. Note that $E I_{e}$ is equal to initial elastic slope and $M_{\mathrm{y}, \mathrm{P}}$ is the yield value of the moment of the idealized bi-linear moment-curvature relationship. For steel piles, $E I_{e}$ may be computed from section properties and material modulus, and $M_{\mathrm{y}, \mathrm{P}}$ may be approximated as $M_{\mathrm{y}, \mathrm{P}} \simeq f_{y}\left(d_{o}^{3}-d_{i}^{3}\right) / 6$.

9. Estimate the yield curvature, $\phi_{y, \mathrm{P}}=M_{y, \mathrm{P}} / \mathrm{EI}_{\mathrm{e}}$. 
10. Establish the curvature of the steel pile, $\phi_{L}$, and corresponding curvature ductility, $\mu_{\phi}=\phi_{L} / \phi_{y, \mathrm{P}}$, when material strain in the pile section reaches the strain limit established in Step 3 for the selected design level.

11. Select the value of $\rho$ which defines the length of the plastic hinge as a fraction of the "effective" length of the pile. The recommended value for hollow-steel piles with dowelconnection is $\rho=0.03$ for Level 1 design and $\rho=0.075$ for Level 2; and for prestressed concrete pile with dowel-connection for both design levels is $\rho=0.05$.

12. Compute the dimensionless parameters: $\eta=M_{y, \mathrm{P}} / M_{y, \mathrm{C}}$, and $\beta=E I_{e} / k_{\theta} L$.

13. Compute the normalized value of the plastic hinge length: $L_{P}^{*}=(\rho \eta) /(1+\eta)$.

14. Compute the yield displacement which corresponds to first effective yielding in the connection as: $\Delta_{y, \mathrm{C}}=\theta_{y, \mathrm{C}} L(1+4 \beta) / 6 \beta$

15. Compute the displacement ductility for yielding in the connection as $\mu_{\Delta}=\left(1+4 \beta \mu_{\theta}\right) /(1+4 \beta)$ if $\mu_{\theta}$ computed in Step 6 is less than or equal to $(\eta-1) / 2 \beta$ otherwise $\mu_{\Delta}=\left(2-\eta+6 \beta \mu_{\theta}\right) /(1+4 \beta)$.

16. Compute displacement ductility for yielding in the pile as $\mu_{\Delta}=(2 \eta-1) /(1+4 \beta)+\left(6 \eta L_{p}^{*}\right)\left(1-L_{p}^{*} / 2\right)\left(\mu_{\phi}-1\right) /(1+4 \beta)$

17. Establish the displacement ductility capacity as lower of the values computed in Steps 15 and 16.

18. Compute the displacement capacity of the pile as product of the yield displacement computed in Step14 and the displacement ductility capacity computed in Step 17.

The recommended value of displacement ductility for piles with full-moment-connection or the simplified formulas for piles with dowel-connection have been shown to provide results that are "accurate" enough for most practical applications. However, it may be useful to verify these recommendations from experimental studies. 


\section{ACKNOWLEDGMENTS}

This research investigation is supported by the California State Lands Commission (CSLC) under Contract No. C2005-051 for Development of LNGTEMS/MOTEMS Performance-Based Seismic Criteria. This support is gratefully acknowledged. The author would especially like to thank Martin Eskijian, CSLC Project Manager and Hosny Hakim of the CSLC for their continuing support. The author would also like to acknowledge advice from following individuals: Gayle Johnson and Bill Bruin of Halcrow; Bob Harn of Berger/ABAM Engineers Inc.; Dr. Omar Jeradat of Moffatt \& Nichol; Peter Yin of Port of Los Angeles; Eduardo Miranda of Stanford University; and Dr. Hassan Sedarat and Tom Ballard of SC Solutions Inc. Finally, the author would like to acknowledge the editorial support provided by John Freckman of the CSLC. Additional support for this research is provided by a grant entitled "C3RP Building Relationships 2008/2010" from the Department of the Navy, Office of Naval Research under award No. N00014-08-1-1209. This support is also acknowledged. 


\section{CONTENTS}

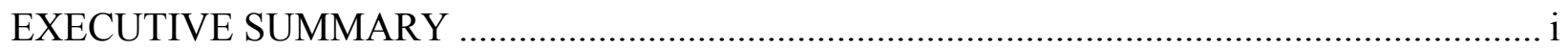

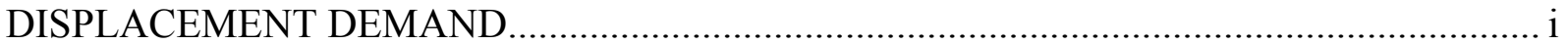

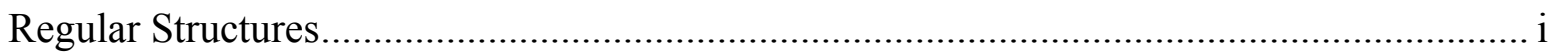

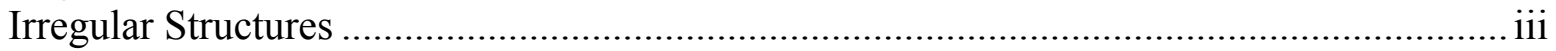

DISPLACEMENT CAPACITY ………………………................................................. iv

Piles with Full-Moment- or Pin-Connection to the Deck Slab .............................................. v

Piles with Dowel-Connection to the Deck Slab..................................................................... vi

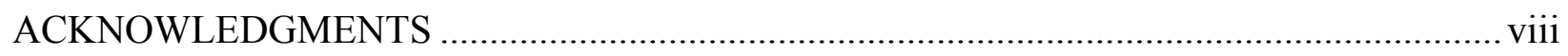

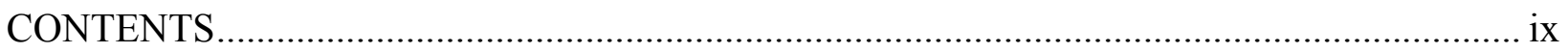

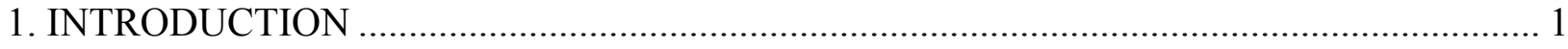

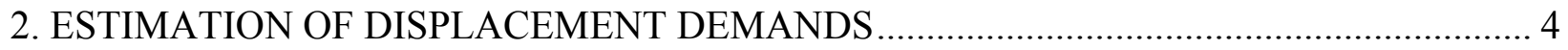

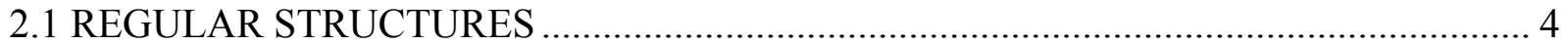

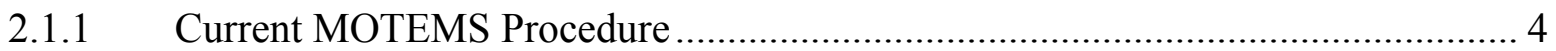

2.1.2 Procedures to Compute Response of Single-Degree-of-Freedom (SDF) Systems ........ 5

2.1.3 Proposed Alternate Displacement Demand Procedure for Regular Structures ............. 9

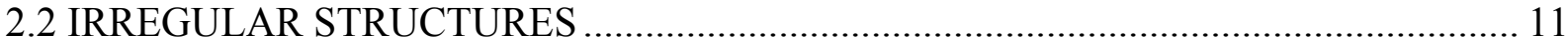

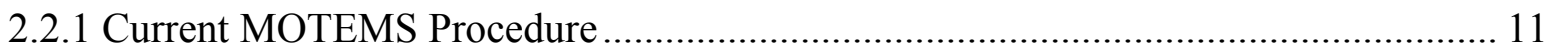

2.2.2 Proposed Nonlinear Static Procedure for Irregular Structures ................................ 12

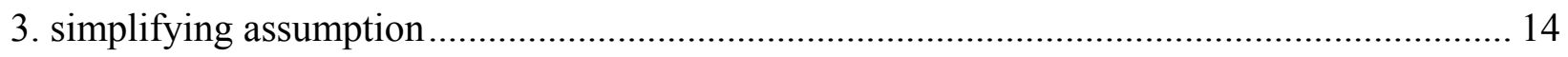

4. MOTEMS PROCEDURE FOR CAPACITY EVALUATION OF PILES …………................ 17

5. SIMPLIFIED PROCEDURE TO COMPUTE PILE DISPLACEMENT CAPACITY ............ 21

6. DISPLACEMENT CAPACITY OF REINFORCED CONCRETE PILES ……………............ 23

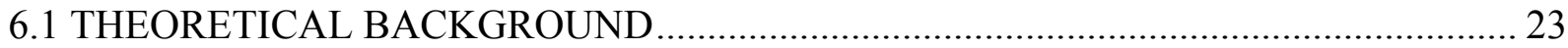

6.2 EVALUATION OF SIMPLIFIED EQUATIONS FOR DUCTILITY CAPACITY ......... 24

6.3 SENSITIVITY OF DISPLACEMENT DUCTILITY TO PILE PARAMETERS .............. 26

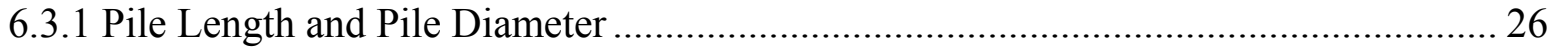

6.3.2 Longitudinal and Transverse Reinforcement Ratio ................................................... 28

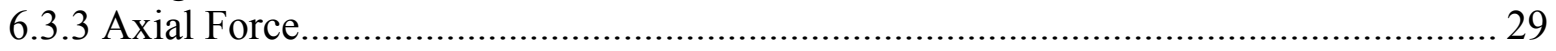

6.4 LOWER BOUND OF DISPLACEMENT DUCTILITY CAPACITY …………............. 29

6.5 SIMPLIFIED PROCEDURE TO COMPUTE DISPLACEMENT CAPACITY ................. 31

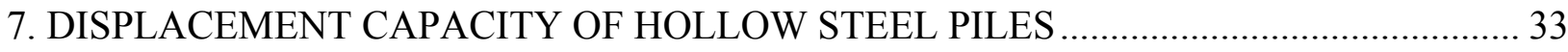

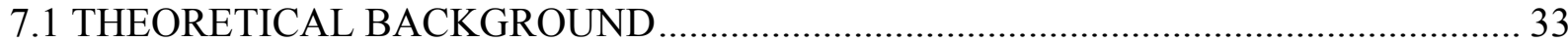

7.2 EVALUATION OF SIMPLIFIED EQUATIONS FOR DUCTILITY CAPACITY ..........33

7.3 SENSITIVITY OF DISPLACEMENT DUCTILITY TO PILE PARAMETERS ............... 36

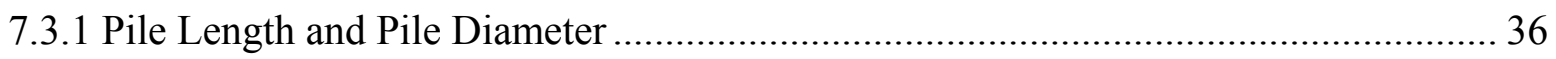

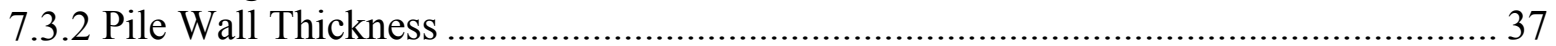

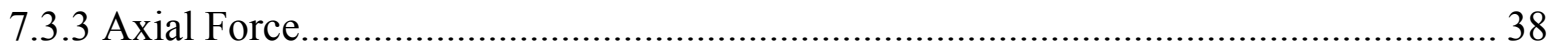

7.4 LOWER BOUND OF DISPLACEMENT DUCTILITY CAPACITY ………….............. 39

7.5 SIMPLIFIED PROCEDURE TO COMPUTE DISPLACEMENT CAPACITY ................ 39

8. DISPLACEMENT CAPACITY OF PILES WITH DOWEL-CONNECTION ........................ 42 


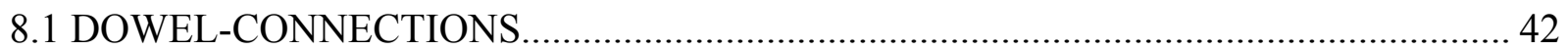

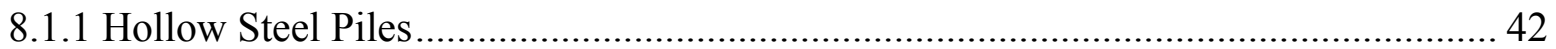

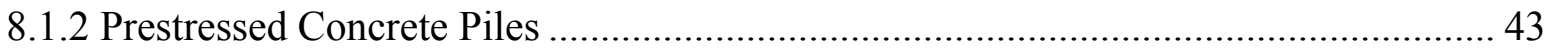

8.1.3 Behavior of Dowel-Connection ................................................................................. 44

8.2 MOMENT-ROTATION RELATIONSHIP OF DOWEL-CONNECTION ........................ 44

9. SIMPLIFIED MODEL OF PILE WITH DOWEL-CONNECTION........................................ 49

9.1 IDEALIZED CONNECTION AND PILE BEHAVIOR.................................................. 49

9.1.1 Moment-Rotation Behavior of Connection ............................................................ 49

9.1.2 Moment-Curvature Behavior of Pile Section ............................................................ 50

9.1.3 Force-Deformation Relationship of Pile with Dowel-Connection ............................... 51

9.2 FORCE-DEFORMATION RESPONSE OF PILE WITH DOWEL-CONNECTION ...... 52

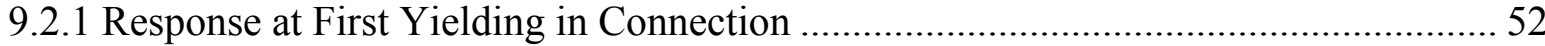

9.2.2 Response at First Yielding in Pile........................................................................... 54

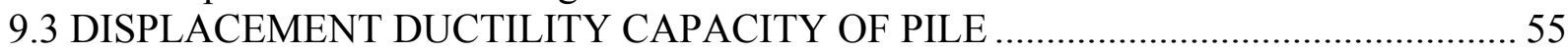

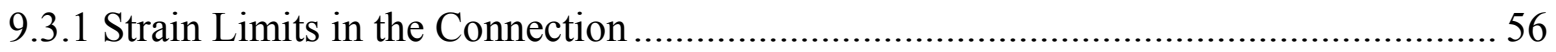

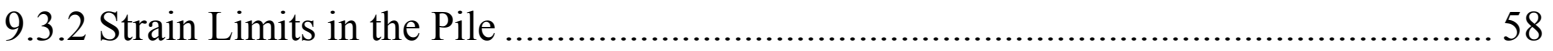

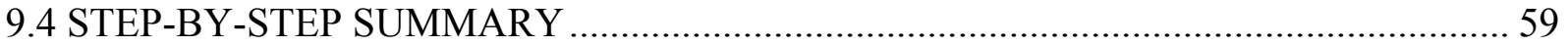

10. DUCTILITY CAPACITY OF HOLLOW STEEL PILES WITH DOWEL-CONNECTION62

11. DUCTILITY CAPACITY OF PRESTRESSED CONCRETE PILES WITH DOWEL-

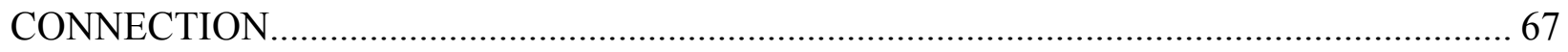

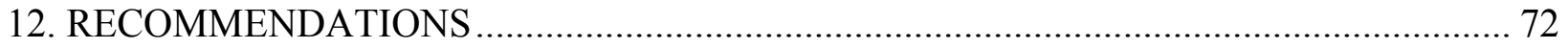

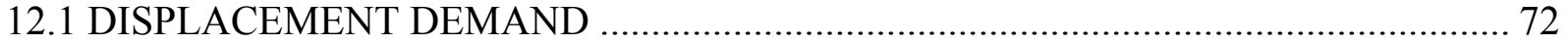

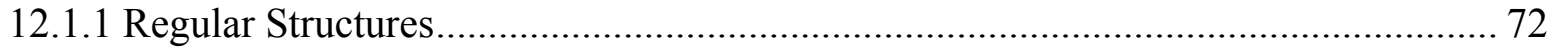

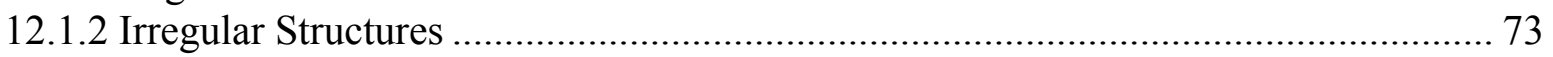

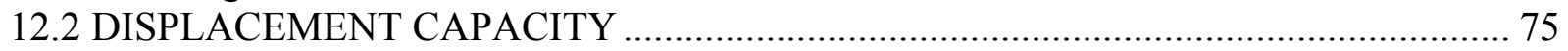

12.2.1 Piles with Full-Moment- or Pin-Connection to the Deck Slab ................................... 75

12.2.2 Piles with Dowel-Connection to the Deck Slab......................................................... 76

12.3 RECOMMENDATIONS FOR FUTURE WORK ………............................................. 78

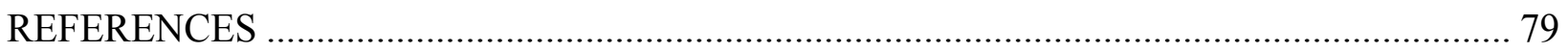




\section{INTRODUCTION}

Seismic design of marine oil terminals in California is governed by 2007 Title 24 California Code of Regulations (CCR), Part 2, California Building Code, Chapter 31F (Marine Oil Terminals). These regulations are commonly known as the "Marine Oil Terminal Engineering and Maintenance Standard" (MOTEMS). The MOTEMS describe the acceptable methods of seismic analysis and provide the specific performance criteria for two levels of earthquake motions to be used in the seismic assessment. The return period of the design earthquake for each level depends on the risk level, which is a function of the oil susceptible to spillage at any given time. For example, Level 1 and Level 2 design earthquakes for high risk terminals correspond to return periods of 72 and 475 years, respectively. The performance goal for Level 1 earthquake is no or minor damage without interruption in service or with minor temporary interruption in service. The performance goal for Level 2 earthquake is controlled inelastic behavior with repairable damage resulting in temporary closure of service, restorable within months and the prevention of a major oil spill (24 CCR 3104F.2.1). This is the formal short form of the above cited regulation and specifies a particular section (24 CCR 3104F.2.1) of the California Code of Regulations. It will be used throughout this document along with the informal "MOTEMS" abbreviation.

The MOTEMS is currently being used for new construction in the Ports of Los Angeles and Long Beach. In addition, the MOTEMS has been referenced in the FEMA 450 document (BSSC, 2003). The MOTEMS has also become the approved methodology for the seismic assessment of US military wharf/pier facilities in high seismic areas (Department of Defense, 2005).

As with marine oil terminals, LNG receiving terminals are considered liquid hydrocarbons reception terminals by the California State Lands Commission (CSLC), and as such fall under the Lempert-Keen-Seastrand Oil Spill and Response Act of 1990. The "Act" states that the "commission (CSLC) shall adopt rules, regulations, guidelines..., performance standards... for all existing and proposed marine terminals within the state...". It is through this "Act" that the CSLC is developing standards for LNG terminals, and in this case mutually applicable to oil terminals. The effort described in this report is through funding obtained by the CSLC for development of standards for LNG terminals. 
The MOTEMS seismic analysis requires that the seismic displacement demand in marine oil terminal structures be determined using nonlinear static procedures except for irregular structures (24 CCR 3104F.1.4) with high or moderate seismic risk classification (see 24 CCR 3104F2.3.2 ). A linear modal procedure is required for irregular structures with high or moderate seismic risk classification. The analysis method specified in the MOTEMS is based on the concept of equivalent linearization presented by Priestley et al. (1996). The seismic design (or acceptability criteria) involves making sure that the material strains at the seismic displacement demand not exceed certain prescribed values.

The primary objective of this investigation is to develop simplified analysis and design procedures for pile supported wharves and piers for Marine Oil and LNG Terminals. For this purpose, a simplified coefficient-based approach is proposed for estimating seismic displacement demand for regular structures. This approach is adopted from the performance-based analysis procedure recently approved for buildings in the ASCE/SEI 41-06 standard (ASCE, 2007). A modal pushover analysis (MPA) approach is proposed for irregular structures. The MPA procedure accounts for the higher-mode effects that are important in irregular structures (Chopra and Goel, 2004). The acceptability of piles in terms of displacement ductility limitation, instead of the material strain limitations, is proposed. For this purpose, simplified expressions for estimating displacement ductility capacity of piles are recommended. These expressions are calibrated such that the material strain limits in the MOTEMS would not be exceeded if the displacement ductility demand is kept below the proposed displacement ductility capacity. These simplified procedures can be used as an alternative to the procedures currently specified in the MOTEMS.

This report is organized as follows:

Chapter 2 presents the development of a simplified procedure for estimating seismic displacement demand in regular and irregular structures.

Chapter 3 describes the equivalent fixity model utilized in developing the simplified seismic acceptability criteria.

Chapter 4 summarizes the approach in the current MOTEMS for seismic evaluation of piles. 
Chapter 5 presents the proposed approach to estimate the displacement ductility capacity of piles.

Chapters 6 and 7 present development and evaluation of simplified expressions for the displacement ductility capacity of reinforced concrete and hollow steel piles, respectively, with full-moment connection to the concrete deck.

Chapter 8 discusses the behavior of partial-moment connections of hollow steel and prestressed concrete piles to the concrete deck.

Chapter 9 presents the theoretical development of simplified expressions for estimating displacement ductility demands in piles with partial-moment connections.

Chapters 10 and 11 evaluate these simplified expressions for hollow steel and prestressed concrete piles, respectively. 


\section{ESTIMATION OF DISPLACEMENT DEMANDS}

The MOTEMS requires that the seismic displacement demand in marine oil terminal structures be determined using nonlinear static procedures except for irregular structures with high or moderate seismic risk classification (MOTEMS, 2007: Section 3104F2.3.2). A linear modal procedure is required for irregular structures with high or moderate seismic risk classification.

\subsection{REGULAR STRUCTURES}

\subsubsection{Current MOTEMS Procedure}

The MOTEMS (2007) specifies that the displacement demand, $\Delta_{d}$, be computed from

$$
\Delta_{d}=S_{A} \frac{T^{2}}{4 \pi^{2}}
$$

in which $S_{A}$ is the spectral response acceleration corresponding to the vibration period $T$ of the structure, with a $5 \%$ damping ratio. The spectral acceleration, $S_{A}$, is computed from United States Geological Survey (USGS) maps, or from site-specific probabilistic seismic hazard analysis (PSHA).

Equation (2.1) assumes that the deformation demand in a system that is deformed beyond the linear elastic limit is equal to that in a linear-elastic system. It is well known that for short period systems, this equal displacement rule may not apply; deformation of a nonlinear system may be larger than that of a linear system. For such systems, nonlinearity in the forcedeformation relationship must be considered to compute the displacement demand.

Therefore, the MOTEMS requires that a refined analysis be used to calculate the displacement demand if the vibration period of the structure $T$ is less than period $T_{o}$ which corresponds to the period at which constant acceleration and constant velocity regions of the design spectrum intersect. The refined analysis (MOTEMS, 2007: Section 3104F.2.3.2.5) utilizes the nonlinear force-deformation behavior of the structure developed from nonlinear static pushover analysis and is based on the concept of equivalent linearization presented by Priestley et al. (1996). 


\subsubsection{Procedures to Compute Response of Single-Degree-of-Freedom (SDF) Systems}

An alternative approach to the equivalent linearization method is the coefficient method in which the deformation of the inelastic SDF system is computed by multiplying the displacement of the elastic SDF system by a coefficient as follows:

$$
\Delta_{i}=C_{R} \Delta_{e}
$$

where $\Delta_{e}$ is the deformation of the elastic SDF system, $\Delta_{i}$ is the deformation of the inelastic SDF system, and $C_{R}$ is the coefficient that converts displacement of the elastic SDF system to displacement of the inelastic SDF system. Several alternative definitions of the coefficient $C_{R}$ are available. The following is a brief review of the ones which are commonly used.

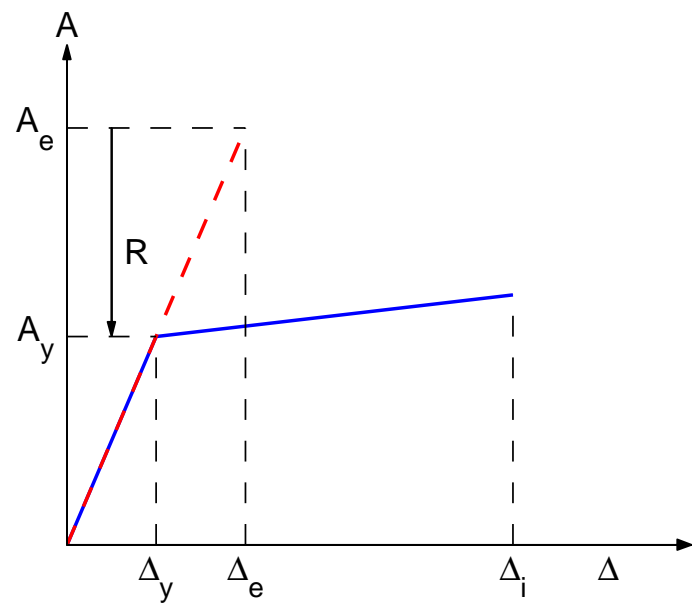

Figure 2.1. Force-deformation properties of an inelastic and elastic SDF system.

Figure 2.1 shows a nonlinear inelastic SDF system with a bilinear force-deformation relationship. The yield strength (or capacity) of the system is $V_{y}$ and its yield displacement is $\Delta_{y}$. The yield strength $V_{y}$ is related to the pseudo-acceleration (or spectral acceleration) at yield level, $A_{y}$, and the seismic weight, $W$, as $V_{y}=A_{y} W$. If the system were to remain elastic, the design force would be $V_{e}=A_{e} W$ with $A_{e}$ being the spectral acceleration of the elastic SDF system. The yield strength reduction factor, $R$, is defined as the ratio of the elastic level force and the yield strength of the inelastic SDF system. Thus $R$ is given as

$$
R=\frac{V_{e}}{V_{y}}=\frac{A_{e}}{A_{y}}
$$


Note that the yield strength reduction factor, $R$, differs from the response modification coefficient, $R$, generally used in the force-based design procedures of building [for example see ASCE/SEI 7-05 (ASCE, 2005)]: the yield strength reduction factor in Equation (2.3) considers the effects of system ductility alone whereas the response modification factor in force-based design accounts for other factors, such as type and past performance of lateral load resisting systems, over strength, etc., in addition to the system ductility.

The coefficient $C_{R}$ is generally defined as a function of vibration period, $T$, yield reduction factor, $R$, and a few other factors. Nassar and Krawinkler (1991) defined $C_{R}$ as

$$
C_{R}=\frac{1}{R}\left[1+\frac{1}{C}\left(R^{c}-1\right)\right]
$$

where the constant $c$ is defined by

$$
c=\frac{T^{a}}{1+T^{a}}+\frac{b}{T}
$$

with constants $a=1$ and $b=0.42$ for $\alpha=0 \%, a=1$ and $b=0.37$ for $\alpha=2 \%$, and $a=0.8$ and $b=0.29$ for $\alpha=10 \%$. The parameter $\alpha$ is defined as the ratio of the post-yield stiffness and initial elastic stiffness expressed as a percentage value. Ruiz-Garcia and Miranda (2003) defined the $C_{R}$ as

$$
C_{R}=1+\left[\frac{1}{a\left(T / T_{s}\right)^{b}}+\frac{1}{C}\right](R-1)
$$

with $T_{s}$ being the site characteristic period selected as 0.75 for site $\mathrm{B}, 0.85$ for site $\mathrm{C}$, and 1.05 for site D; and constants $a=50, b=1.8$, and $c=55$. Chopra and Chintanapakdee (2004) defined $C_{R}$ as

$$
C_{R}=1+\left[\left(L_{R}-1\right)^{-1}+\left(\frac{a}{R^{b}}+c\right)\left(\frac{T}{T_{s}}\right)^{d}\right]^{-1}
$$

in which

$$
L_{R}=\frac{1}{R}\left(1+\frac{R-1}{\alpha}\right)
$$


$T_{s}$ is the period corresponding to the transition between constant pseudo-acceleration and constant pseudo-velocity regions of the design spectrum, $a=61, b=2.4, c=1.5$, and $d=2.4$.

The $C_{R}$ is also defined in several building design guidelines. For example, FEMA-356 (ASCE, 2000), defines $C_{R}$ as

$$
C_{R}=C_{1} C_{2} C_{3}
$$

where $C_{1}$ is the modification factor to relate a maximum displacement of nonlinear elasticperfectly-plastic SDF system to displacement of elastic SDF system given by

$$
C_{1}=\left\{\begin{array}{lr}
1.0 ; & \text { for } T \geq T_{s} \\
\frac{1}{R}+\left(1-\frac{1}{R}\right)\left(\frac{T_{s}}{T}\right) \leq 1.5 ; & \text { for } T<T_{s}
\end{array}\right.
$$

$C_{2}$ is the modification factor to represent effects of pinched hysteretic shape, stiffness degradation, and strength deterioration (Table 2.1), and $C_{3}$ is the modification factor to represent P-Delta effects given by

$$
C_{3}=1+\frac{|\alpha|(R-1)^{3 / 2}}{T}
$$

Table 2.1. Values of modification factor $C_{2}$ in FEMA-356 (ASCE 2000).

\begin{tabular}{|l|c|c|c|c|}
\hline \multirow{2}{*}{$\begin{array}{c}\text { Structural } \\
\text { Performance Level }\end{array}$} & \multicolumn{2}{c|}{$T \leq 0.1 \mathrm{~s}$} & \multicolumn{2}{c|}{$T \geq T_{s}$} \\
\cline { 2 - 5 } & $\begin{array}{c}\text { Framing } \\
\text { Type 1 }\end{array}$ & $\begin{array}{c}\text { Framing } \\
\text { Type 2 }\end{array}$ & $\begin{array}{c}\text { Framing } \\
\text { Type 1 }\end{array}$ & $\begin{array}{c}\text { Framing } \\
\text { Type 2 }\end{array}$ \\
\hline Immediate Occupancy & 1.0 & 1.0 & 1.0 & 1.0 \\
\hline Life safety & 1.3 & 1.0 & 1.1 & 1.0 \\
\hline Collapse Prevention & 1.5 & 1.0 & 1.2 & 1.0 \\
\hline
\end{tabular}

The coefficients in FEMA-356 were re-examined and an improved version was proposed in FEMA-440 (ATC, 2005). This proposal has also been adopted in ASCE/SEI 41-06 standard (ASCE, 2007). The $C_{R}$ in FEMA-440 and ASCE/SEI 41-06 is defined as

$$
C_{R}=C_{1} C_{2}
$$

where $C_{1}$ is the modification factor to relate maximum displacement of a nonlinear elasticperfectly-plastic SDF system to displacement of an elastic SDF system defined by 


$$
C_{1}=\left\{\begin{array}{lr}
1.0 ; & T>1.0 \mathrm{~s} \\
1.0+\frac{R-1}{a T^{2}} ; & 0.2 \mathrm{~s}<T \leq 1.0 \mathrm{~s} \\
1.0+\frac{R-1}{0.04 a} ; & T \leq 0.2 \mathrm{~s}
\end{array}\right.
$$

with $a=130$ for Site Class B, 90 for Site Class C, and 60 for Site Class D. and $C_{2}$ is the modification factor to represent effects of cyclic degradation in stiffness and strength given by

$$
C_{2}= \begin{cases}1.0 ; & T>0.7 \mathrm{~s} \\ 1+\frac{1}{800}\left(\frac{R-1}{T}\right)^{2} ; & T \leq 0.7 \mathrm{~s}\end{cases}
$$

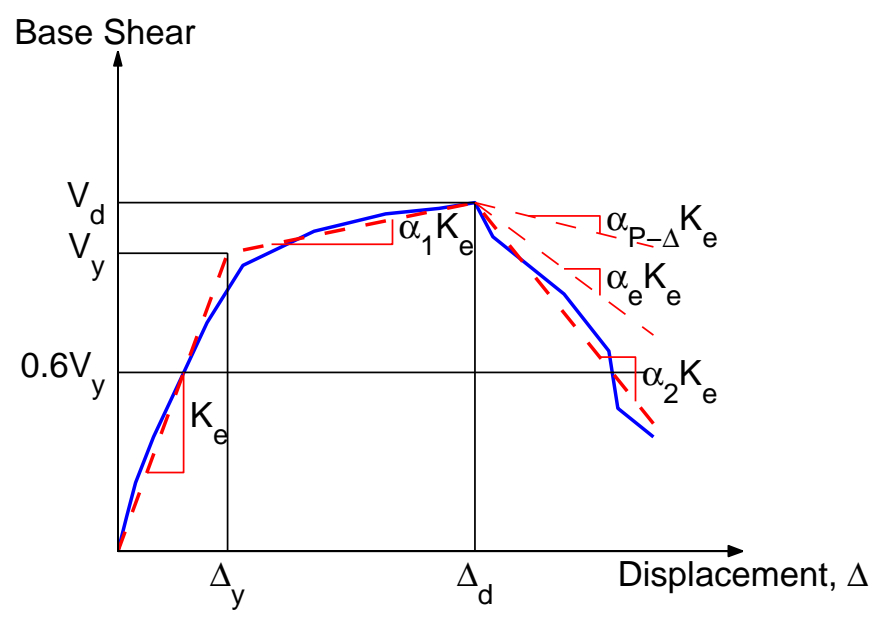

Figure 2.2. Idealized force-deformation curve for nonlinear static analysis.

The provisions of FEMA-440 and ASCE/SEI 41-06 can be used provided that $R$ does not exceed the limiting value given by

$$
R_{\max }=\frac{\Delta_{d}}{\Delta_{y}}+\frac{\left|\alpha_{e}\right|^{-h}}{4} ; \quad h=1.0+0.15 \ln (T)
$$

in which $\Delta_{d}$ is the deformation corresponding to peak strength, $\Delta_{y}$ is the yield deformation, and $\alpha_{e}$ is the effective negative post-yield slope given by

$$
\alpha_{e}=\alpha_{P-\Delta}+\lambda\left(\alpha_{2}-\alpha_{P-\Delta}\right)
$$

where $\alpha_{2}$ is the negative post-yield slope ratio defined in Figure 2.2, $\alpha_{P-\Delta}$ is the negative slope 
ratio caused by $P-\Delta$ effects, and $\lambda$ is the near-field effect factor given as 0.8 for $S_{1} \geq 0.6$ and 0.2 for $S_{1}<0.6 \quad\left(S_{1}\right.$ is defined as the 1-second spectral acceleration for the Maximum Considered Earthquake). The $\alpha_{2}$ slope includes $P-\Delta$ effects, in-cycle degradation, and cyclic degradation.

Finally, FEMA-450 (BSSC, 2003) defines $C_{R}$ as

$$
C_{R}=\left\{\begin{array}{c}
1.0 ; \text { for } T>T_{s} \\
\frac{1}{R}\left[1+\frac{(R-1) T_{s}}{T}\right] ; \text { for } T \leq T_{s}
\end{array}\right.
$$

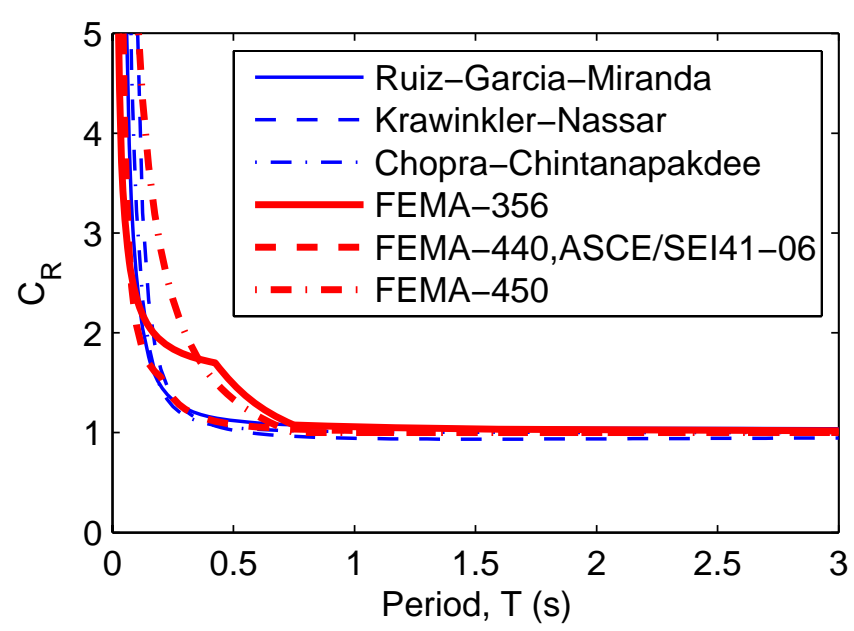

Figure 2.3. Comparison of $C_{R}$ from various recommendations. Results are for $R=3$ and site class B.

Figure 2.3 compares the $C_{R}$ values from the aforementioned recommendations. This comparison indicates that all recommendations lead to essentially identical values of $C_{R}$ for periods longer than $1 \mathrm{sec}$. The values due to FEMA-356 and FEMA-450 differ significantly from those due to the remaining recommendations primarily for periods shorter than $0.5 \mathrm{sec}$.

\subsubsection{Proposed Alternate Displacement Demand Procedure for Regular Structures}

Presented here is an alternative procedure for estimating the seismic displacement demand of regular structures with period $T$ less than period $T_{o}$ that can be idealized as a single-degree-offreedom (SDF) system. This procedure utilizes the nonlinear force-deformation behavior of the structure developed from nonlinear static pushover analysis. The computation of the 
displacement demand is adopted from the procedure recommended in the FEMA-440 document (ATC, 2005) and ASCE/SEI 41-06 standard (ASCE 2007). Although this procedure has been described previously in Section 2.1.2, it is re-organized here to be compatible with the current MOTEMS procedure. The proposed alternative procedure involves estimating the displacement demand in a nonlinear SDF system from

$$
\Delta_{d}=C_{1} C_{2} S_{A} \frac{T^{2}}{4 \pi^{2}}
$$

in which $C_{1}$ and $C_{2}$ are the coefficients that convert displacement demand of a linear-elastic SDF system to displacement demand of nonlinear SDF system.

The coefficient $C_{1}$ is given by

$$
C_{1}=\left\{\begin{array}{lr}
1.0 ; & T>1.0 \mathrm{~s} \\
1.0+\frac{R-1}{a T^{2}} ; & 0.2 \mathrm{~s}<T \leq 1.0 \mathrm{~s} \\
1.0+\frac{R-1}{0.04 a} ; & T \leq 0.2 \mathrm{~s}
\end{array}\right.
$$

in which $a$ is a site dependent constant equal to 130 for Site Class A and B, 90 for Site Class C, and 60 for Site Class D, E, and F; and $R$ is the ratio of the elastic to the yield strength of the system and is defined as

$$
R=\frac{S_{A}}{g} \frac{W}{V_{y}}
$$

in which $S_{A}$ is the spectral acceleration used in Equation (2.1), $W$ is the seismic weight of the system, $V_{y}$ is the yield force (or base shear) of the system, and $g$ is the acceleration due to gravity. The coefficient $\mathrm{C}_{2}$ is given by

$$
C_{2}= \begin{cases}1.0 ; & T>0.7 \mathrm{~s} \\ 1+\frac{1}{800}\left(\frac{R-1}{T}\right)^{2} ; & T \leq 0.7 \mathrm{~s}\end{cases}
$$

Equation (2.19) can be used to compute the displacement demand for systems in which $R \leq R_{\max }$ where $R_{\max }$ is given by 


$$
R_{\max }=\frac{\bar{\Delta}_{d}}{\Delta_{y}}+\frac{\left|\alpha_{e}\right|^{-t}}{4}
$$

in which $\bar{\Delta}_{d}$ is smaller than the computed displacement demand, $\Delta_{d}$, from Equation (2.19) or the displacement corresponding to the maximum strength in the pushover curve, $\Delta_{y}$ is the yield displacement of the idealized bilinear force-deformation curve, $t$ is a constant computed from

$$
t=1+0.15 \ln (T)
$$

and $\alpha_{e}$ is the effective post-elastic stiffness ratio computed from

$$
\alpha_{e}=\alpha_{P-\Delta}+\lambda\left(\alpha_{2}-\alpha_{P-\Delta}\right)
$$

where $\lambda$ is a near-field effect factor equal to 0.8 for sites that are subjected to near-field effects and 0.2 for sites that are not subjected to near field effects. The near field effects may be considered to exist if the 1 second spectral value, $S_{1}$, at the site for the maximum considered earthquake is equal to or exceeds $0.6 \mathrm{~g}$. The P-Delta stiffness ratio, $\alpha_{P-\Delta}$, and the maximum negative post-elastic stiffness ratio, $\alpha_{2}$, in Equation (2.25) are estimated from the idealized force-deformation curve in Figure 2.2. The $\alpha_{P-\Delta}$ needed in Equation (2.25) may be estimated by conducting pushover analysis with and without P-Delta effects.

\subsection{IRREGULAR STRUCTURES}

\subsubsection{Current MOTEMS Procedure}

The current MOTEMS procedure requires that the seismic displacement demand in irregular concrete or steel structures with high or moderate seismic risk classification be computed from linear modal analysis. This procedure assumes that the displacement demand in irregular structures deformed beyond the linear elastic range may be approximated by that of a linear elastic structure. For irregular concrete and steel structures with low seismic risk, the displacement demand must be computed by a nonlinear static procedure; the nonlinear static procedure for such irregular structures appears to be similar to that for regular structures. 


\subsubsection{Proposed Nonlinear Static Procedure for Irregular Structures}

Presented here is a rational nonlinear static procedure for estimating displacement demand in irregular structures. Proposed initially by Chopra and Goel (2004) to estimate seismic demands in unsymmetric-plan buildings, this procedure has been slightly modified to estimate displacement demands in irregular Marine Oil and LNG Terminals. The following is a step-bystep summary of this procedure.

1. Compute the natural frequencies, $\omega_{n}$ and modes, $\phi_{n}$, for linearly elastic vibration of the irregular Marine Oil and LNG Terminal.

2. Select a reference point where the displacement, $u_{r n}$, is to be monitored in the selected direction of analysis during the pushover analysis. Ideally, this reference point should be the location on the structure with largest value of $\phi_{r n}$ in the selected direction of analysis.

3. For the nth-mode, develop the pushover curve, $V_{b n}-u_{r n}$, for the nth modal force distribution, $\boldsymbol{s}_{n}^{*}=\mathbf{M} \phi_{n}$, where $\mathbf{s}_{n}^{*}$ is the vector of lateral forces used during the pushover analysis, $\mathbf{M}$ is the mass matrix of the structure, and $\phi_{n}$ is the nth mode shape. The base shear $V_{b n}$ should be monitored in the same direction as the direction of selected reference point displacement $u_{r n}$.

4. Convert the $V_{b n}-u_{r n}$ pushover curve to the force-displacement, $F_{s n} / L_{n}-D_{n}$, relation for the nth -"mode" inelastic SDF system by utilizing $F_{s n} / L_{n}=V_{b n} / M_{n}^{*}$ and $D_{n}=u_{r n} / \Gamma_{n} \phi_{r n}$ in which $\phi_{r n}$ is the value of $\phi_{n}$ at the reference point in the direction under consideration, $M_{n}^{*}=\left(\phi_{n}^{T} \mathbf{M} \mathbf{\imath}\right)^{2} / \phi_{n}^{T} \mathbf{M} \phi_{n}$ is the effective modal mass, and $\Gamma_{n}=\phi_{n}^{T} \mathbf{M} \mathbf{\imath} / \phi_{n}^{T} \mathbf{M} \phi_{n}$ with $\mathbf{\imath}$ equal to the influence vector. The influence vector $\mathbf{l}$ is a vector of size equal to the total number of degrees of freedom. For analysis in the x-direction, the components of $\mathbf{l}$ corresponding to $\mathrm{X}$ degree-of-freedom are equal to one and the remaining components equal to zero. Similarly the components of $\mathbf{l}$ corresponding to y-degree-of-freedom are equal to one and the remaining components equal to zero for analysis in the y-direction.

5. Idealize the force-displacement, $F_{s n} / L_{n}-D_{n}$, curve as a bilinear curve and compute the yield value $F_{\text {sny }} / L_{n}$. 
6. Compute the yield strength reduction factor, $R=S_{A} /\left(F_{\text {sny }} / L_{n}\right)$.

7. Compute the peak deformation $D_{n}=\Delta_{d}$ of the nth-"mode" inelastic SDF system defined by the force-deformation relation developed in Step 4 and damping ratio $\zeta_{n}$, from Equation (2.19). The elastic vibration period of the system is based on the effective slope of the $F_{s n} / L_{n}-D_{n}$ curve, which for a bilinear curve is given by $T_{n}=2 \pi\left(L_{n} D_{n y} / F_{s n y}\right)^{1 / 2}$.

8. Calculate peak reference point displacement $u_{r n}$ associated with the nth-"mode" inelastic SDF system from $u_{r n}=\Gamma_{n} \phi_{r n} D_{n}$.

9. Push the structure to reference point displacement equal to $u_{r n}$ and note the values of desired displacement $\delta_{\text {no }}$.

10. Repeat Steps 3 to 9 for all significant modes identified.

11. Combine the peak modal displacement, $\delta_{n o}$, by an appropriate modal combination rule, e.g., $\mathrm{CQC}$, to obtain the peak dynamic response, $\Delta_{o}$. 


\section{SIMPLIFYING ASSUMPTION}

Figure 3.1b shows the mathematical model of a free-head pile of Figure 3.1a supported on bedrock (or other competent soil) and surrounded by soil between the bedrock and mud line. In this model, the pile is represented by beam-column elements and soil by Winkler reaction springs connected to the pile between the bedrock and the mud line (Priestley et al., 1996). The properties of the beam-column element are established based on the pile cross section whereas properties of the reaction springs are specified based on geotechnical data (e.g., see Priestley et al., 1996; Dowrick, 1987). Figure 3.1c shows the height-wise distribution of bending moment under lateral load applied to the pile tip. Note that the maximum bending moment occurs slightly below the mud line at a depth equal to $D_{m}$, typically denoted as the depth-to-maximum-moment below the mud line (Figure 3.1c). Lateral displacement at the pile tip can be calculated based on this bending moment distribution or from a discrete element model implemented in most commonly available computer programs for structural analysis.

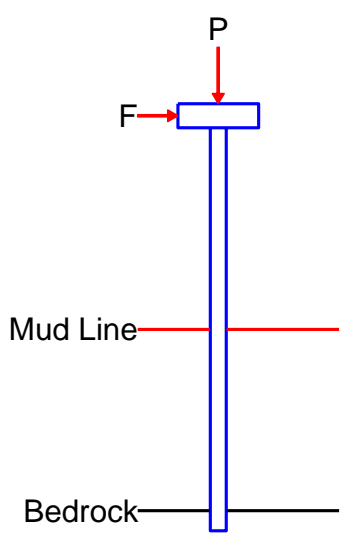

(a)

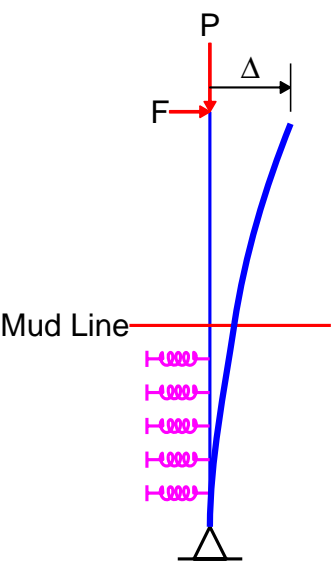

(b)

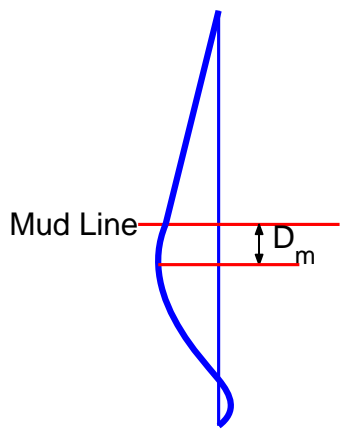

(c)

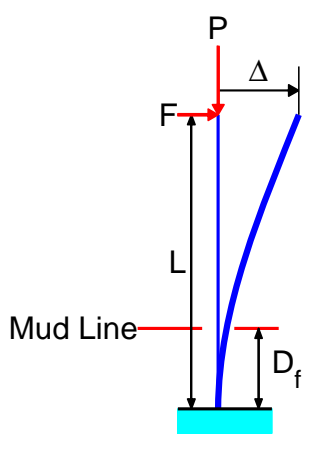

(d)

Figure 3.1. Simplified model of the pile-soil system for displacement capacity evaluation: (a) Pile supported on bedrock; (b) Mathematical model of the pile; (c) Height-wise variation of bending moment; and (d) Equivalent fixity model for displacement calculation.

An alternative approach to modeling soil flexibility effects of the pile with discrete soil springs is the effective fixity approach (Priestley et al., 1996: Sec. 4.4.2; Dowrick, 1987: Sec. 6.4.5.3). In this approach (Figure 3.1d), the depth-to-fixity, $D_{f}$, is defined as the depth that produces in a fixed-base column with soil removed above the fixed base the same top-of-the-pile lateral displacement under the lateral load, $F$, as that in the actual pile-soil system (Priestley et al., 1996). Both the axial load, $P$, and top-of-the-pile moment, $M$ (not shown in Figure 3.1d) 
need to be considered. The depth-to-fixity, which depends on the pile diameter and soil properties, is typically provided by the geotechnical engineer, estimated from charts available in standard textbooks on the subject (e.g., Priestley, et al., 1996; Dowrick, 1987) or from recommendations in several recent references (e.g., Chai, 2002; Chai and Hutchinson, 2002).

The equivalent fixity model is typically used for estimating displacement of piles that remain within the linear-elastic range. For piles that are expected to be deformed beyond the linear-elastic range, however, nonlinear analysis of the discrete soil spring model approach of Figure 3.1b is recommended (Priestley et al., 1996: Sec. 4.4.2) because the plastic hinge forms at the location of the maximum bending moment, i.e., at the depth-to-maximum-moment, $D_{m}$, and not at the depth-to-fixity, $D_{f}$. A recent investigation has developed equations for estimating lateral displacement of equivalent fixity model of the nonlinear soil-pile system by recognizing that the plastic hinge forms at the depth-to-maximum-moment (Chai, 2002); expressions for estimating displacement ductility capacity of pile-soil system are also available (Priestley et al., 1996: Sec. 5.3.1). However, calculation of lateral displacement capacity of nonlinear soil-pile systems using these approaches requires significant information about the soil properties.

This investigation uses a simplifying assumption that the equivalent fixity model may directly be used to estimate lateral displacement capacity of nonlinear piles. Clearly, such an approach indicates that the plastic hinge would form at the depth-to-fixity, $D_{f}$, which differs from the actual location at the depth-to-maximum-moment, $D_{m}$. It is useful to note that $D_{f}$ is typically in the range of 3 to 5 pile diameter whereas $D_{m}$ is in the range of 1 to 2 pile diameter (see Priestley et al., 1996). Obviously, plastic hinge at $D_{f}$ in the equivalent fixity model would provide slightly larger plastic displacement compared to the plastic displacement if the plastic hinge was correctly located at $D_{m}$; note that plastic displacement is given by $\Delta_{p}=\theta_{p}\left(L_{a}+D_{f}\right.$ or $\left.D_{m}\right)$ where $\theta_{p}$ is the plastic hinge rotation and $L_{a}$ is the free-standing height of the pile. However, the simplifying assumption used in this investigation is appropriate because difference between $D_{f}$ and $D_{m}$ is unlikely to significantly affect the plastic displacement for piles with very long free-standing height used in marine oil terminals. Note that the freestanding height of piles in marine oil terminals is typically in excess of twenty times the pile diameter. 
It is useful to emphasize that the simplified approach proposed in this investigation is intended to be used for preliminary design of piles or as a check on the results from the detailed nonlinear analysis. It is expected that this approach would provide results that are sufficiently "accurate" for this purpose.

The recommendations to estimate displacement capacity of the pile using the equivalent fixity approach are strictly valid only if the displacement demand is also estimated by utilizing the equivalent fixity pile model - a practice that is commonly used for analysis of large piers and wharves with many piles. The recommendations developed in this report should be used with caution if the displacement demand is estimated from a model consisting of piles with soil springs. 


\section{MOTEMS PROCEDURE FOR CAPACITY EVALUATION OF PILES}

The displacement capacity of piles in the MOTEMS is estimated from nonlinear static pushover analysis. In this analysis, a force of increasing magnitude is applied statically in the transverse direction (perpendicular to the pile) permitting the materials in the pile - steel and/or concrete to deform beyond their linear-elastic range. The displacement capacity is defined as the maximum displacement that can occur at the tip of the pile without material strains exceeding the permissible values corresponding to the desired design level.

The displacement capacity of a pile at a selected design level in the MOTEMS is obtained from the procedure proposed by Priestley et al. (1996) as illustrated in Figure 4.1. This procedure requires development of the pile section moment-curvature relationship. The moment-curvature relationship may be developed from any standard moment-curvature analysis programs using material constitutive relationships specified in the MOTEMS; the MOTEMS specifies guidelines for selecting material properties such as concrete and steel strengths as well as stress-strain curves for unconfined concrete, confined concrete, reinforcing steel, and prestressing steel. The moment-curvature relationship is idealized as a bilinear relationship as shown in Figure 4.2.

It is useful to note that the formulation presented here is for a cantilever, i.e., a pile with a pin-connection to the deck. Similar formulation is available for piles with full-momentconnection to the deck that uses "effective" length defined as the length between points of contra-flexure (e.g., see CALTRANS, 2006).

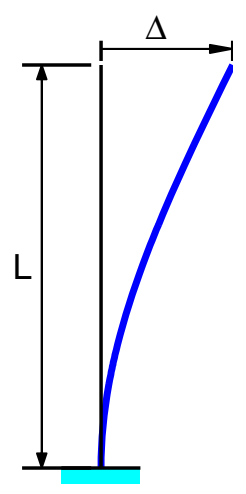

(a) Member

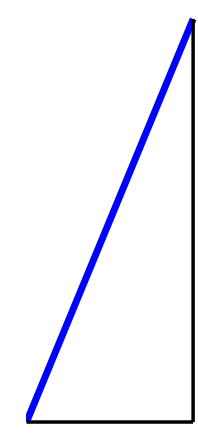

(b) BM

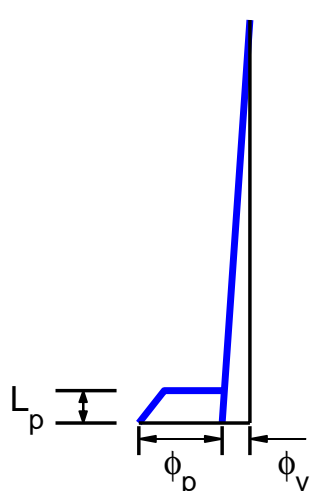

(c) Curvature

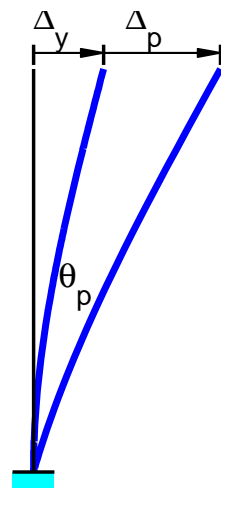

(d) Deflections

Figure 4.1. Deformation capacity of a pile: (a) Deflected shape, (b) Bending moment (BM) diagram, (c) Curvature distribution, and (d) Yield and plastic displacements.

The total displacement capacity of the pile is computed as 


$$
\Delta=\Delta_{y}+\Delta_{P}
$$

in which $\Delta_{y}$ is the yield displacement and $\Delta_{p}$ is the plastic displacement of the pile. The yield displacement can be estimated as

$$
\Delta_{y}=\frac{\phi_{y} L^{2}}{3}
$$

where $\phi_{y}$ is the yield curvature computed from

$$
\phi_{y}=\frac{M_{y}}{E_{c} I_{e}}
$$

with $M_{y}$ being the yield moment and $E_{c} I_{e}$ being the slope of the initial elastic portion of the bilinear idealization of the moment-curvature relationship, and $L$ is the pile "effective" length. The "effective" length, defined as the length between points of contraflexure, for a cantilever becomes equal to its total length (Figure 4.1).

It is useful to note that the yield displacement, $\Delta_{y}$, of reinforced-concrete pile may be estimated from Equation (4.2), without the need for section moment-curvature analysis, by using the following expression for dimensionless yield curvature (Priestley et al., 1996: Sec. 7.4.6):

$$
\phi_{y} D=2.45 \varepsilon_{y} \pm 0.15
$$

in which $D$ is the pile diameter and $\varepsilon_{y}$ is the longitudinal yield reinforcement. Similar expression for hollow-steel pile is currently not available.

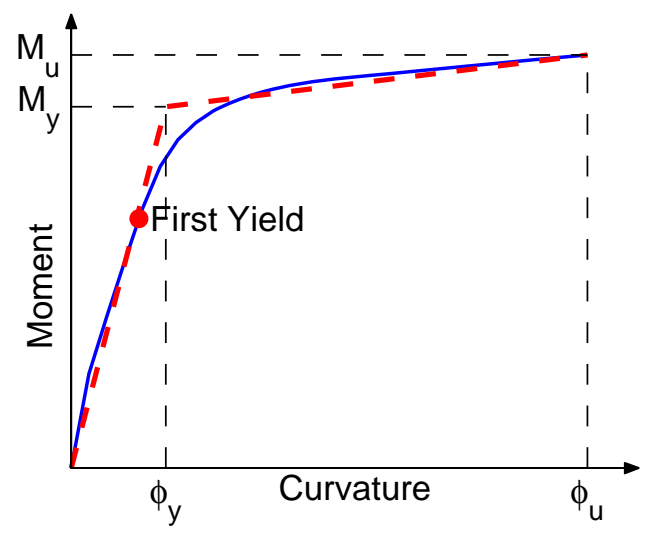

Figure 4.2. Bilinear idealization of the moment-curvature relationship. 
The plastic displacement, $\Delta_{p}$, is computed from

$$
\Delta_{p}=\left(\frac{M_{u}}{M_{y}}-1\right) \Delta_{y}+L_{p}\left(\phi_{u}-\phi_{y}\right)\left(L-0.5 L_{p}\right)
$$

The plastic displacement given by Equation (4.5) includes components due to the elastic displacement resulting from the increase in moment from $M_{y}$ to $M_{u}$, i.e., post-yield stiffness of the moment-curvature relationship (see Figure 4.2) and due to plastic rotation $\theta_{p}$ of the pile. In order to compute the plastic rotation, it is assumed that a constant plastic curvature, $\phi_{p}=\phi_{u}-\phi_{y}$, occurs over a plastic hinge length $L_{p}$ of the pile (see Figure 4.1c). Therefore, the plastic rotation is given by

$$
\theta_{p}=L_{p} \phi_{p}=L_{p}\left(\phi_{u}-\phi_{y}\right)
$$

The values of $M_{u}$ and $\phi_{u}$ in equation (4.5) are the largest values of the pile section moment and curvature, respectively, without exceeded the material strains at selected design level.

The MOTEMS specify the formula for estimating the plastic hinge length required in Equation (4.5). If the hinge were to form against a supporting member, i.e., at the pile-deck interface, the plastic hinge length is computed from

$$
L_{p}=\left\{\begin{array}{cl}
0.08 L+0.022 f_{y e} d_{b l} \geq 0.044 f_{y e} d_{b l} & \left(f_{y e} \text { in MPA }\right) \\
0.08 L+0.15 f_{y e} d_{b l} \geq 0.3 f_{y e} d_{b l} & \left(f_{y e} \text { in ksi }\right)
\end{array}\right.
$$

in which $f_{y e}$ is the expected yield strength of the reinforcing steel, and $d_{b l}$ is the diameter of the longitudinal reinforcement. If the plastic hinge forms in-ground, the MOTEMS provide a chart to estimate the plastic hinge length that depends on the pile diameter, subgrade modulus, effective stiffness of the pile, and the distance from ground to the pile point of contraflexure. It is useful to note that Equation (4.7), as specified in Priestley et al., (1996) or in the MOTEMS (2006), does not explicitly impose an upper limit even though there may be some experimental evidence that the plastic hinge length should not be greater than the pile diameter. 
The plastic hinge length formula of Equation (4.7) specified in the MOTEMS is based on the recommendation by Priestley et al. (1996) for reinforced concrete sections. The MOTEMS do not provide recommendations for plastic hinge length for steel piles or prestressed concrete piles.

The MOTEMS specify material strain limits for two levels of seismic design: Level 1 and Level 2. These strain limits depend on whether the plastic hinge forms in-ground or at the piledeck interface. These strain limits are listed in Table 4.1.

Table 4.1. Material strain limits in the MOTEMS.

\begin{tabular}{|c|c|c|c|c|}
\hline Pile Type & Material & Hinge Location & Level 1 & Level 2 \\
\hline \multirow{4}{*}{$\begin{array}{c}\text { Reinforced-Concrete } \\
\text { Pile }\end{array}$} & \multirow[t]{2}{*}{ Concrete } & Pile-Deck & $\varepsilon_{c} \leq 0.004$ & $\varepsilon_{c} \leq 0.025$ \\
\hline & & In-Ground & $\varepsilon_{c} \leq 0.004$ & $\varepsilon_{c} \leq 0.008$ \\
\hline & \multirow[t]{2}{*}{ Steel rebar } & Pile-Deck & $\varepsilon_{s} \leq 0.01$ & $\varepsilon_{s} \leq 0.05$ \\
\hline & & In-Ground & $\varepsilon_{s} \leq 0.01$ & $\varepsilon_{s} \leq 0.025$ \\
\hline \multirow{2}{*}{$\begin{array}{l}\text { Prestressed Concrete } \\
\text { Pile with Dowel- } \\
\text { Connection }\end{array}$} & \multirow[t]{2}{*}{ Strands } & In-Ground & $\begin{array}{c}\varepsilon_{p} \leq 0.005 \\
\text { (Incremental) }\end{array}$ & $\begin{array}{c}\varepsilon_{p} \leq 0.025 \\
(\text { Total })\end{array}$ \\
\hline & & Pile-Deck & $\varepsilon_{s} \leq 0.01$ & $\varepsilon_{s} \leq 0.05$ \\
\hline Hollow Steel Pile & Steel & & $\varepsilon_{s} \leq 0.008$ & $\varepsilon_{s} \leq 0.025$ \\
\hline \multirow{2}{*}{$\begin{array}{l}\text { Hollow Steel Pile with } \\
\text { Dowel-Connection }\end{array}$} & \multirow[t]{2}{*}{ Steel } & In-Ground $^{1}$ & $\varepsilon_{s} \leq 0.008$ & $\varepsilon_{s} \leq 0.025$ \\
\hline & & Pile-Deck $^{2}$ & $\varepsilon_{s} \leq 0.01$ & $\varepsilon_{s} \leq 0.05$ \\
\hline
\end{tabular}

\footnotetext{
${ }^{1}$ The strain values are the same as for steel in hollow steel pile.

${ }^{2}$ The strain values are the same as for steel rebar at the pile-deck connection of a RC pile.
} 


\section{SIMPLIFIED PROCEDURE TO COMPUTE PILE DISPLACEMENT CAPACITY}

Estimation of displacement capacity of the pile according to the seismic provisions of the MOTEMS require monitoring of material strains during the nonlinear static pushover analysis of the pile if the pile is modeled using a distributed-plasticity approach in which section properties are specified by a fiber-section. The estimation of the displacement capacity requires monitoring of material strains during moment-curvature analysis if the pile is modeled using a concentratedplasticity approach in which nonlinearity is represented by rotational springs at two ends of the pile. The nonlinear moment-rotation relationship of this spring is computed from the momentcurvature relationship and estimated length of the plastic hinge. In either approach, the displacement capacity is defined as the maximum displacement that can occur at the tip of the pile without material strains exceeding the strain limits specified in the MOTEMS for any selected design level.

Monitoring strains during pushover analysis of piles using a distributed-plasticity model is cumbersome. Moreover, structural analysis programs commonly used by practicing engineers may not have the capability to directly monitor strains during the pushover analysis. Although, the concentrated-plasticity model, such as that employed in the current MOTEMS (see description in Chapter 4), does not require direct monitoring of material strains during pushover analysis; however, it still requires monitoring of material strains during moment-curvature analysis. Most commercially available programs for moment-curvature analysis do provide the capability to monitor material strains. However, this approach requires estimation of plastic hinge length in order to convert the moment-curvature relationship to the moment-rotation relationship of the rotational spring. While the MOTEMS provide guidelines for estimating plastic hinge length for reinforced concrete piles [see Equation (4.7)], such guidelines are not available for steel piles or prestressed concrete piles indicating that estimation of displacement capacity of such piles using concentrated-plasticity model may also be cumbersome. Therefore, there is a need to develop a simplified approach that avoids the need to monitor strains to the extent possible and yet provides a "good" estimate of displacement capacity of the pile without exceeding material strain limits specified in the MOTEMS.

It is useful to note that formulas and/or charts for estimating the plastic hinge length have

been recommended by several researchers (e.g., Priestley et al., 1996; Chai, 2002; Chai and 
Hutchinson, 2002; Budek et al., 2000; Song et al., 2004). However, these recommendations were developed for piles deformed significantly into the inelastic range. While such recommendations are appropriate for seismic design of piles for Level 2, where piles are expected to be deformed significantly into the inelastic range, they may not be appropriate for design of piles for Level 1 which corresponds to much lower level of inelastic action.

A simplified procedure is proposed in this report to compute the displacement capacity of piles commonly used in Marine Oil and LNG Terminals. This approach computes the displacement capacity as

$$
\Delta_{c}=\mu_{\Delta} \Delta_{y}
$$

where $\Delta_{y}$ is the yield displacement of the pile and $\mu_{\Delta}$ is the displacement ductility capacity of the pile. The displacement ductility capacity is selected such that the material strains remain within the limits specified in the MOTEMS.

The guidelines to select the displacement ductility capacity and estimate the yield displacement are developed next in this report for four types of piles: (1) reinforced-concrete piles with either pin or full-moment connection to the deck; (2) hollow steel pipe pile with either pin or full-moment connection to the deck; (3) hollow steel pipe pile with a dowel- connection to the deck; and (4) prestressed concrete pile with a dowel-connection to the deck. The guidelines developed for these piles utilize the concept of equivalent fixity model described in Chapter 3 of this report.

Similar displacement ductility capacity based approaches have been proposed previously (e.g., Priestly et al., 1996; Budek at al., 2000; Chai, 2002; Song et al., 2004). However, this investigation specifically developed recommendations for displacement ductility capacity of long piles typically used in Marine Oil and LNG Terminals.

The simplified procedure to estimate displacement capacity of piles presented in this report is intended either for preliminary design of piles or as a quick check on the capacity that may be obtained from detailed nonlinear analyses. The design engineers may still use the elaborate analysis for final design of piles for a Marine Oil and LNG Terminals. 


\section{DISPLACEMENT CAPACITY OF REINFORCED CONCRETE PILES}

This Chapter presents development of a simplified procedure for estimating displacement capacity of reinforced concrete piles connected to the deck either by a pin connection or by a moment connection. For this purpose, the current approach in the MOTEMS (see Equations 4.1 to 4.7 in Chapter 4) is further simplified. Presented first in this Chapter is development of simplified equations to compute displacement ductility of reinforced concrete piles that are independent of the pile length and depend only on the pile section curvature ductility and seismic design level. The accuracy of these equations is next evaluated against results from nonlinear finite element analyses. Subsequently, results of a parametric study are presented to understand the sensitivity of the displacement ductility capacity on pile diameter, longitudinal reinforcement ratio, transverse reinforcement ratio, and axial force. Based on these results, lower bound estimates of the ductility capacity of reinforced concrete piles for two design levels - Level 1 and Level 2 - are proposed. Finally, it is demonstrated that the lower-bound displacement ductility values along with simplified expressions for yield displacement provide very good estimate of the displacement capacity of piles when compared against values from nonlinear finite element analysis.

\subsection{THEORETICAL BACKGROUND}

The displacement ductility capacity of reinforced concrete piles is defined as (Priestley et al., 1996)

$$
\mu_{\Delta}=\frac{\Delta_{y}+\Delta_{p}}{\Delta_{y}}=1+\frac{\Delta_{p}}{\Delta_{y}}=\frac{M_{u}}{M_{y}}+3\left(\mu_{\phi}-1\right)\left(\frac{L_{p}}{L}\right)\left(1-0.5 \frac{L_{p}}{L}\right)
$$

in which $\mu_{\phi}$ is the pile section curvature ductility capacity given by

$$
\mu_{\phi}=\frac{\phi_{u}}{\phi_{y}}
$$

with $\phi_{u}$ being the section curvature at a selected design level material strain and $\phi_{y}$ is the yield curvature defined by Equation (4.3) and Figure 4.2. For piles in Marine Oil and LNG Terminals, which typically use piles with very long free-standing height, the second term in Equation (4.7) for plastic hinge length becomes negligibly small compared to the first term implying that this 
term may be ignored without introducing significant error. Therefore, the plastic hinge length may be expressed as

$$
L_{p} \simeq 0.08 L
$$

Equation (6.3) implies that the ratio $L_{p} / L$ needed in Equation (6.1) is independent of the member "effective" length. It is useful to note that neglecting the second term in the Equation (4.6) for the plastic hinge location leads to smaller plastic hinge length and therefore is likely to provide a conservative estimate of the displacement ductility capacity of the pile.

The preceding approximation permits the following important simplification in Equation (6.1):

$$
\mu_{\Delta}=\frac{M_{u}}{M_{y}}+3\left(\mu_{\phi}-1\right)(0.08)(1-0.5 \times 0.08)=\frac{M_{u}}{M_{y}}+0.2304\left(\mu_{\phi}-1\right)
$$

which implies that the pile displacement ductility capacity is independent of its "effective" length; it depends only on the section curvature ductility, $\mu_{\phi}$, and ratio of ultimate and yield moments $M_{u} / M_{y}$. For moment-curvature relationship that exhibit very little post-yield stiffness, i.e., $M_{u} \simeq M_{y}$, Equation (6.4) can be further simplified as

$$
\mu_{\Delta}=1+0.2304\left(\mu_{\phi}-1\right)=0.7696+0.2304 \mu_{\phi}
$$

Equation (6.5) indicates that member displacement ductility capacity can be computed directly from the section curvature ductility capacity.

\subsection{EVALUATION OF SIMPLIFIED EQUATIONS FOR DUCTILITY CAPACITY}

The accuracy of Equations (6.5) in estimating displacement ductility capacity of reinforced concrete piles at seismic design Level 2 and Level 1, respectively, is evaluated in this section. For this purpose, displacement ductility capacity of reinforced concrete piles is evaluated from nonlinear static pushover analysis of a finite element model. The pile is considered to be fixed at top and bottom. These boundary conditions correspond to a pile that is connected to the pile-cap with a full-moment connection, and utilizes the equivalent displacement fixity assumption at the bottom. The axial load on the pile is assumed to be $0.05 A_{g} f_{c}^{\prime}$ in which $A_{g}$ is the gross cross- 
section area of the pile and $f_{c}^{\prime}$ is the compressive strength of concrete. The longitudinal and transverse reinforcements in the pile section are assumed to be equal to $1 \%$ and $0.6 \%$, respectively.

The pile is modeled with a nonlinear beam-column element in computer program Open System for Earthquake Engineering Simulation (OpenSees) (McKenna and Fenves, 2001). The distributed plasticity is considered by specifying the section properties by a fiber section model and then using seven integration points along the element length; details of such modeling may be found in McKenna and Fenves (2001). The material properties are specified as per the MOTEMS specifications (MOTEMS, 2007; Mander et al., 1988).

Strains in the concrete and steel are monitored during the pushover analysis. The limiting values of compressive strain in concrete and tensile strain in reinforcing steel are 0.004 and 0.01 , respectively, for Level 1 and 0.025 and 0.05 , respectively, for Level 2 . If the hinge forms below ground, the limiting value of compressive strain in concrete and tensile strain in reinforcing steel are 0.004 and 0.01 , respectively, for Level 1 and 0.008 and 0.025 , respectively, for Level 2. The concrete strains are assumed to be specified just inside the reinforcement cage. The displacement ductility at a selected design level corresponds to the largest displacement that can occur at the tip of the pile without strain limits either in concrete or steel being exceeded.

The results are presented in Figure 6.1 for four pile diameters $-61 \mathrm{~cm}, 76 \mathrm{~cm}, 91 \mathrm{~cm}$, and $107 \mathrm{~cm}$ - and pile length in the range of $5 \mathrm{~m}$ to $40 \mathrm{~m}$. These results confirm expectations from Equation (6.5) that the displacement ductility capacity is independent of the pile length. This becomes apparent from essentially no variation in the ductility capacity from the nonlinear finite element analysis of the pile lengths in Figure 6.1 for both design levels and all pile diameters. The presented results also demonstrate that Equation (6.5) provides a very good estimate of the displacement ductility capacity of reinforced concrete piles (see Figure 6.1).

It is useful to note that the plastic hinge length used in this investigation does not include contribution to the plastic hinge length due to strain-penetration effects. It would be useful to verify these findings from experiments on reinforced concrete piles. 
(a) Level 1, IG or PD
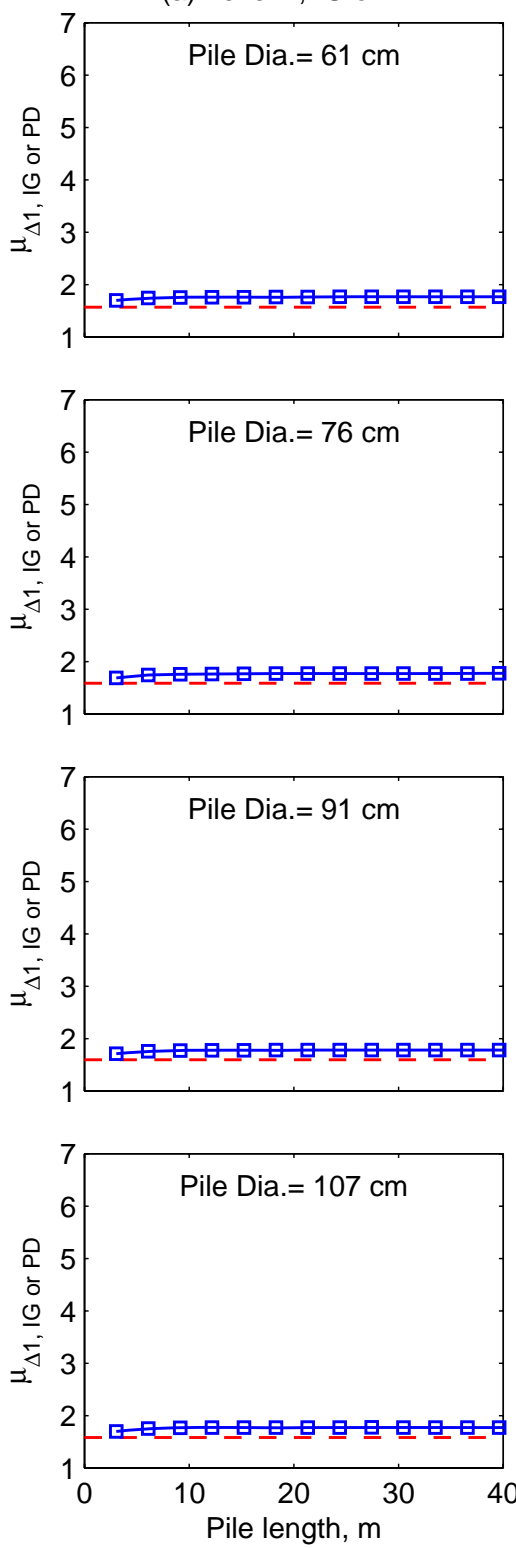

(b) Level 2, IG
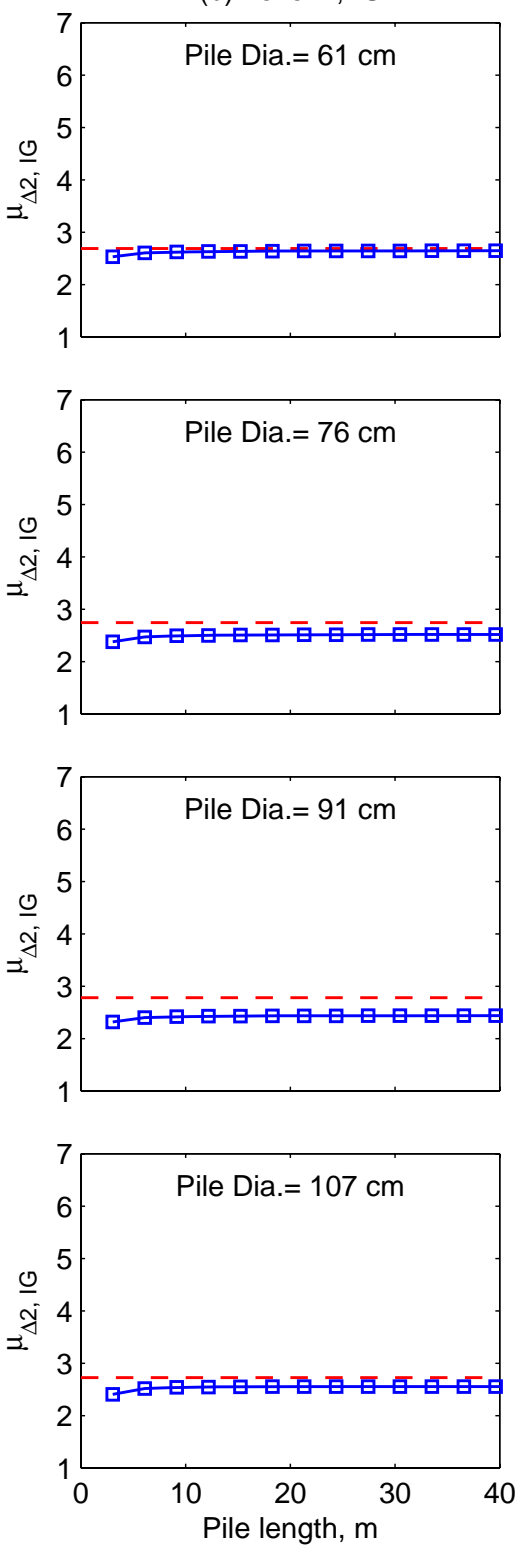

(c) Level 2, PD
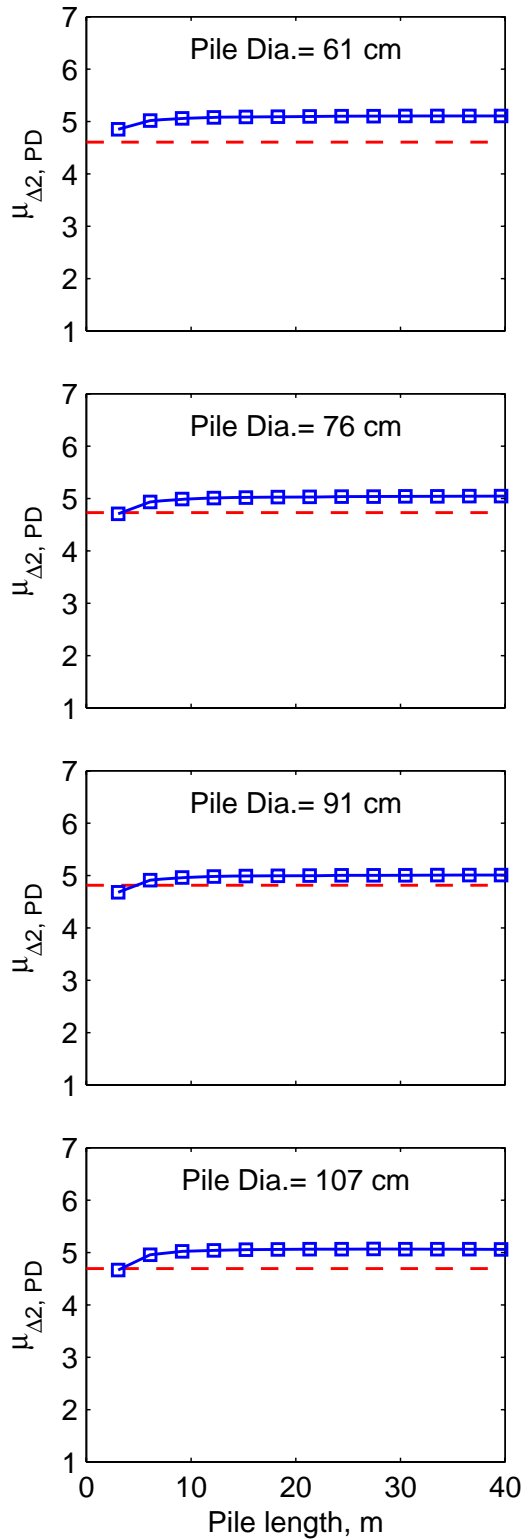

Figure 6.1. Displacement ductility capacity from simplified equation (shown in dashed line) and nonlinear finite element analysis (NLFEA) for seismic design (a) Level 1 for in-ground (IG) or pile-deck (PD) hinge formation, (b) Level 2 for IG hinge formation, and (c) Level 2 for PD hinge formation.

\subsection{SENSITIVITY OF DISPLACEMENT DUCTILITY TO PILE PARAMETERS}

\subsubsection{Pile Length and Pile Diameter}

Figure 6.2 presents variation of displacement ductility capacity with pile length for four values of pile diameters: $61 \mathrm{~cm}, 76 \mathrm{~cm}, 91 \mathrm{~cm}$, and $107 \mathrm{~cm}$. The results are presented for piles with $1 \%$ longitudinal reinforcement and $0.6 \%$ transverse reinforcement. As noted previously, results of 
Figure 6.2 also indicate that the displacement ductility capacity of piles is essentially independent of the pile length. This is expected because Equation (6.5) becomes independent of the pile length. The results of Figure 6.2 indicate that the displacement ductility capacity of the pile is also essentially independent of the pile diameter as apparent from almost identical curves for the four pile diameters considered in Figure 6.2.

(a) Level 1, IG or PD

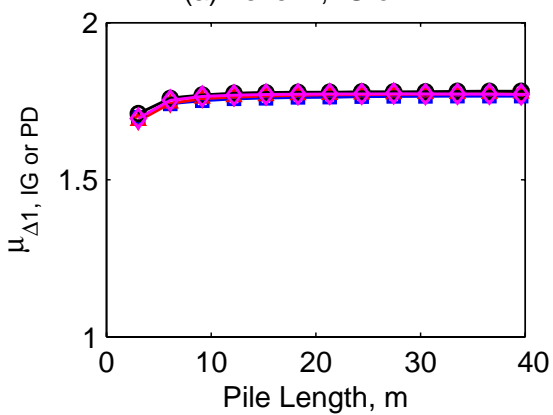

(b) Level 2, IG

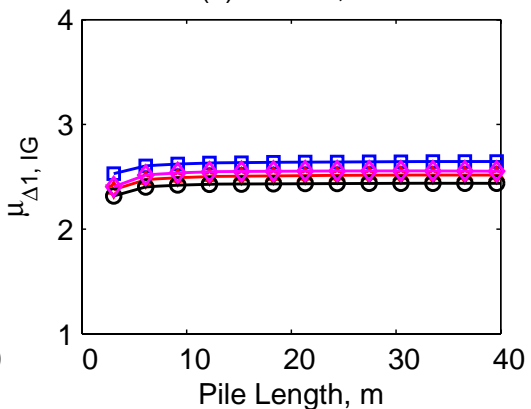

(c) Level 2, PD

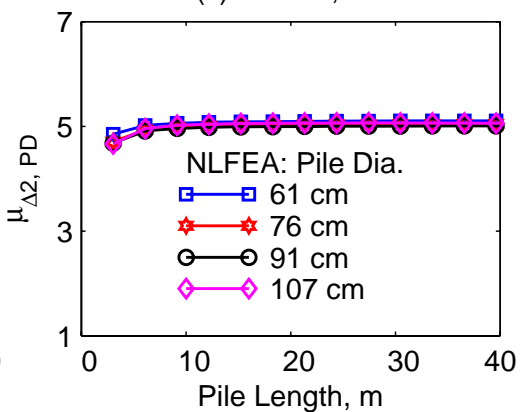

Figure 6.2. Variation of displacement ductility capacity computed from nonlinear finite element analysis (NLFEA) with pile length and pile diameter: (a) Level 1 for in-ground (IG) or pile-deck (PD) hinge formation, (b) Level 2 for IG hinge formation, and (c) Level 2 for PD hinge formation.

In order to understand the aforementioned trend, i.e., independence of the displacement ductility capacity of the pile diameter, it is useful to examine the variation of pile section curvature ductility capacity. The results presented in Figure 6.3 indicate that the section curvature ductility capacity is essentially independent of the pile diameter. This observation, along with Equation (6.5), then confirms that the pile displacement ductility capacity should also be independent of the pile diameter.

(a) Level 1, IG or PD

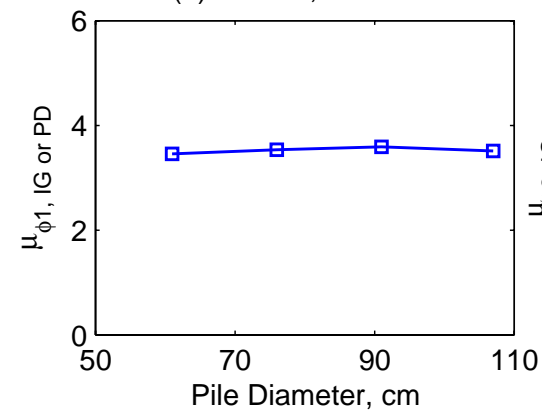

(b) Level 2, IG

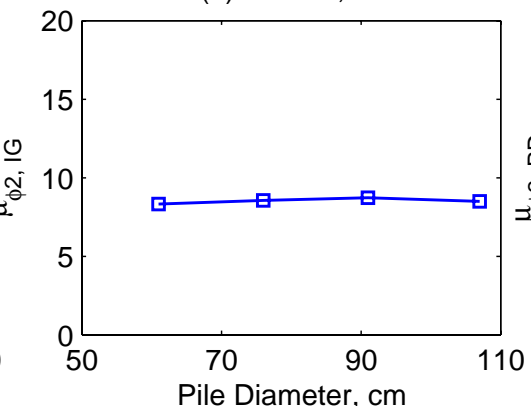

(c) Level 2, PD

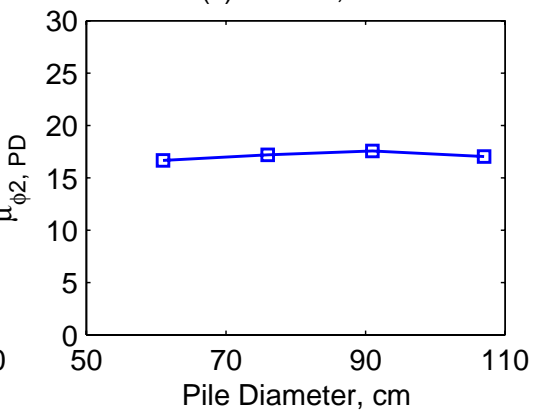

Figure 6.3. Variation of section curvature ductility capacity pile diameter: (a) Level 1 for inground (IG) or pile-deck (PD) hinge formation, (b) Level 2 for IG hinge formation, and (c) Level 2 for PD hinge formation. 


\subsubsection{Longitudinal and Transverse Reinforcement Ratio}

Figures 6.4 and 6.5 present variations of the displacement ductility capacity with longitudinal and transverse reinforcement ratio, respectively. The results presented are for a pile with $91 \mathrm{~cm}$ diameter and $15 \mathrm{~m}$ length. The values of longitudinal reinforcement varying between $0.5 \%$ and $2 \%$ and transverse reinforcement between $0.5 \%$ and $1.5 \%$ were considered.

(a) Level 1, IG or PD

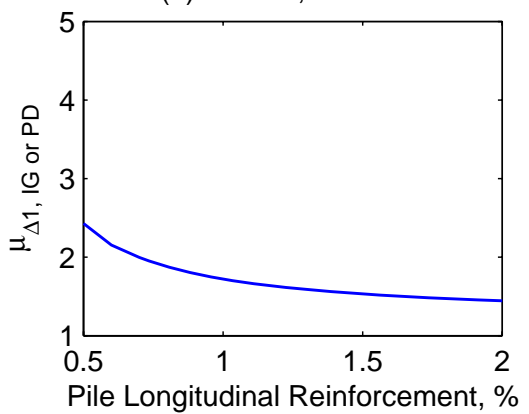

(b) Level 2, IG

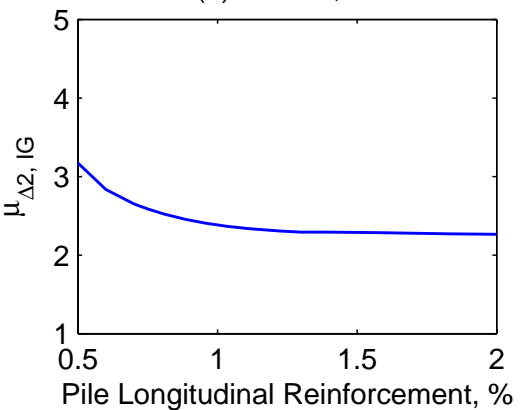

(c) Level 2, PD

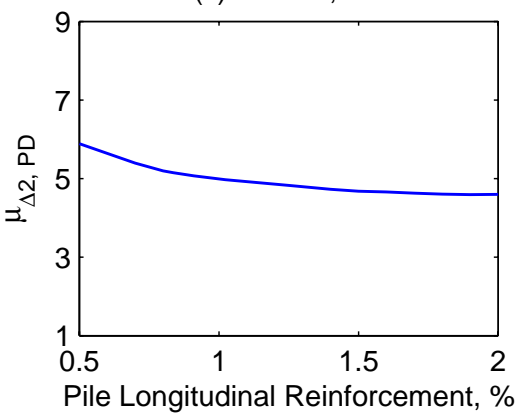

Figure 6.4. Variation of displacement ductility capacity computed from nonlinear finite element analysis (NLFEA) with pile longitudinal reinforcement ratio: (a) Level 1 for in-ground (IG) or pile-deck (PD) hinge formation, (b) Level 2 for IG hinge formation, and (c) Level 2 for PD hinge formation.

The results presented in Figure 6.4 indicate that the displacement ductility decreases with increasing longitudinal reinforcement ratio for values up to about $1 \%$. For longitudinal reinforcement ratio in excess of about 1\%, as may be the case for seismic piles in Marine Oil and LNG Terminals, the displacement ductility capacity of piles is much less sensitive to the value of the longitudinal reinforcement ratio. For such values, the displacement ductility capacity may be considered to be essentially independent of the longitudinal reinforcement ratio.

(a) Level 1, IG or PD

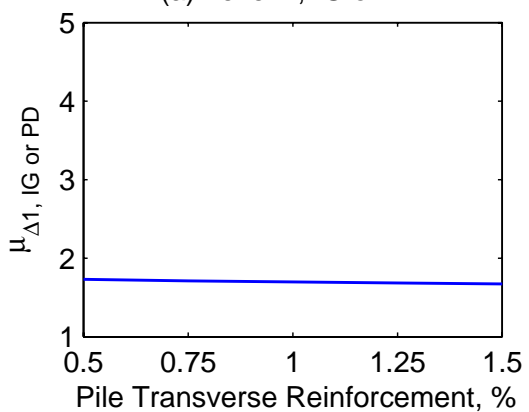

(b) Level 2, IG

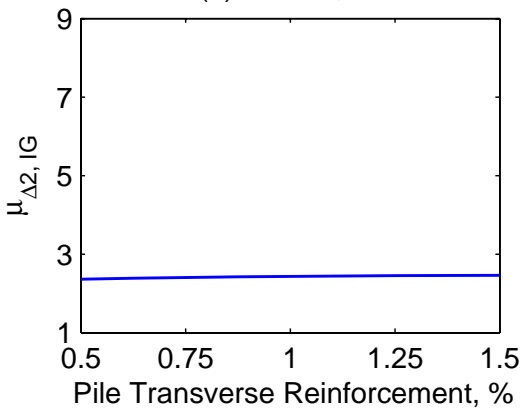

(c) Level 2, PD

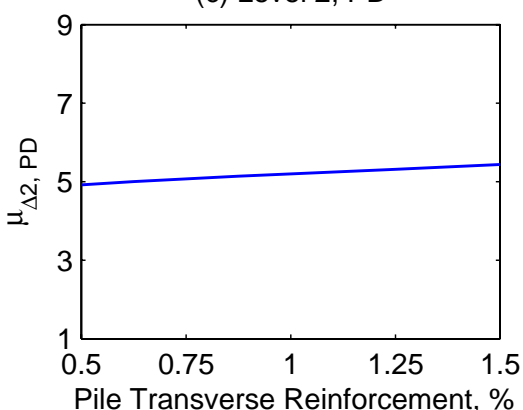

Figure 6.5. Variation of displacement ductility capacity computed from nonlinear finite element analysis (NLFEA) with pile transverse reinforcement ratio: (a) Level 1 for in-ground (IG) or pile-deck (PD) hinge formation, (b) Level 2 for IG hinge formation, and (c) Level 2 for PD hinge formation. 
The results presented in Figure 6.5 show that displacement ductility capacity of piles does not depend on the transverse reinforcement ratio. This becomes apparent from essentially flat variation of the displacement ductility capacity with pile transverse reinforcement ratio.

\subsubsection{Axial Force}

Figure 6.6 presents variation of displacement ductility capacity with axial force in the pile. The presented results are for a pile with $91 \mathrm{~cm}$ diameter and $15 \mathrm{~m}$ length for values of axial force varying from zero to $0.2 A_{g} f_{c}^{\prime}$. These results show that the displacement ductility for Level 1 tends to increase with increasing pile axial force (Figure 6.6 (a)). However, the ductility for Level 2 appears to be insensitive to the axial force values (Figure 6.6 (b) and 6.6(c)).

(a) Level 1, IG or PD

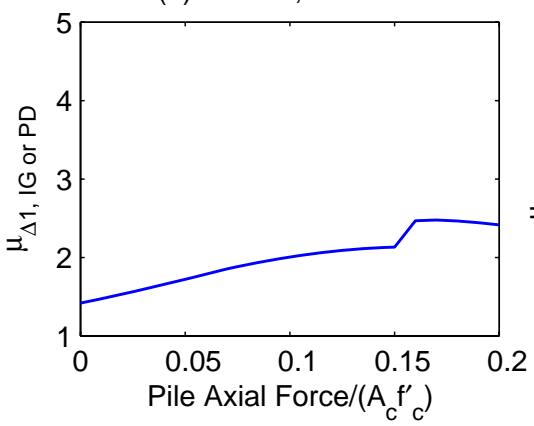

(b) Level 2, IG

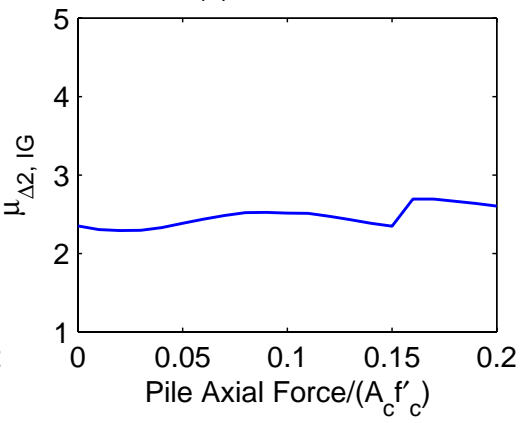

(c) Level 2, PD

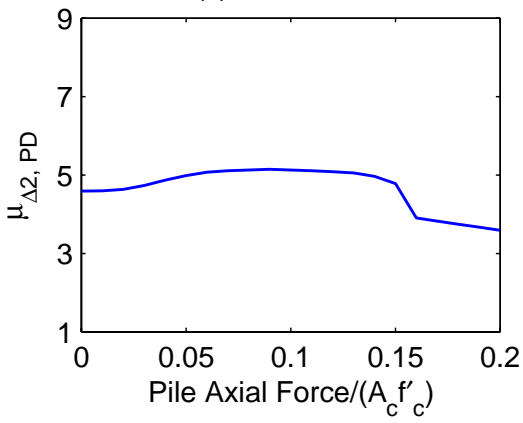

Figure 6.6. Variation of displacement ductility capacity computed from nonlinear finite element analysis (NLFEA) with pile axial load ratio: (a) Level 1 for in-ground (IG) or pile-deck (PD) hinge formation, (b) Level 2 for IG hinge formation, and (c) Level 2 for PD hinge formation.

\subsection{LOWER BOUND OF DISPLACEMENT DUCTILITY CAPACITY}

The results presented in the preceding section indicate that the displacement ductility is relatively insensitive to pile length, pile diameter, pile longitudinal (for practical range), and transverse steel. Furthermore, the displacement ductility for Level 2 is also independent of the pile axial force. Therefore, the displacement ductility appears to be a very robust parameter that can be used in simplified design of piles instead of the various axial strain limits which are currently specified in the MOTEMS. While the displacement ductility may be related to the pile curvature ductility using Equation (6.5), the results presented in the preceding section also indicate that a lower bound of the member displacement ductility capacity may be estimated without any knowledge about the section curvature ductility capacity for practical range of various parameters. 
(a) Level 1

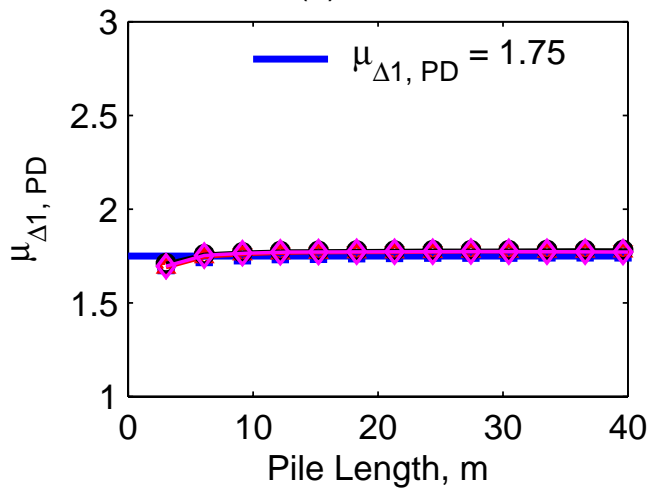

(b) Level 2

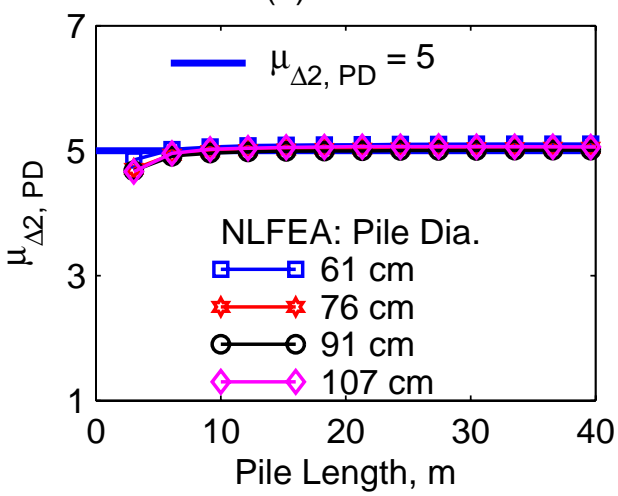

Figure 6.7. Lower-bound value of displacement ductility capacity due to pile-deck hinge formation for seismic design (a) Level 1, and (b) Level 2.

The results presented in Figure 6.7 for a pile-deck hinge indicates that the displacement ductility capacity may be limited to 1.75 for seismic design Level 1 and 5.0 for seismic design Level 2. Note that the displacement ductility for Level 1 is likely to be slightly lower for axial force values than the $0.05 A_{g} f_{c}^{\prime}$ value considered in developing these results (see Figure 6.6 (a)). Similarly, the displacement ductility is likely to be slightly larger for longitudinal reinforcement less than the $1 \%$ value considered in developing these results (see Figure 6.4 (a)).

The displacement ductility capacity for an in-ground hinge is 1.75 for seismic design Level 1 and 2.5 for seismic design Level 2 (Figure 6.8). While the ductility capacity for in-ground hinge is the same as for pile-deck hinge for design Level 1, it is much lower for design Level 2. This is because the steel strain limit for design Level 2 is much lower for the in-ground hinge compared to the pile-deck hinge.

(a) Level 1

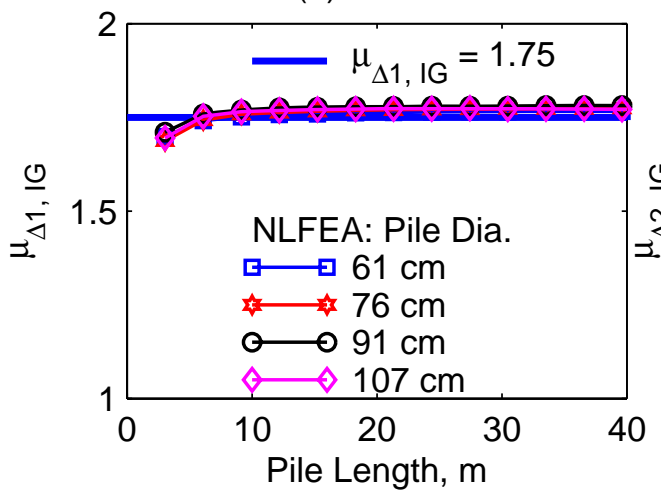

(b) Level 2

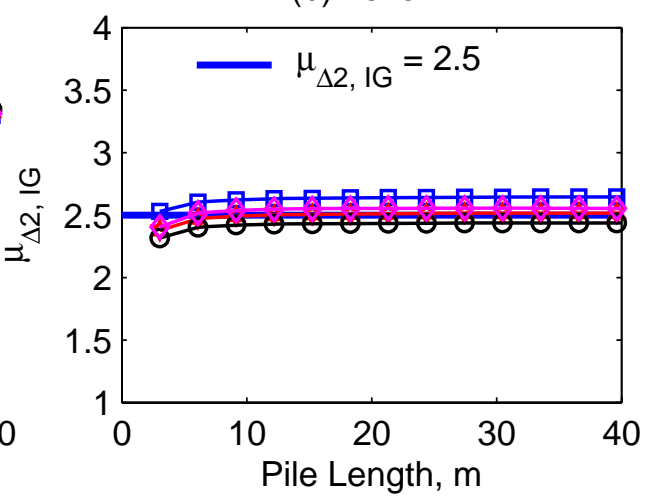

Figure 6.8. Lower-bound value of displacement ductility capacity due to in-ground hinge formation for seismic design (a) Level 1, and (b) Level 2. 


\subsection{SIMPLIFIED PROCEDURE TO COMPUTE DISPLACEMENT CAPACITY}

Displacement capacity of piles at a selected design level may be estimated from

$$
\Delta_{c}=\mu_{\Delta} \Delta_{y}
$$

in which $\mu_{\Delta}$ is the ductility capacity at a selected design level and location of hinge, i.e., equal to 1.75 for Level 1 design and 5 for Level 2 design if the hinge were to form in the pile near the deck, and equal to 1.75 for Level 1 and 2.5 for Level 2 if the hinge were to form in-ground, and $\Delta_{y}$ is the yield displacement of the pile. The yield displacement can be computed from nonlinear pushover analysis of the pile. Alternatively, the yield displacement may be estimated based on section yield moment and effective section $E I_{e}$. For example, the yield displacement of a pile that is fixed at the bottom and prevented from rotation at the top due to a rigid deck may be estimated from

$$
\Delta_{y}=\frac{M_{y} L^{2}}{6 E I_{e}}
$$

and yield displacement of a cantilever may be estimated from

$$
\Delta_{y}=\frac{M_{y} L^{2}}{3 E I_{e}}
$$

in which $M_{y}$ is the section yield moment and $E I_{e}$ is the effective value of $E I$ that can be estimated from the section moment-curvature relationship analysis as the initial slope of the idealized bilinear moment-curvature relationship (see Figure 4.2).

The accuracy of the procedure to estimate the displacement capacity of piles is evaluated next. For this purpose, the approximate displacement capacity is computed first from Equation (6.6) by utilizing the yield displacement from Equation (6.7) or (6.8) depending on the boundary conditions. The exact displacement capacity is computed next from Equation (6.6) but with yield displacement estimated from nonlinear static pushover analysis of the pile. For both cases, the value of the ductility capacity obtained from the pushover analysis is used. The approximate and exact displacement capacities are compared in Figure 6.9 for a pile with $91 \mathrm{~cm}$ diameter. These 
results indicate that the approximate analysis provides an excellent estimate of the displacement capacity of the pile for Level 1 as well as Level 2 design.

(a) Level 1, IG or PD

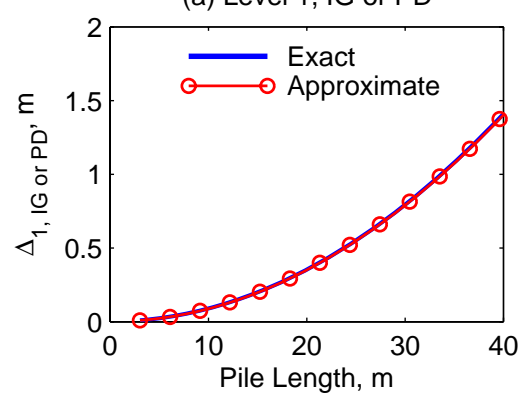

(b) Level 2, IG

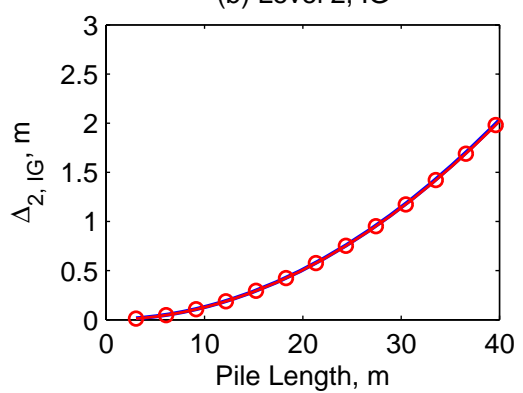

(c) Level 2, PD

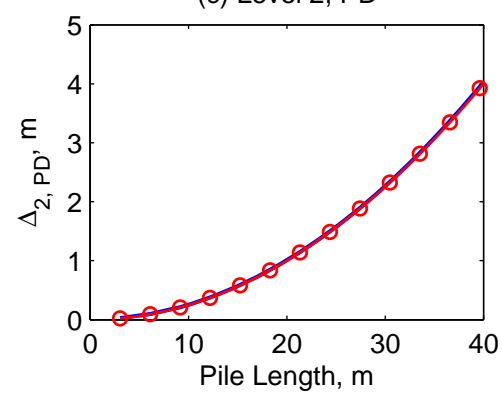

Figure 6.9. Comparison of displacement capacities due to pile-deck hinge formation from exact and approximate analyses.

The approximate analysis is attractive because it eliminates the need for nonlinear static analysis of the pile. However, it must be noted that the approximate analysis may only be used for the soil-pile-deck system that can be idealized either by a fixed-fixed column or by a cantilever column - the two cases for which closed form solutions to estimate yield displacement are available (see Equations 6.7 and 6.8) - using the equivalent displacement fixity concept. For other cases, the yield displacement may have to be estimated from nonlinear static pushover analysis of the soil-pile-deck system. 


\section{DISPLACEMENT CAPACITY OF HOLLOW STEEL PILES}

This Chapter presents development of a simplified procedure for estimating displacement capacity of hollow steel piles connected to the deck either by a pin connection or by a fullmoment-connection strong enough to force hinging in the steel pile. For this purpose, the current approach in the MOTEMS (see Equations 4.1 to 4.6 in Chapter 4) is further simplified. Presented first is the development of simplified equations to compute displacement ductility of hollow steel piles that are independent of the pile length and depend only on the pile section ductility and seismic design level. The accuracy of these equations is then evaluated against results from nonlinear finite element analyses. Subsequently, results of a parametric study are presented to show the sensitivity of the displacement ductility capacity on pile diameter, pile thickness, and axial force level. Based on these results, lower bound estimates of the ductility capacity of hollow steel piles for two design levels - Level 1 and Level 2 - are proposed. Finally, it is demonstrated that the lower-bound displacement ductility values along with simplified expressions for yield displacement provide very good estimates of the displacement capacity of piles when compared against values from nonlinear finite element analysis.

\subsection{THEORETICAL BACKGROUND}

Similar to the displacement ductility of reinforced concrete piles, the displacement ductility capacity of hollow steel piles may also be defined as

$$
\mu_{\Delta} \simeq 1+3\left(\mu_{\phi}-1\right)\left(\frac{L_{p}}{L}\right)\left(1-0.5 \frac{L_{p}}{L}\right)
$$

The MOTEMS does not explicitly provide guidelines for selecting length of the plastic hinge for hollow steel piles. Based on calibration of results from finite element analysis against those from Equation (7.1) (see results presented later in Figure 7.1), it was found that the following plastic hinge lengths are appropriate for the two seismic design levels for hollow steel piles in Marine Oil and LNG Terminals:

$$
\begin{gathered}
L_{p} \simeq 0.03 L \text { for Level } 1 \\
L_{p} \simeq 0.075 L \text { for Level } 2
\end{gathered}
$$


With the plastic hinge length selected as given by Equations (7.2(a) and 7.2(b)), Equation (7.1) simplifies to

$$
\begin{array}{ll}
\mu_{\Delta}=0.9113+0.0886 \mu_{\phi} & \text { for Level } 1 \\
\mu_{\Delta}=0.7834+0.2166 \mu_{\phi} & \text { for Level } 2
\end{array}
$$

As noted previously for reinforced concrete piles, Equations (7.3(a) and 7.3(b)) for displacement ductility capacity of hollow steel piles also indicates that the displacement ductility capacity is independent of the pile length and it can be computed directly from the section curvature ductility capacity. Because the plastic hinge length differs for the two design levels, the displacement ductility also depends on the seismic design level.

\subsection{EVALUATION OF SIMPLIFIED EQUATIONS FOR DUCTILITY CAPACITY}

The accuracy of Equations (7.3(a) and 7.3(b)) in estimating displacement ductility capacity of hollow steel piles at seismic design Level 1 and Level 2, respectively, is evaluated in this section. For this purpose, displacement ductility capacity of hollow steel piles is evaluated from nonlinear static pushover analysis of a finite element model. The pile is considered to be fixed at top and bottom. These boundary conditions correspond to a pile that is connected to the pile-cap with a full-moment connection that would force formation of a plastic hinge in the steel pile, and utilizes the equivalent displacement fixity assumption at the bottom. The axial load on the pile is assumed to be $0.05 A f_{y}$ in which $A$ is the cross section area of the pile and $f_{y}$ is the yield strength of steel. The pile wall thickness is assumed to be $1.27 \mathrm{~cm}$.

The pile is modeled with a nonlinear beam-column element using the computer program "Open System for Earthquake Engineering Simulation (OpenSees)", (McKenna and Fenves, 2001). The distributed plasticity is considered by specifying the section properties by a fiber section model and the using seven integration points along the element length; details of such modeling may be found in McKenna and Fenves (2001). Strains in steel are monitored during the pushover analysis. The limiting values of strain in steel are 0.008 and 0.025 for Level 1 and Level 2, respectively for in-ground or pile-deck hinge formation. The displacement ductility at a selected design level corresponds to the largest displacement that can occur at the tip of the pile without the strain limit in steel being exceeded. 
The results are presented in Figure 7.1 for three pile diameters $-61 \mathrm{~cm}, 91 \mathrm{~cm}$, and $107 \mathrm{~cm}$. These results permit two important observations. First, results from the nonlinear finite element analysis confirm expectations from Equation (7.3(a) and 7.3(b)) that the displacement ductility capacity is independent of the pile length. This becomes apparent by essentially no variation in the ductility capacity from the nonlinear finite element analysis with the various pile lengths in Figure 7.1 for both design levels and all pile diameters.

(a) Level 1
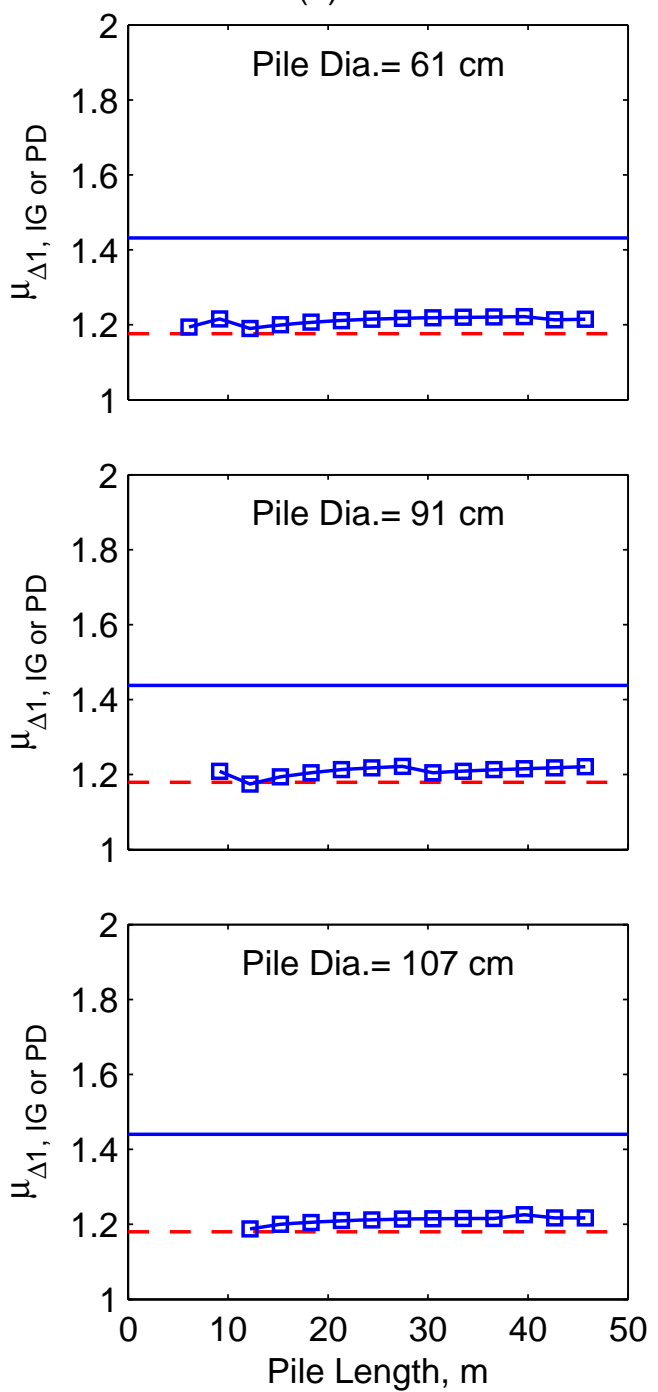

(b) Level 2
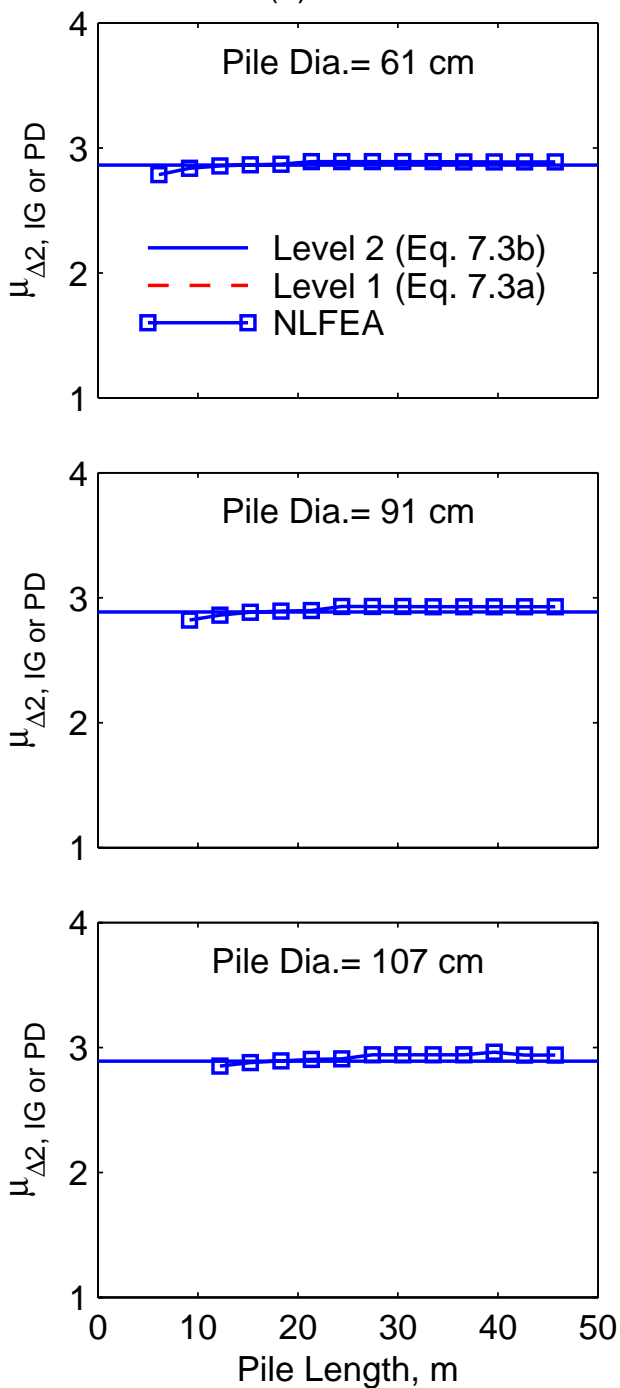

Figure 7.1. Displacement ductility capacity from simplified equations and nonlinear finite element analysis (NLFEA) for seismic design (a) Level 1 and (b) Level 2.

Second, Equations (7.3(a) and 7.3(b)) provide very good estimates of the displacement ductility capacity of hollow steel piles at seismic design Level 1 (see Figure 7.1(a)) and Level 2 (see Figure 7.1(b)), respectively. If Equation (7.3(b)) were to be used to estimate, displacement 
ductility capacity at seismic design Level 1 , it would provide an estimate that significantly exceeds the value from nonlinear finite element analysis (see Figure 7.1(a)). Therefore, a lower value of the plastic hinge length, as has been used in Equation (7.3(a)) for seismic design Level 1 is justified.

These results indicate that the moment-rotation relationship to be used in the concentrated plasticity model of hollow steel piles should consider different plastic hinge lengths for the two design levels. If the same plastic hinge length, i.e., that for seismic design Level 2, is used in the model that computes the displacement ductility capacity for Level 1, it may significantly overestimate the displacement capacity for that design level (Level 1).

It is useful to note that the plastic hinge length for hollow steel piles in this investigation is proposed based on calibration against nonlinear finite element results. It would be useful to verify these findings from experiments on hollow steel pile conducted at displacement levels that are expected during seismic design Level 1 and Level 2.

(a) Level 1

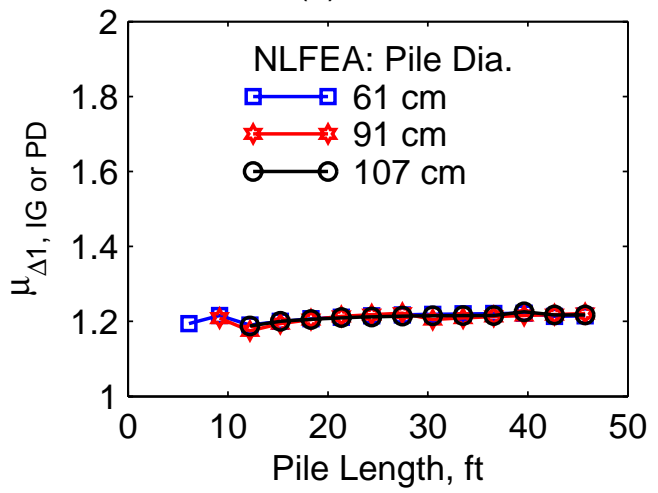

(b) Level 2

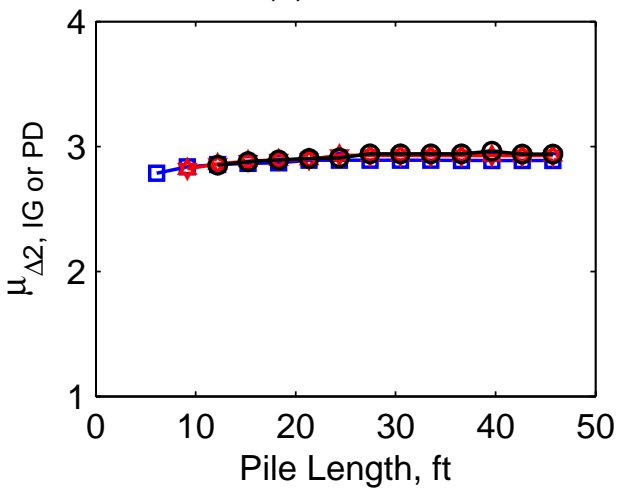

Figure 7.2. Variation of displacement ductility capacity computed from nonlinear finite element analysis (NLFEA) with pile length and pile diameter: (a) Level 1, and (b) Level 2.

\subsection{SENSITIVITY OF DISPLACEMENT DUCTILITY TO PILE PARAMETERS}

\subsubsection{Pile Length and Pile Diameter}

Figure 7.2 presents variation of displacement ductility capacity with pile length for three values

of pile diameters: $61 \mathrm{~cm}, 91 \mathrm{~cm}$, and $107 \mathrm{~cm}$. The results are presented for piles with wall thickness of $1.27 \mathrm{~cm}$. Results in Figure 7.2 indicate that the displacement ductility capacity of piles is essentially independent of the pile length. This is expected because Equations (7.3(a) and 7.3(b)) becomes independent of the pile length. The results of Figure 7.2 also indicate that the 
displacement ductility capacity of the pile is also essentially independent of the pile diameter as apparent from almost identical curves for the three pile diameters considered.

In order to understand the aforementioned trend, i.e., independence of the displacement ductility capacity of pile diameter, it is useful to examine the variation of pile section curvature ductility capacity. The results presented in Figure 7.3 indicate that the section curvature ductility capacity is essentially independent of the pile diameter. This observation, along with Equations (7.3(a) and 7.3(b)), then confirms that the pile displacement ductility capacity should also be independent of the pile diameter.

(a) Level 1

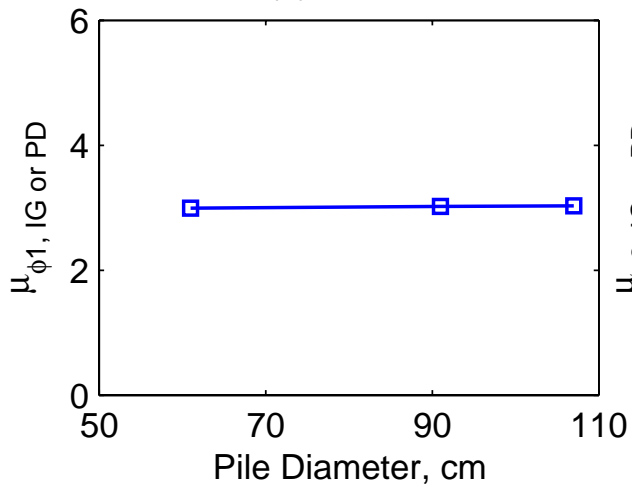

(b) Level 2

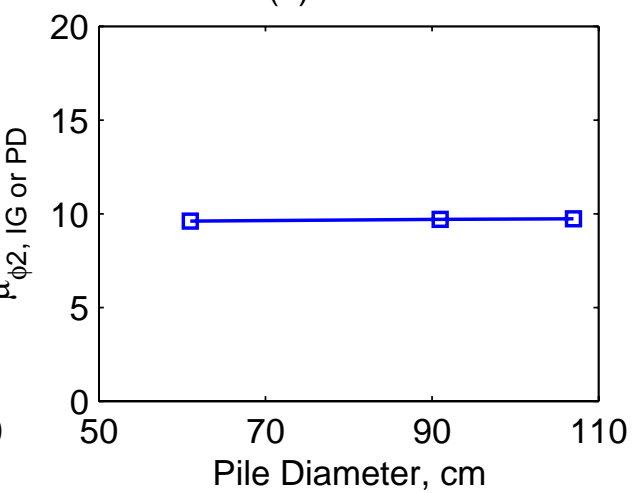

Figure 7.3. Variation of section curvature ductility capacity with pile diameter: (a) Level 1, and (b) Level 2.

\subsubsection{Pile Wall Thickness}

The effects of the pile wall thickness on the displacement ductility capacity are examined next. For this purpose, variations of displacement ductility with pile length for three values of pile thickness are compared in Figure 7.4. The results presented are for a pile with $91 \mathrm{~cm}$ diameter and axial force equal to $0.05 A f_{y}$. These results show that the displacement ductility is essentially independent of the pile wall thickness as indicated by essentially identical curves for the three values of pile wall thickness. 
(a) Level 1

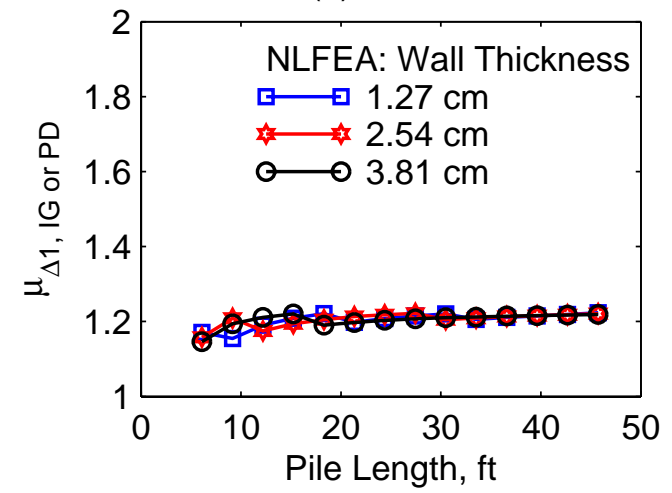

(b) Level 2

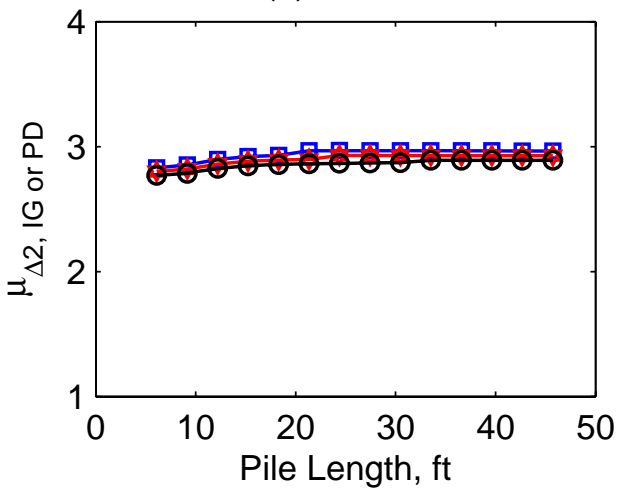

Figure 7.4. Variation of displacement ductility capacity computed from nonlinear finite element analysis (NLFEA) with pile length for three values of pile wall thickness: (a) Level 1, and (b) Level 2.

\subsubsection{Axial Force}

Figure 7.5 presents variation of displacement ductility capacity with axial force in the pile. The presented results are for a pile with $91 \mathrm{~cm}$ diameter and $15 \mathrm{~m}$ length with values of axial force varying from zero to $0.2 A f_{y}$. These results show that the displacement ductility for Level 1 is essentially independent of the pile axial load (Figure 7.5(a)). For Level 2, while the displacement ductility may depend on the axial load for very-low axial loads, it becomes essentially independent of the axial load for more realistic values. However, the ductility for Level 2 appears to be insensitive to the axial force values, i.e., axial loads greater than $0.05 A f_{y}$ (Figure $7.5(b))$.

(a) Level 1

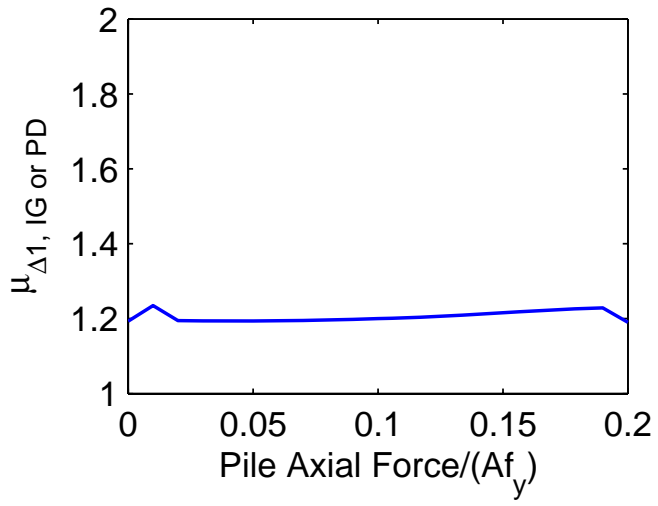

(b) Level 2

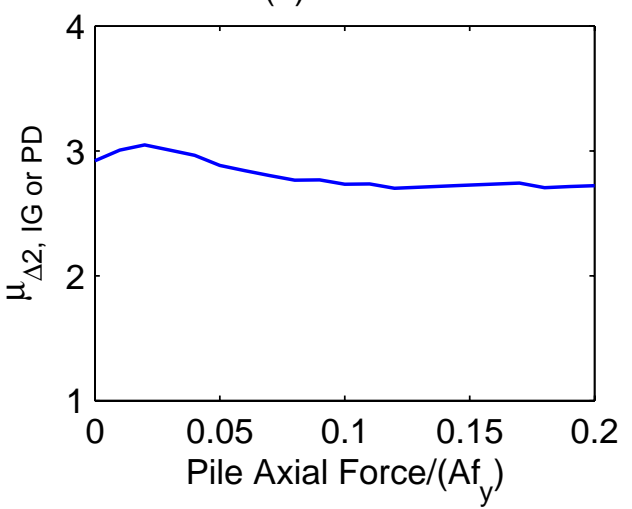

Figure 7.5. Variation of displacement ductility capacity computed from nonlinear finite element analysis with pile axial load ratio: (a) Level 1, and (b) Level 2. 


\subsection{LOWER BOUND OF DISPLACEMENT DUCTILITY CAPACITY}

The results presented so far indicate that the displacement ductility of hollow steel piles is relatively insensitive to pile length, pile diameter, pile wall thickness, and pile axial load. Therefore, the displacement ductility appears to be a very robust parameter that can be used in simplified design of piles instead of the various axial strain limits which are currently specified in the MOTEMS. While the displacement ductility may be related to the pile curvature ductility using Equation (7.3), the results presented in the preceding section also indicate that a lower bound of the member displacement ductility capacity may be estimated without any knowledge about the section curvature ductility capacity for practical range of various parameters. The results presented in Figure 7.6 for pile-deck hinge indicate that the displacement ductility capacity may be limited to 1.2 for seismic design Level 1 and 2.75 for seismic design Level 2 .

(a) Level 1

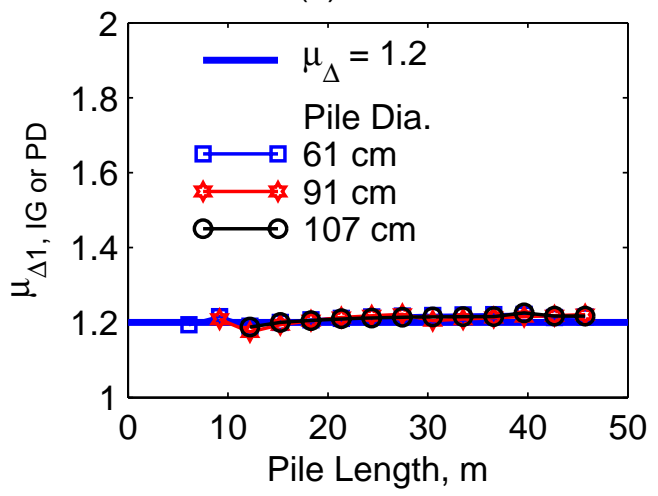

(b) Level 2

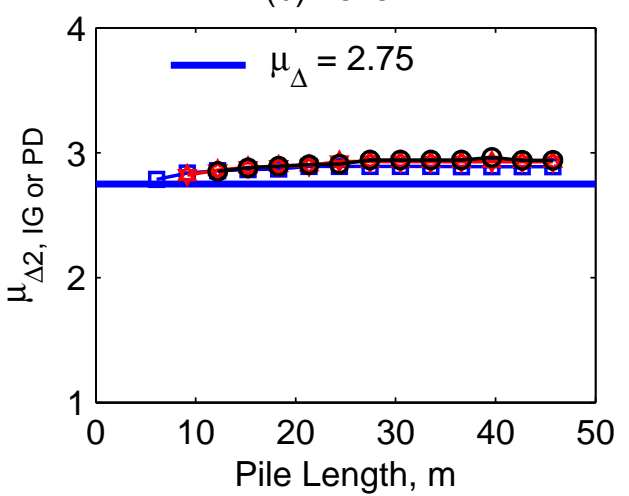

Figure 7.6. Lower-bound value of displacement ductility capacity of hollow steel piles for seismic design (a) Level 1, and (b) Level 2.

\subsection{SIMPLIFIED PROCEDURE TO COMPUTE DISPLACEMENT CAPACITY}

Displacement capacity of piles at a selected design level may be estimated from

$$
\Delta_{c}=\mu_{\Delta} \Delta_{y}
$$

in which $\mu_{\Delta}$ is the ductility capacity at a selected design level, i.e., equal to 1.2 for Level 1 design and 2.75 for Level 2 design, and $\Delta_{y}$ is the yield displacement of the pile. The yield displacement can be computed from nonlinear pushover analysis of the pile. Alternatively, the yield displacement may be computed based on section properties. For example, the yield displacement of a pile that is fixed at the bottom and prevented from rotation at the top due to 
rigid deck may be estimated from

$$
\Delta_{y}=\frac{M_{y} L^{2}}{6 E I}
$$

and yield displacement of a cantilever may be estimated from

$$
\Delta_{y}=\frac{M_{y} L^{2}}{3 E I}
$$

in which $M_{y}$ is the effective section yield moment that can be estimated from section momentcurvature analysis and $I$ is the section moment of inertia that can be estimated from the section properties, and $E$ is the modulus of elasticity for steel.

The accuracy of the approximate procedure to estimate the displacement capacity of piles is evaluated next. For this purpose, the approximate displacement capacity is computed first from Equation (7.4) by utilizing the yield displacement from Equation (7.5) or (7.6) depending on the boundary conditions. The exact displacement capacity is computed next from Equation (7.4) but with yield displacement estimated from nonlinear the static pushover analysis of the pile. For both cases, value of the ductility capacity obtained from the pushover analysis is used. The approximate and exact displacement capacities are compared in Figure 7.7 for a pile with $91 \mathrm{~cm}$ diameter. These results indicate that the approximate analysis provides an excellent estimate of the displacement capacity of the pile for Level 1 as well as Level 2 design.

(a) Level 1

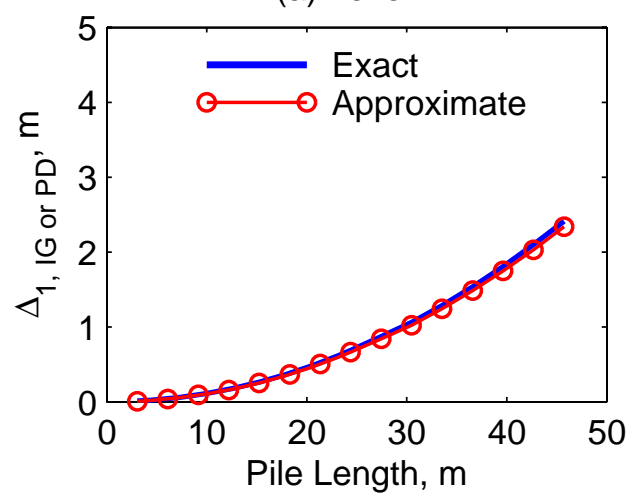

(b) Level 2

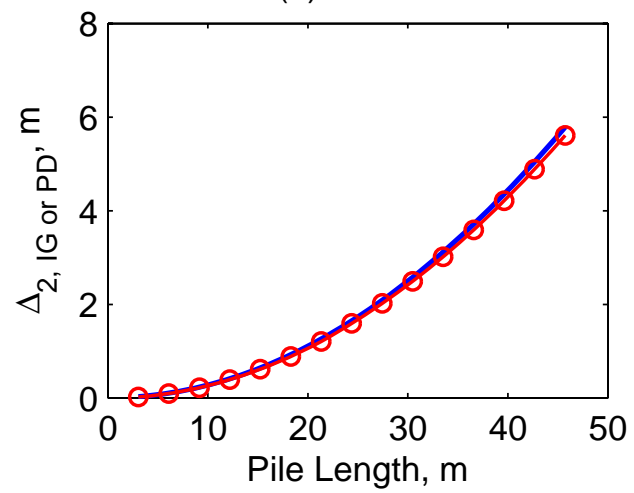

Figure 7.7. Comparison of displacement capacities from exact and approximate analyses.

The approximate analysis is attractive because it eliminates the need for nonlinear static analysis of the pile. However, it must be noted that the approximate analysis may only be used 
for the soil-pile-deck system that can be idealized either by a fixed-fixed column or by a cantilever column - the two cases for which closed form solutions to estimate yield displacement are available (see Equations 7.5 and 7.6) - using equivalent displacement fixity concept. For other cases, the yield displacement may have to be estimated from nonlinear static pushover analysis of the soil-pile-deck system. 


\section{DISPLACEMENT CAPACITY OF PILES WITH DOWEL-CONNECTION}

Piles are often connected to the deck using dowels. The size and number of dowel bars are typically selected so that the moment capacity of the connection is smaller than the moment capacity of the pile. As a result, the yielding is expected to occur in the connection rather than the pile. The nonlinear behavior of piles with such partial-moment connection to the deck slab may differ significantly compared to the piles with full-moment connections presented in the previous chapters. This chapter describes two types of dowel-connections - hollow steel piles connected to the deck by a concrete plug and dowels, and prestressed concrete piles connected to the deck by dowels grouted into the pile and embedded in the deck concrete. Subsequently, nonlinear behavior of such connections is examined. Finally, closed form solutions for estimating displacement capacity of piles with partial-moment connections are presented.

\subsection{DOWEL-CONNECTIONS}

\subsubsection{Hollow Steel Piles}

Figure 8.1 shows details of the connections between a hollow steel pile and the concrete deck of a Marine Oil or LNG Terminal. In this connection, denoted as the concrete-plug connection, dowels are embedded in a concrete plug at the top of the pile. The concrete plug is held in place by shear rings at its top and bottom; the shear rings would prevent the concrete plug from slipping out (or popping-out) during lateral loads imposed by earthquakes. Others have proposed details in which the concrete plug is held in place either by natural roughness of the inside surface of the steel shell or use of weld-metal laid on the inside of the steel shell in a continuous spiral in the connection region prior to placing the concrete plug (Ferritto et al., 1999). The dowels are then embedded in the concrete deck to provide sufficient development length. A small gap may or may not be provided between top of the pile and top of the concrete plug. This concrete-plug connection has been shown to provide remarkable ductility capacity of hollow steel piles (Priestley and Park, 1984; Park et al., 1987). The force transfer mechanism between the steel pile and the concrete plug has also been investigated by Nezamian et al. (2006). 


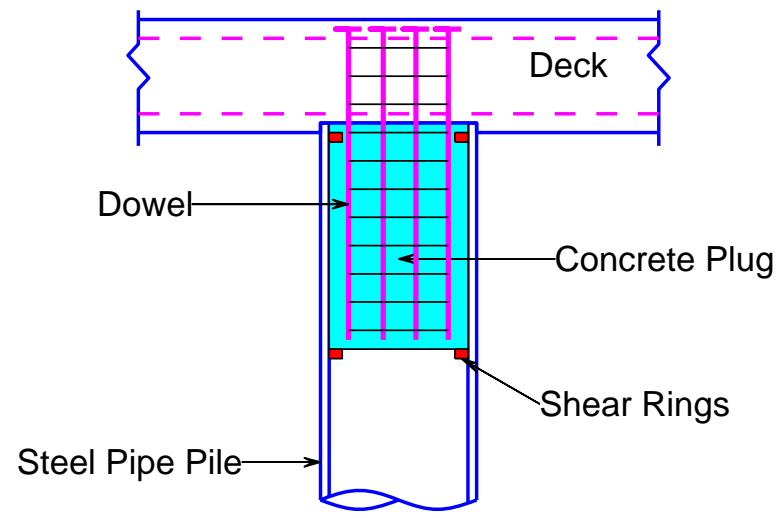

Figure 8.1. Concrete-plug connection between hollow steel pile and concrete deck.

\subsubsection{Prestressed Concrete Piles}

Figure 8.2 shows details of the connections between a prestressed pile and the concrete deck of a Marine Oil or LNG Terminal (Klusmeyer and Harn, 2004; Wray et al., 2007; Roeder et al., 2005). Prestressed piles typically have corrugated metal sleeves that are embedded in the concrete. These sleeves are located inside of the confined concrete core formed by the prestressing strands and confining steel. Once the prestressed pile has been driven to the desired depth, the dowels are grouted into the sleeves. If higher flexibility of the connection is desired, a small portion of the dowel at the top of the pile may be wrapped in Teflon to ensure de-bonding between the dowel and the grout. The dowels are then embedded in the concrete deck to provide sufficient development length. Note that Figure 8.2 shows only two outermost dowels; the other dowels are not shown to preserve clarity in the figure.

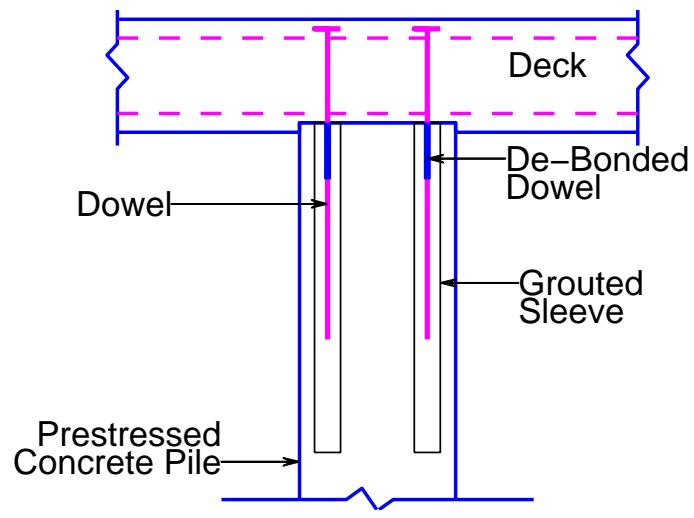

Figure 8.2. Dowel-connection between prestressed concrete pile and concrete deck. 


\subsubsection{Behavior of Dowel-Connection}

While analyzing Marine Oil and LNG Terminal structures, nonlinear behavior of pile and connection is typically represented by moment-rotation relationships. The moment-rotation relationship is developed based on the assumption of a plane section remaining plane and a perfect bond between the steel reinforcing bars and concrete. For the concrete-plug connection between hollow steel piles and deck or the dowel-connection between a prestressed pile and deck; however, such assumptions may not be valid. In particular, the pile in a such connection rotates about a small area on compression side of the pile forming a gap between the top of the pile and the deck on the tension side of the pile (see Figure 8.3). This behavior is akin to the pile acting like a crowbar bearing on a small compression area. This behavior leads to de-bonding of the dowel (or strain penetration) on each side of the joint. Additional de-bonding may also occur in the dowel over the portion that is intentionally wrapped in Teflon.

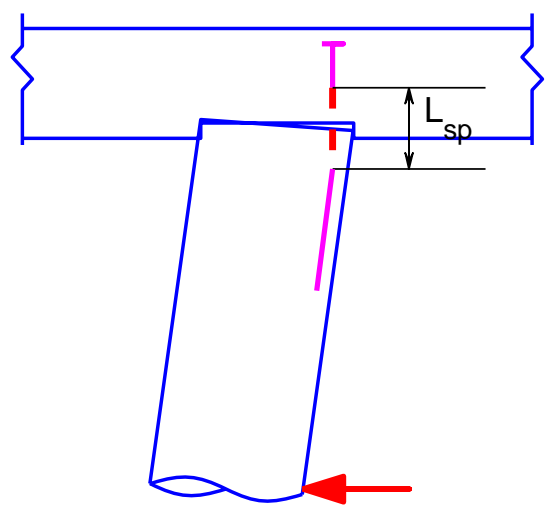

Figure 8.3. Behavior of piles with concrete-plug or dowel-connection.

\subsection{MOMENT-ROTATION RELATIONSHIP OF DOWEL-CONNECTION}

Bob Harn and George Sheng of Berger/ABAM Engineers Inc recently proposed a simple analytical model for developing nonlinear moment-rotation behavior of concrete-plug connections for hollow steel piles (see Figure 8.4) or dowel-connections for prestressed piles (see Figure 8.5). For a selected value of the reinforcing bar yield stress, $f_{y}$, concrete strength, $f_{c}^{\prime}$, diameter and area of reinforcing bars, $d_{b i}$ and $A_{s i}$, respectively, bearing strength of deck concrete against pile concrete as $f_{m}^{\prime}=1.7 f_{c}^{\prime}$, and bearing strength of deck concrete against steel shell of hollow steel pile as $f_{m}^{\prime}=5.6 f_{c}^{\prime}$, the moment-rotation relationship is developed as 
follows:

1. Select a value of strain in the outermost dowel on the tension side, $\varepsilon_{1}$. Typically the first strain value is selected as the yield strain in steel, $\varepsilon_{y}$.

2. Establish the location of the neutral axis of the section by the following iterative procedure:

2.1. Guess the location of the neutral axis.

2.2. Calculate strains in all dowels.

2.3. Calculate forces in all dowels, $T_{i}$. Note that dowel forces would be tensile on the tension side of the neutral axis and compressive on the compression side of the neutral axis.

2.4. Calculate compressive force, $C_{c}$, in concrete on compression side of the neutral axis.

2.5. Calculate compressive force, $C_{s}$, due to bearing of steel shell against the deck for hollow steel piles. Note that this step would not be necessary for prestressed concrete piles.

2.6. Check that summation of all forces, including any axial force on the pile, is equal to zero.

2.7. Repeat Steps 2.1 to 2.6 until summation of forces in Step 2.6 is essentially equal to zero.

3. Estimate the length of strain-penetration in the dowel: $L_{s p}=0.15 f_{s} d_{b}+L_{d b}$ in which $f_{s}$ is the allowable dowel stress in units of ksi, $d_{b}$ is the dowel diameter in inches, and $L_{d b}$ is the length of de-bonded reinforcing bar (as may be the case for prestressed concrete piles). Alternatively, the strain penetration length may be selected as $L_{s p}=5 d_{b}+L_{d b}$ or as per the recommendations by Raynor et al. (2002).

4. Compute the elongation of the outermost dowel: $\Delta L_{1}=\varepsilon_{1} L_{s p}$.

5. Compute the rotation of the concrete-plug connection: $\theta=\Delta L_{1} / Y_{1}$ in which $Y_{1}$ is the distance between the neutral axis and the outermost dowel on the tension side of the neutral axis.

6. Compute the moment, $M$, as the summation of moments at the center of the pile due to tensile as well as compressive forces.

7. Repeat Steps 1 to 6 to develop the entire moment-rotation relationship of the connection.

8. Idealize the moment-rotation relationship by using a bi-linear curve. 


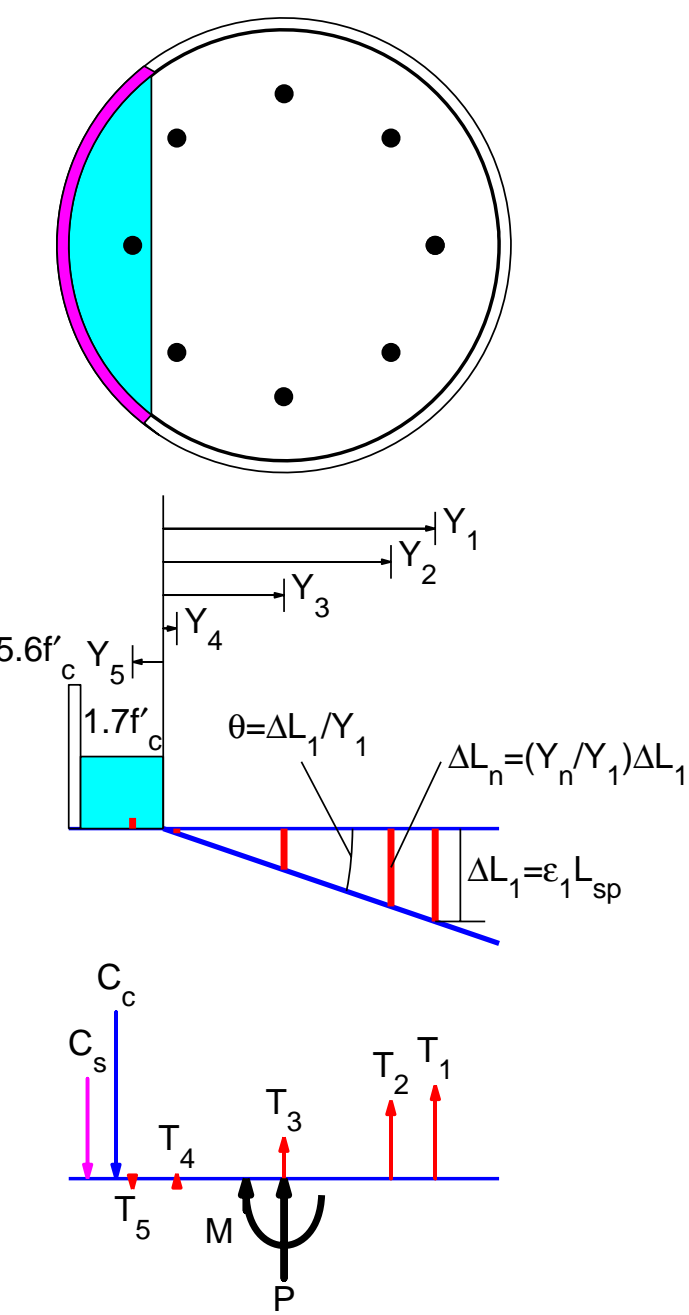

Figure 8.4. Analytical model to generate the moment-rotation relationship of the concrete-plug connection between a hollow steel pile and a concrete deck.

Figures 8.6 and 8.7 show the moment rotation relationship of the concrete-plug connection for a hollow steel pile, a dowel connection and for a prestressed concrete pile, respectively. The nonlinear moment-rotation relationship (shown in solid line) has been idealized by a bilinear moment-rotation relationship (shown in dashed line). It is apparent from these results that the post-yield slope of the moment-rotation relationship is very small compared to the slope in the linear-elastic portion. Therefore, it may be possible to simply idealize this curve with an elasticperfectly-plastic curve without much loss in accuracy. 


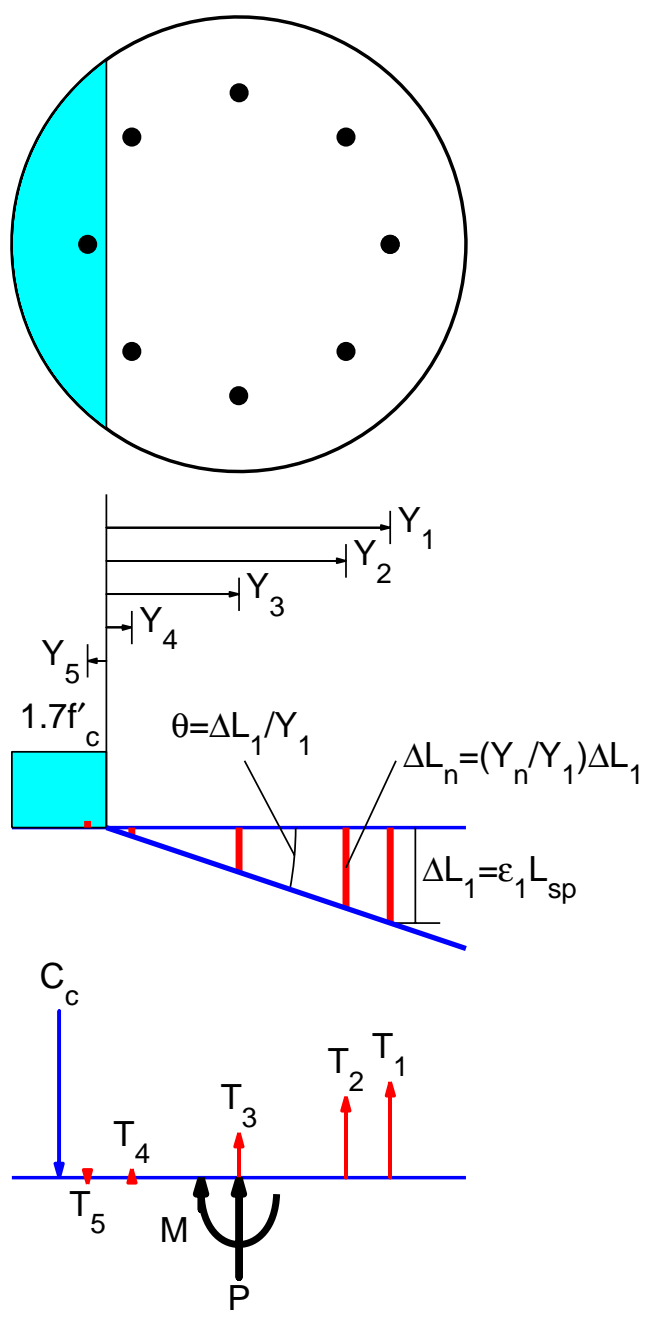

Figure 8.5. Analytical model to generate the moment-rotation relationship of a dowel connection between a prestressed concrete pile and a concrete deck. 


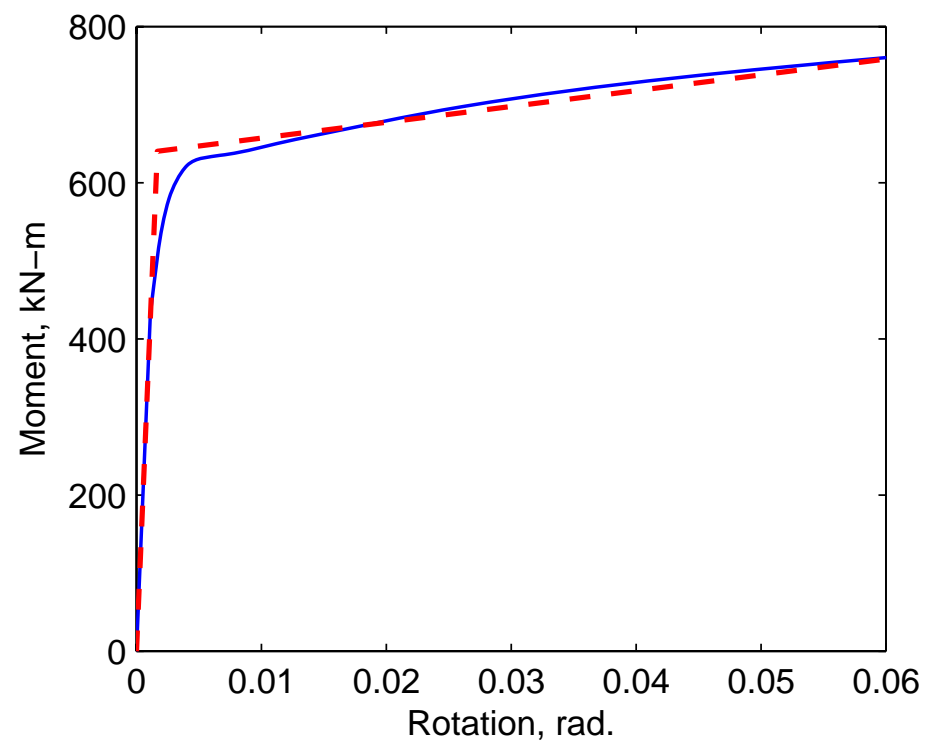

Figure 8.6. Moment-rotation relationship of a concrete-plug connection for hollow steel piles. The results are for a steel pile of $61 \mathrm{~cm}$ diameter, $1.27 \mathrm{~cm}$ wall thickness, axial load of $0.05 f_{y} A$, and 8 dowels each with an area of $8.2 \mathrm{~cm}^{2}$.

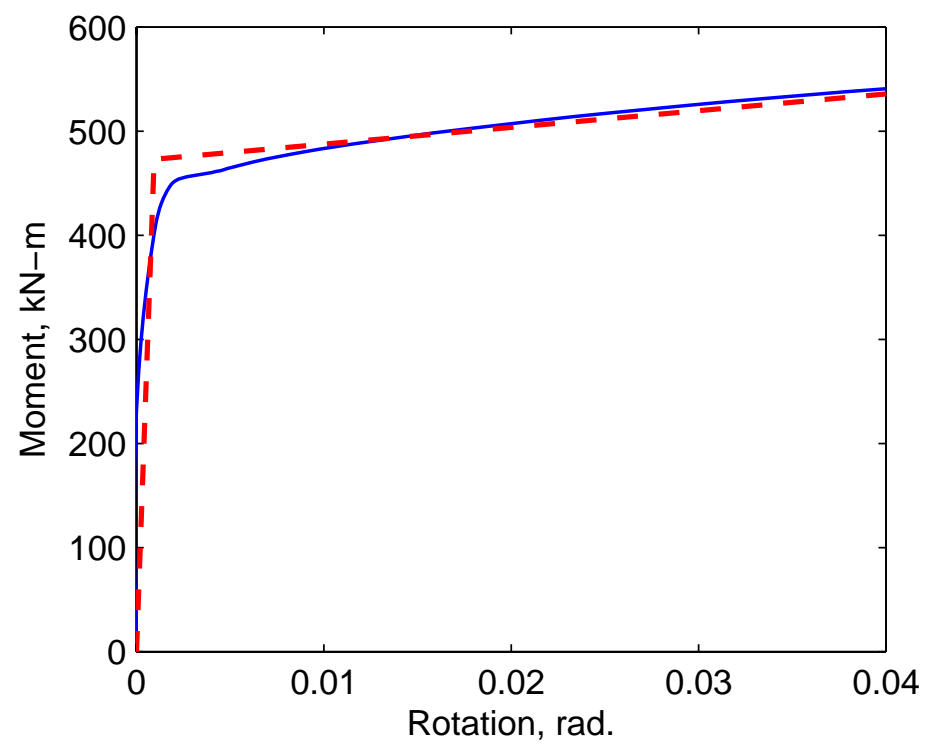

Figure 8.7. Moment-rotation relationship of a dowel connection for prestressed concrete piles. The results are for a steel pile of $61 \mathrm{~cm}$ diameter pile, axial load of $0.05 f_{c}^{\prime} A, 8$ dowels each with an area of $3.9 \mathrm{~cm}^{2}$, and de-bonded length of reinforcing bars equal to $30 \mathrm{~cm}$. 


\section{SIMPLIFIED MODEL OF PILE WITH DOWEL-CONNECTION}

A hollow steel pile with a concrete-plug connection or a prestressed pile with a dowel connection to the deck may be idealized as a beam-column element fixed at the base and a rotational spring at the top (Figure 9.1). The length of the element is equal to the free-standing height of the pile plus the depth of fixity below the mud-line. This length is selected as the length of a fixed-base cantilever that would have same lateral displacement at the pile top as the actual pile (see Priestley at al., 1996; Chai, 2002). The rotational spring at the top of the pile represents the nonlinear behavior of the concrete-plug or the dowel connection. Ignoring axial deformations in the pile, this system can be modeled with two displacement degrees-of-freedom: lateral displacement, $\Delta$, and rotation, $\theta$, at the top. When a lateral force, $F$, is applied at the top of the pile, a moment, $M$, also develops at the top due to the rotational resistance provided by the rotational spring representing the concrete-plug or the dowel connection. Note that the rotation in the rotational springs is equal to rotation at top of the pile.

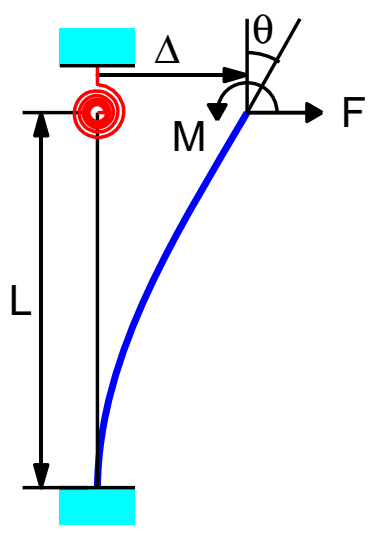

Figure 9.1. Simplified model of the pile with partial-moment connection to the deck.

Presented in this chapter is the development of a simplified procedure for estimating the displacement capacity of hollow steel piles with concrete-plugs or prestressed piles with dowel connections at the deck without the need to monitor strains during the pushover analysis. In particular, formulas for estimating displacement capacity of such piles are developed.

\subsection{IDEALIZED CONNECTION AND PILE BEHAVIOR}

\subsubsection{Moment-Rotation Behavior of Connection}

The moment-rotation relationship for the concrete-plug or dowel connection between the pile 
and the deck may be idealized as a bilinear (elastic-perfectly-plastic) curve (Figure 9.2). The initial elastic stiffness and yield moment of the partial-moment-connection are defined by $k_{\theta}$ and $M_{y, \mathrm{C}}$, respectively. If $\theta_{L}$ is the rotation in the rotational spring when the strain in the outermost dowel of the concrete-plug connection for hollow steel piles or the dowel connection in prestressed concrete piles just reaches the strain limit specified for a selected design level, the rotational ductility of the connection at specified strain limits is defined by

$$
\mu_{\theta}=\frac{\theta_{L}}{\theta_{y}}
$$

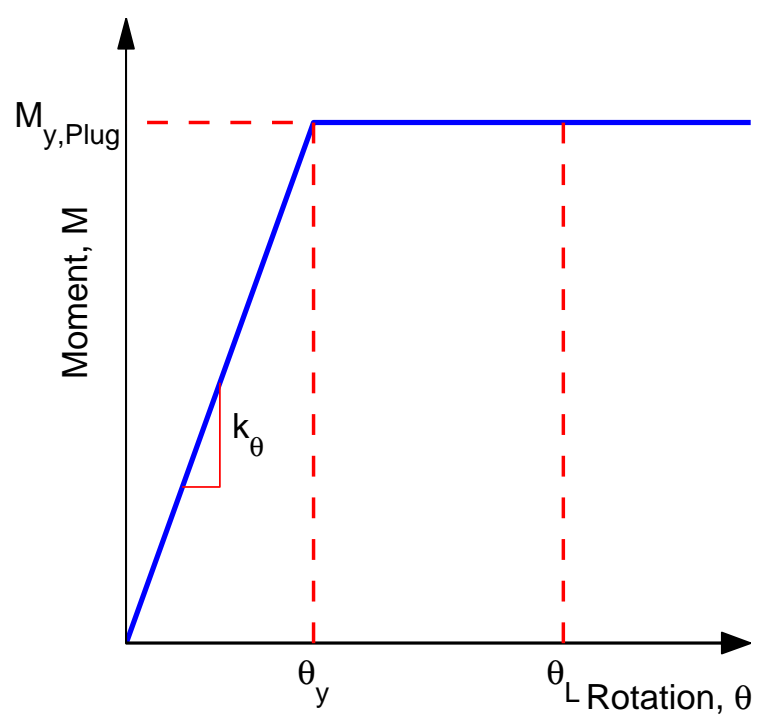

Figure 9.2. Idealized moment-rotation relationship of the dowel-connection.

\subsubsection{Moment-Curvature Behavior of Pile Section}

The moment-curvature relationship of the pile section can also be idealized as a bilinear curve (Figure 9.3). The initial slope of this curve is equal to $E I$ and post-yield slope is equal to $\alpha E I$ in which $\alpha$ is the ratio of the post-yield slope and initial slope of the curve. The moment and curvature at effective yielding of the pile are $M_{y, \mathrm{P}}$ and $\phi_{y}$, respectively. Note that the effective yield moment, $M_{y, \mathrm{P}}$, of the pile section in the idealized bi-linear moment-curvature relationship differs slightly from the yield moment at initiation of first yielding in the outermost fiber of the hollow steel pile or outermost strand of the prestressed concrete pile. While the $M_{y, \mathrm{P}}$ for prestressed concrete piles should be estimated from the moment-curvature relationship, $M_{y, \mathrm{P}}$ for 
hollow steel piles may be estimated from the formula for its plastic moment capacity as

$$
M_{\mathrm{y}, \mathrm{P}}=f_{y}\left(\frac{d_{o}^{3}-d_{i}^{3}}{6}\right)
$$

If $\phi_{L}$ is the curvature of the pile section when the material strain just reaches the strain limit specified for a selected design level, the pile section curvature ductility is defined as

$$
\mu_{\phi}=\frac{\phi_{L}}{\phi_{y}}
$$

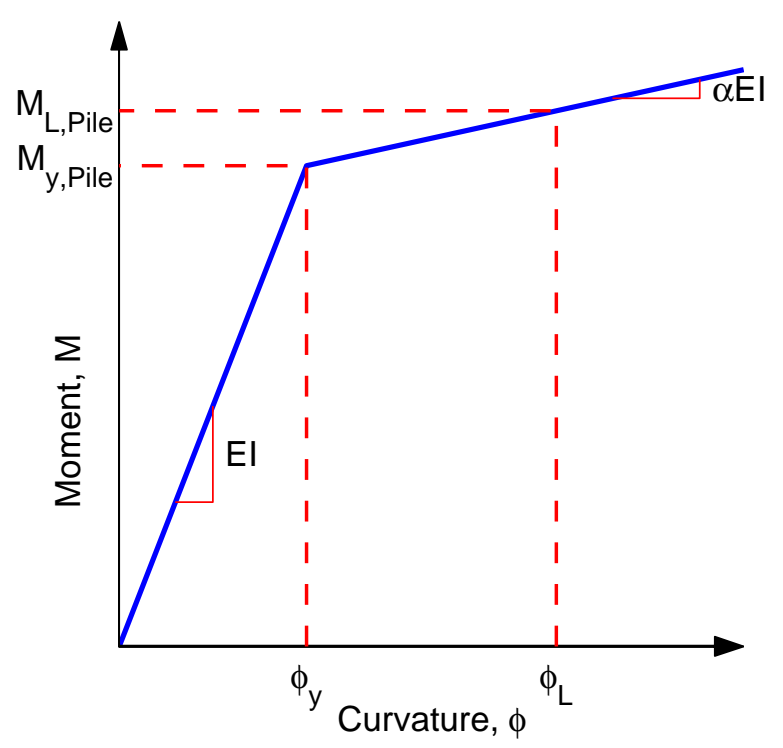

Figure 9.3. Idealized moment-curvature relationship of the pile section.

\subsubsection{Force-Deformation Relationship of Pile with Dowel-Connection}

The force-deformation behavior (or pushover curve) of a pile with fixed-base and a rotational spring at the top may be idealized by a tri-linear relationship shown in Figure 9.3. For piles with dowel-connections to the deck, the yield moment of the connection is typically selected to be smaller than the yield moment of the pile section. For such a condition, the first yielding in the pile system would occur in the connection at lateral force and displacement equal to $F_{y, C}$ and $\Delta_{y, \mathrm{C}}$, respectively. Since the pile has not yet reached its yield moment, the lateral force in the pile system would continue to increase with displacement until yielding occurs in the steel pile at force and displacement equal to $F_{y, \mathrm{P}}$ and $\Delta_{y, \mathrm{P}}$, respectively. Subsequently, the lateral force in the pile system would increase with displacement only due to strain-hardening effects in the pile 
material.

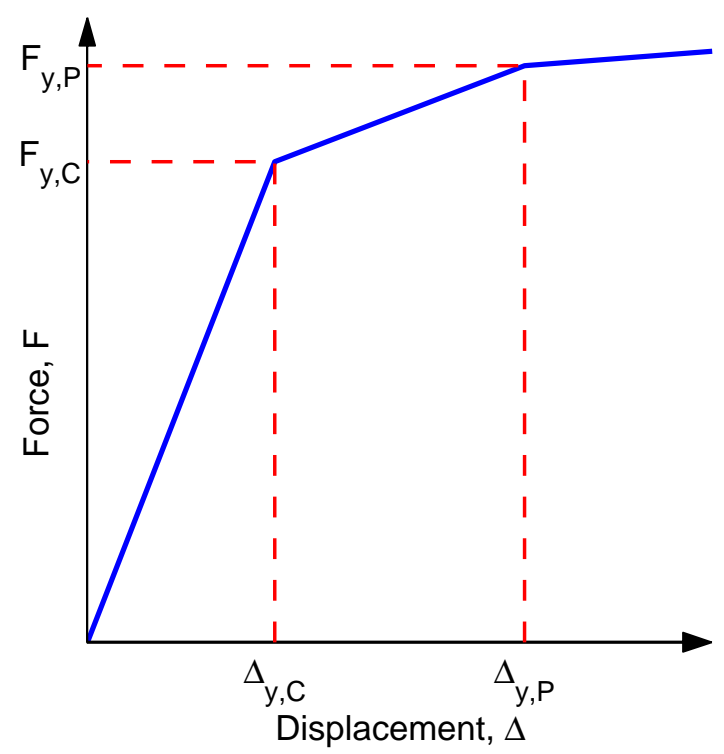

Figure 9.4. Idealized pushover curve of pile with dowel-connection to the deck.

\subsection{FORCE-DEFORMATION RESPONSE OF PILE WITH DOWEL-CONNECTION}

This section presents development of formulas for estimating displacement capacity of piles with dowel connections to the deck. For this purpose let us define two dimensionless constants, $\eta$ and $\beta$ as

$$
\begin{gathered}
\eta=\frac{M_{y, \mathrm{P}}}{M_{y, \mathrm{C}}} \\
\beta=\frac{E I}{k_{\theta} L}
\end{gathered}
$$

in which $\eta$ is the ratio of yield moment of the pile and the connection, and $\beta$ is indicative of the relative rotational stiffness of the pile and the connection.

\subsubsection{Response at First Yielding in Connection}

To compute the rotation and deflection at the top of the hollow steel pile with a concrete-plug in the initial elastic region, i.e., $\Delta \leq \Delta_{y, C}$, consider the cantilever with a moment equal to $k_{\theta} \theta$ and a lateral force equal to $F$ at the top (Figure 9.5(a)) with a bending moment diagram (Figure 9.5(b)) and the curvature diagram (Figure 9.5(c)). Using the moment-area method for structural 
analysis, the rotation and deflection at the top of the pile are given by

$$
\theta=\frac{F L^{2}}{2 E I}-\frac{k_{\theta} L \theta}{E I}=\frac{F L^{2}}{2 E I}-\frac{\theta}{\beta}
$$

and

$$
\Delta=\frac{F L^{3}}{3 E I}-\frac{k_{\theta} \theta L^{2}}{2 E I}=\frac{F L^{3}}{3 E I}-\frac{\theta L}{2 \beta}
$$

Equation (9.6) can be further simplified to obtain the rotation as

$$
\theta=\left(\frac{F L^{2}}{2 E I}\right)\left(\frac{\beta}{1+\beta}\right)
$$

Utilizing Equation (9.8), Equation (9.7) can also be simplified to obtain the deflection as

$$
\Delta=\left(\frac{F L^{3}}{12 E I}\right)\left(\frac{1+4 \beta}{1+\beta}\right)
$$

The first yielding in the pushover curve (Figure 9.4) occurs at the yielding of the connection at yield rotation at the top of the pile equal to

$$
\theta_{y, \mathrm{C}}=\frac{M_{y, \mathrm{C}}}{k_{\theta}}
$$

Inserting Equation (9.10) in Equation (9.8) gives the lateral force at the yield level as

$$
F_{y, \mathrm{C}}=\frac{2 M_{y, \mathrm{C}}}{L}(1+\beta)
$$

and utilizing Equation (9.11) in Equation (9.9) gives the yield displacement as

$$
\Delta_{y, \mathrm{C}}=\frac{M_{y, \mathrm{C}} L^{2}}{6 E I}(1+4 \beta)=\frac{k_{\theta} \theta_{y, \mathrm{C}} L^{2}}{6 E I}(1+4 \beta)=\theta_{y, \mathrm{C}} L\left(\frac{1+4 \beta}{6 \beta}\right)
$$




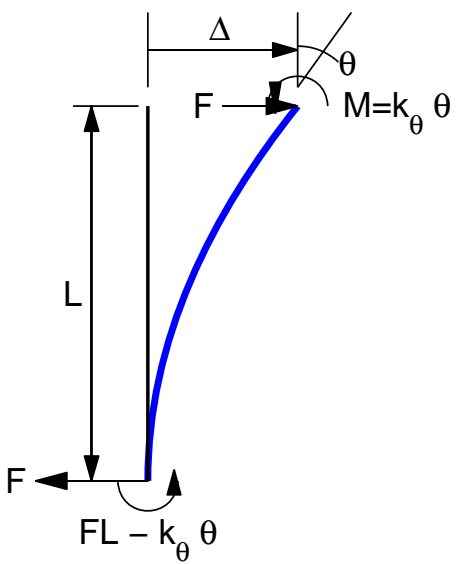

(a)

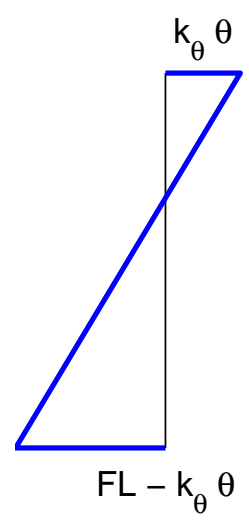

(b)

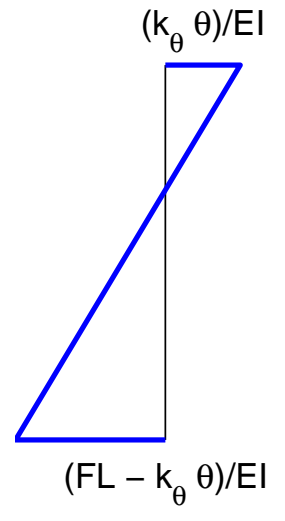

(c)

Figure 9.5. Response behavior of a pile with dowel-connection up to yielding in the connection: (a) forces; (b) bending moment diagram; and (c) curvature diagram.

\subsubsection{Response at First Yielding in Pile}

The response in the range $\Delta_{y, \mathrm{C}} \leq \Delta \leq \Delta_{y, \mathrm{P}}$ may be computed by an incremental approach in which the system may be treated as a cantilever fixed at the base and free at the top (Figure 9.6). For this system, the incremental displacement and rotation at the top are given by

$$
\begin{aligned}
& \left(\Delta-\Delta_{y, \mathrm{C}}\right)=\frac{L^{3}}{3 E I}\left(F-F_{y, \mathrm{C}}\right) \\
& \left(\theta-\theta_{y, \mathrm{C}}\right)=\frac{L^{2}}{2 E I}\left(F-F_{y, \mathrm{C}}\right)
\end{aligned}
$$

which leads to the expression for the total displacement and rotation as

$$
\begin{gathered}
\Delta=\Delta_{y, \mathrm{C}}+\frac{L^{3}}{3 E I}\left(F-F_{y, \mathrm{C}}\right)=\frac{M_{y, \mathrm{C}} L^{2}}{6 E I}(1+4 \beta)+\frac{L^{3}}{3 E I}\left(F-F_{y, \mathrm{C}}\right) \\
\theta=\theta_{y, \mathrm{C}}+\frac{L^{2}}{2 E I}\left(F-F_{y, \mathrm{C}}\right)=\frac{M_{y, \mathrm{C}}}{k_{\theta}}+\frac{L^{2}}{2 E I}\left(F-F_{y, \mathrm{C}}\right)
\end{gathered}
$$




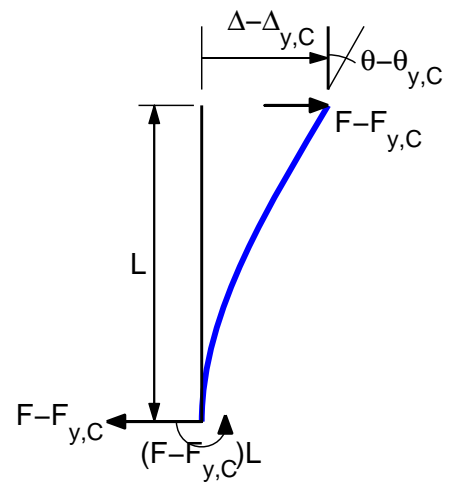

(a)

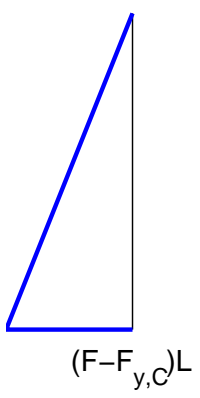

(b)

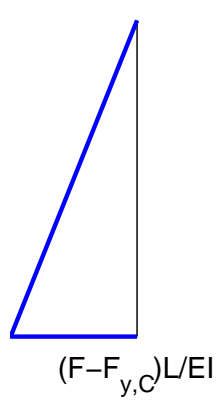

(c)

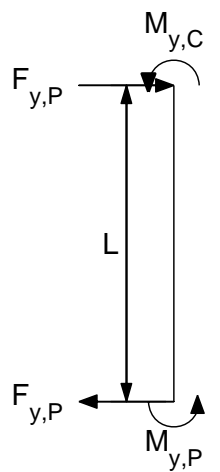

(d)

Figure 9.6. Response behavior of a pile with dowel-connection between yielding in the connection and yielding in the pile: (a) forces; (b) bending moment diagram; (c) curvature diagram; and (d) equilibrium at pile yielding.

The lateral force when the pile yields can be computed from the equilibrium of the cantilever (Figure 9.6(d)) as

$$
F_{y, \mathrm{P}}=\frac{M_{y, \mathrm{C}}+M_{y, \mathrm{P}}}{\mathrm{L}}
$$

Utilizing Equation (9.17) in Equations (9.15) and (9.16) leads to displacement and rotation at yielding of the pile as

$$
\begin{aligned}
\Delta_{y, \mathrm{P}}= & \frac{M_{y, \mathrm{C}} L^{2}}{6 E I}(1+4 \beta)+\frac{L^{3}}{3 E I}\left(F_{y, \mathrm{P}}-F_{y, \mathrm{C}}\right) \\
= & \frac{M_{y, \mathrm{C}} L^{2}}{6 E I}(1+4 \beta)+\frac{M_{y, \mathrm{P}} L^{2}}{3 E I}+\frac{M_{y, \mathrm{C}} L^{2}}{3 E I}-\frac{2 M_{y, \mathrm{C}}}{L}(1+\beta) \frac{L^{3}}{3 E I} \\
= & \left(\frac{M_{y, \mathrm{P}} L^{2}}{3 E I}\right)\left(\frac{2 \eta-1}{2 \eta}\right) \\
\theta_{y, \mathrm{P}}= & \frac{M_{y, \mathrm{C}}}{k_{\theta}}+\frac{L^{2}}{2 E I}\left(F_{y, \mathrm{P}}-F_{y, \mathrm{C}}\right) \\
= & \frac{M_{y, \mathrm{C}}}{k_{\theta}}+\frac{M_{y, \mathrm{P}} L}{2 E I}+\frac{M_{y, \mathrm{C}} L}{2 E I}-\frac{2 M_{y, \mathrm{C}}}{L}(1+\beta) \frac{L^{2}}{2 E I} \\
= & \left(\frac{M_{y, \mathrm{P}} L}{2 E I}\right)\left(\frac{\eta-1}{\eta}\right)
\end{aligned}
$$

\subsection{DISPLACEMENT DUCTILITY CAPACITY OF PILE}

This section develops the formulas for computing displacement ductility capacity of piles with a 
partial-moment connection. Presented first are the formulas for the ductility controlled by material strain limits in the connection. Subsequently, formulas for the ductility controlled by material strains in the pile section are presented. The displacement ductility capacity is then defined as the lower of the two ductility values. Finally, a step-by-step summary to compute the displacement ductility capacity of piles with partial-moment connection is presented.

\subsubsection{Strain Limits in the Connection}

Let $\theta_{L}$ be the rotation in the connection spring for a selected design level, i.e., specified value of strain in the outermost dowel for a selected design level. For the pile-connection system, this rotation may occur either prior to pile yielding, i.e., $\theta_{y, \mathrm{C}}<\theta_{L}<\theta_{y, \mathrm{P}}$, or after pile yielding, i.e., $\theta_{L}>\theta_{y, \mathrm{P}}$. The connection rotation ductility at onset of pile yielding is given by

$$
\begin{aligned}
\mu_{\theta, \mathrm{P}} & =\frac{\theta_{y, \mathrm{P}}}{\theta_{y, \mathrm{C}}}=\frac{k_{\theta}}{M_{y, \mathrm{C}}}\left(\frac{M_{y, \mathrm{P}} L}{2 E I}\right)\left(\frac{\eta-1}{\eta}\right) \\
& =\left(\frac{M_{y, \mathrm{P}}}{M_{y, \mathrm{C}}}\right)\left(\frac{k_{\theta} L}{2 E I}\right)\left(\frac{\eta-1}{\eta}\right) \\
& =\frac{\eta-1}{2 \beta}
\end{aligned}
$$

The displacement capacity of the pile-connection system when considering strain limits in the outermost dowel of the connection depends on whether the pile remains elastic or the pile yields when the dowel strain limit is reached. Note that the pile would remain elastic if $\mu_{\theta}$ is less than $\mu_{\theta, \mathrm{P}}$ as given by Equation (9.20). If the pile remains elastic, the rotation in the plug at a selected design level, $\theta_{L}$, is related to the lateral force $F$ by Equation (9.16) as

$$
\theta_{L}=\theta_{y, \mathrm{C}}+\frac{L^{2}}{2 E I}\left(F-F_{y, \mathrm{C}}\right)
$$

which gives

$$
\left(F-F_{y, \mathrm{C}}\right)=\left(\theta_{L}-\theta_{y, \mathrm{C}}\right)\left(\frac{2 E I}{L^{2}}\right)=\theta_{y, \mathrm{C}}\left(\mu_{\theta}-1\right)\left(\frac{2 E I}{L^{2}}\right)
$$

Using Equation (9.15), the displacement is then given as 


$$
\begin{aligned}
\Delta_{L} & =\frac{M_{y, \mathrm{C}} L^{2}}{6 E I}(1+4 \beta)+\frac{L^{3}}{3 E I} \theta_{y, \mathrm{C}}\left(\mu_{\theta}-1\right)\left(\frac{2 E I}{L^{2}}\right) \\
& =\frac{\theta_{y, \mathrm{C}} k_{\theta} L^{2}}{6 E I}(1+4 \beta)+\frac{2 L}{3} \theta_{y, \mathrm{C}}\left(\mu_{\theta}-1\right) \\
& =\theta_{y, \mathrm{C}} L\left[\frac{1+4 \beta}{6 \beta}+\frac{2\left(\mu_{\theta}-1\right)}{3}\right]
\end{aligned}
$$

The displacement ductility capacity is then defined as

$$
\begin{aligned}
\mu_{\Delta} & =\frac{\Delta_{L}}{\Delta_{y, \mathrm{C}}}=\frac{\theta_{y, \mathrm{C}} L\left[\frac{1+4 \beta}{6 \beta}+\frac{2\left(\mu_{\theta}-1\right)}{3}\right]}{\theta_{y, \mathrm{C}} L\left(\frac{1+4 \beta}{6 \beta}\right)}=1+\left(\mu_{\theta}-1\right)\left(\frac{4 \beta}{1+4 \beta}\right) \\
= & \frac{1+4 \beta \mu_{\theta}}{1+4 \beta}
\end{aligned}
$$

If the pile yields prior to the connection reaching $\theta_{L}$, i.e., if $\mu_{\theta}$ is more than $\mu_{\theta, \mathrm{P}}$, the deflection at the pile top can be approximated as

$$
\Delta_{L}=\Delta_{y, \mathrm{P}}+\left(\theta_{L}-\theta_{y, \mathrm{P}}\right) L
$$

which can be re-written as

$$
\begin{aligned}
\Delta_{L} & =\Delta_{y, \mathrm{P}}+\theta_{y, \mathrm{C}} L\left(\mu_{\theta}-\frac{\theta_{y, \mathrm{P}}}{\theta_{y, \mathrm{C}}}\right) \\
& =\Delta_{y, \mathrm{C}}+\frac{M_{y, \mathrm{P}} L^{2}}{3 E I}+\frac{M_{y, \mathrm{C}} L^{2}}{3 E I}-\frac{2 M_{y, \mathrm{C}}}{L}(1+\beta) \frac{L^{3}}{3 E I}+\theta_{y, \mathrm{C}} L\left(\mu_{\theta}-\frac{\eta-1}{2 \beta}\right)
\end{aligned}
$$

The displacement ductility capacity is then defined as

$$
\begin{aligned}
\mu_{\Delta} & =\frac{\Delta_{L}}{\Delta_{y, \mathrm{C}}}=1+\frac{1}{\frac{M_{y, \mathrm{C}} L^{2}}{6 E I}(1+4 \beta)}\left[\begin{array}{l}
\frac{M_{y, \mathrm{P}} L^{2}}{3 E I}+\frac{M_{y, \mathrm{C}} L^{2}}{3 E I}-\frac{2 M_{y, \mathrm{C}}}{L}(1+\beta) \frac{L^{3}}{3 E I} \\
+\theta_{y, \mathrm{C}} L\left(\mu_{\theta}-\frac{\eta-1}{2 \beta}\right)
\end{array}\right] \\
& =\frac{2-\eta+6 \beta \mu_{\theta}}{1+4 \beta}
\end{aligned}
$$

The displacement ductility capacity of the pile-concrete-plug system can be summarized as 


$$
\mu_{\Delta}=\left\{\begin{array}{c}
\frac{1+4 \beta \mu_{\theta}}{1+4 \beta} \text { for } \mu_{\theta} \leq \frac{\eta-1}{2 \beta} \\
\frac{2-\eta+6 \beta \mu_{\theta}}{1+4 \beta} \text { for } \mu_{\theta}>\frac{\eta-1}{2 \beta}
\end{array}\right.
$$

Equation (9.28) applies only for displacement ductility capacity when the strain in the outermost fiber of the dowel in the connection reaches the strain limit for a selected design level.

\subsubsection{Strain Limits in the Pile}

The preceding section developed the expression for displacement ductility capacity of the pileconnection system controlled by the strain limit in the dowel of the connection. However, it is possible that the strain limit in the pile may occur prior to the system reaching the displacementductility capacity given by Equation (9.28). Therefore, the relationship for displacement-ductility of the pile-connection system at strain limits in the pile is developed next.

Let us consider the equilibrium of the pile when the strain limit reaches the limiting value at a selected design level (Figure 9.7). The moment at the top of the pile is equal to $M_{y, \mathrm{C}}$ and at the bottom is equal to $M_{y, \mathrm{P}}$. The length $L_{2}$ is then given by

$$
L_{2}=\frac{\eta}{1+\eta} L
$$

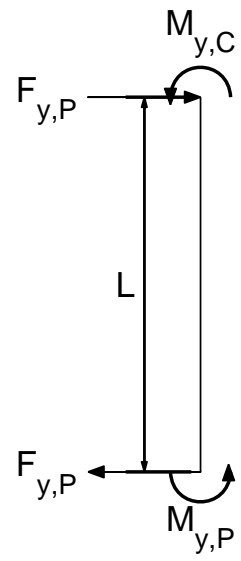

(a)

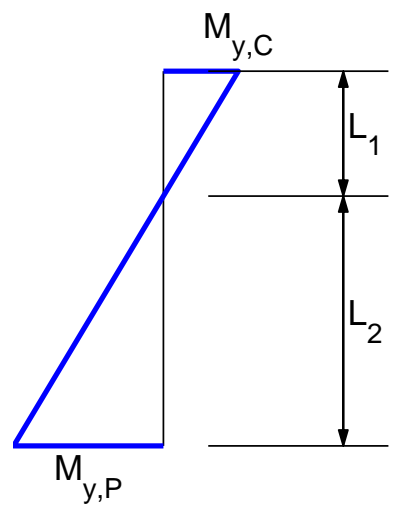

(b)

Figure 9.7. Equilibrium of the pile when strain reaches the limiting value in the pile-hinge. 
Defining the plastic hinge length as

$$
L_{p}=\rho L_{2}
$$

in which $\rho$ is the length of the plastic hinge as a fraction of the "effective" length defined as the distance from the critical section to the point of contra-flexure $\left(=L_{2}\right.$ for this case). Using Equation (9.29) in Equation (9.30) gives a plastic hinge length normalized by the total pile length as

$$
L_{p}^{*}=\frac{L_{p}}{L}=\frac{\rho \eta}{1+\eta}
$$

Using concepts similar to those developed previously for piles with perfect moment connection [see Figure 4.1 and Equation (4.4)], the displacement capacity of the pile is given by

$$
\begin{aligned}
\Delta_{L} & =\Delta_{y, \mathrm{P}}+\left(L-\frac{L_{p}}{2}\right)\left[L_{p}\left(\phi_{L}-\phi_{y}\right)\right] \\
& =\Delta_{y, \mathrm{P}}+\phi_{y} L^{2}\left(1-\frac{L_{p}^{*}}{2}\right)\left(L_{p}^{*}\right)\left(\mu_{\phi}-1\right) \\
& =\Delta_{y, \mathrm{P}}+\left(\frac{M_{y, \mathrm{P}} L^{2}}{E I}\right)\left(1-\frac{L_{p}^{*}}{2}\right)\left(L_{p}^{*}\right)\left(\mu_{\phi}-1\right)
\end{aligned}
$$

Dividing Equation (9.32) by the yield displacement given by Equation (9.12), the displacementductility capacity is given by

$$
\begin{aligned}
\mu_{\Delta} & =\frac{\Delta_{L}}{\Delta_{y, \mathrm{C}}}=\frac{2 \eta-1}{1+4 \beta}+\left(\frac{6 \eta L_{p}^{*}}{1+4 \beta}\right)\left(1-\frac{L_{p}^{*}}{2}\right)\left(\mu_{\phi}-1\right) \\
& =\frac{2 \eta-1}{1+4 \beta}+\left(\frac{6 \eta}{1+4 \beta}\right)\left(\frac{\rho \eta}{1+\eta}\right)\left(1-\frac{\rho \eta}{2(1+\eta)}\right)\left(\mu_{\phi}-1\right)
\end{aligned}
$$

Equation (9.33) applies only to the displacement ductility capacity when the material strain in the pile reaches the strain limit for a selected design level. i.e., hinging in the pile.

\subsection{STEP-BY-STEP SUMMARY}

The following is a step-by-step summary of the procedure to compute the displacement capacity of hollow steel piles with concrete-plug connections or prestressed concrete piles with a dowel 
connection at the deck.

1. Establish the axial load, $P$, on the pile.

2. Estimate the pile length based on an equivalent-fixity assumption.

3. Select an appropriate design level - Level 1 or Level 2 - and establish various strain limits for the selected design level.

4. Develop the moment-rotation relationship of the concrete-plug connection for a hollow steel pile or the dowel connection for a prestressed concrete pile using the procedure described in Chapter 8 (Section 8.2) of this report.

5. Determine rotational stiffness, $k_{\theta}$, yield moment, $M_{y, \mathrm{C}}$, and yield rotation, $\theta_{y, \mathrm{C}}$ of the connection from the moment-rotation relationship developed in Step 4.

6. Establish the rotation of the plug, $\theta_{L}$, and corresponding ductility, $\mu_{\theta}=\theta_{L} / \theta_{y, \mathrm{C}}$, when strain in the outer-most dowel of the connection reaches the strain limit established in Step 3 for the selected design level.

7. Conduct the moment-curvature analysis of the pile section and idealize the momentcurvature relationship by a bi-linear curve. For this analysis, apply the axial load on the pile prior to moment-curvature analysis.

8. Compute the effective, $E I_{e}$, and effective yield moment, $M_{\mathrm{y}, \mathrm{P}}$, from the pile momentcurvature relationship. Note that $E I_{e}$ is equal to the initial elastic slope and $M_{\mathrm{y}, \mathrm{P}}$ is the yield value of the moment of the idealized bi-linear moment-curvature relationship. For steel piles, EI may be computed from section properties and material modulus, and $M_{\mathrm{y}, \mathrm{P}}$ may be approximated as $M_{\mathrm{y}, \mathrm{P}}=f_{y}\left(d_{o}^{3}-d_{i}^{3}\right) / 6$.

9. Estimate the yield curvature, $\phi_{y, \mathrm{P}}=M_{y, \mathrm{P}} / E I_{e}$.

10. Establish the curvature of the steel pile, $\phi_{L}$, and corresponding curvature ductility, $\mu_{\phi}=\phi_{L} / \phi_{y, \mathrm{P}}$, when material strain in the pile section reaches the strain limit established in Step 3 for the selected design level. 
11. Select the value of $\rho$ which defines the length of the plastic hinge as a fraction of the "effective: length of the pile. Guidelines for selection values of $\rho$ for hollow steel piles and prestressed concrete piles are provided in subsequent Chapters of this report.

12. Compute the dimensionless parameters: $\eta=M_{y, \mathrm{P}} / M_{y, \mathrm{C}}$, and $\beta=E I_{e} / k_{\theta} L$.

13. Compute the normalized value of the plastic hinge length: $L_{P}^{*}=(\rho \eta) /(1+\eta)$.

14. Compute the yield displacement which corresponds to first effective yielding in the connection as: $\Delta_{y, \mathrm{C}}=\theta_{y, \mathrm{C}} L(1+4 \beta) / 6 \beta$

15. Compute the displacement ductility for yielding in the connection as $\mu_{\Delta}=\left(1+4 \beta \mu_{\theta}\right) /(1+4 \beta)$ if $\mu_{\theta}$ computed in Step 6 is less than or equal to $(\eta-1) / 2 \beta$ otherwise $\mu_{\Delta}=\left(2-\eta+6 \beta \mu_{\theta}\right) /(1+4 \beta)$.

16. Compute displacement ductility for yielding in the pile as $\mu_{\Delta}=(2 \eta-1) /(1+4 \beta)+\left(6 \eta L_{p}^{*}\right)\left(1-L_{p}^{*} / 2\right)\left(\mu_{\phi}-1\right) /(1+4 \beta)$

17. Establish the displacement ductility capacity as the lower of the values computed in Steps 15 and 16.

18. Compute the displacement capacity of the pile as a product of the yield displacement computed in Step14 and the displacement ductility capacity computed in Step 17. 


\section{DUCTILITY CAPACITY OF HOLLOW STEEL PILES WITH DOWEL- CONNECTION}

The displacement ductility capacity of hollow steel piles with a dowel-connection to the deck is investigated in this chapter. For this purpose, two design levels - Level 1 and Level 2 - specified for seismic analysis of Marine Oil and LNG Terminals in the MOTEMS are considered. The strain limits specified in the MOTEMS for reinforcing steel are 0.01 for Level 1 and 0.05 for Level 2 if the hinge were to form in the connection. If the hinge were to form in the steel pile below the ground level, these strain limits are 0.008 for Level 1 and 0.025 for Level 2. Two pile diameters $-61 \mathrm{~cm}$ and $91 \mathrm{~cm}$ - each with two wall thicknesses $-1.27 \mathrm{~cm}$ inch and $2.54 \mathrm{~cm}-$ are considered. Furthermore, two configurations of reinforcing details in the concrete-plug connection are considered: 8 dowels and 12 dowels, with area of each dowel being equal to 8.2 $\mathrm{cm}^{2}$. The piles are considered to be fixed at the bottom to reflect the equivalent-fixity assumption at the bottom. The axial load on the pile is assumed to be $0.05 A f_{y}$ or $0.1 A f_{y}$ in which $A$ is the cross-section area of the pile and $f_{y}$ is the yield strength of steel. The pile is modeled in computer program OPENSEES (McKenna and Fenves, 2001) using fiber section and nonlinear beam-column elements.

Figures 10.1 to 10.4 present the variation of displacement ductility capacity of hollow-steel piles with concrete-plug connections with pile length for two conditions: (1) formation of hinge in the concrete-plug connection and (2) formation of hinge in the steel pile. These results were generated by nonlinear-finite element analysis of the pile system shown in Figure 9.1. The

presented results indicate that the ductility capacity due to pile hinging tends to increase slightly with pile length for shorter piles. For longer piles, however, the ductility capacity is essentially independent of the pile length as apparent from the almost-flat curves. The ductility capacity due to concrete-plug hinging, however, reduces significantly with pile length. However, this ductility capacity may become insensitive to the pile length for longer piles.

The design ductility capacity of hollow steel piles with concrete plugs is lower for the ductility capacities due to hinging in the steel pile and in the concrete plug. Therefore, the results of Figures 10.1 to 10.4 also permit another important observation: hinging in the steel pile may control the design ductility capacity of shorter piles whereas hinging in concrete-plug almost always controls the design ductility capacity of longer piles. As such, for a given pile length, the 
lower of the ductility capacity from hinging in the pile and hinging in the connection must be selected as the design ductility capacity.
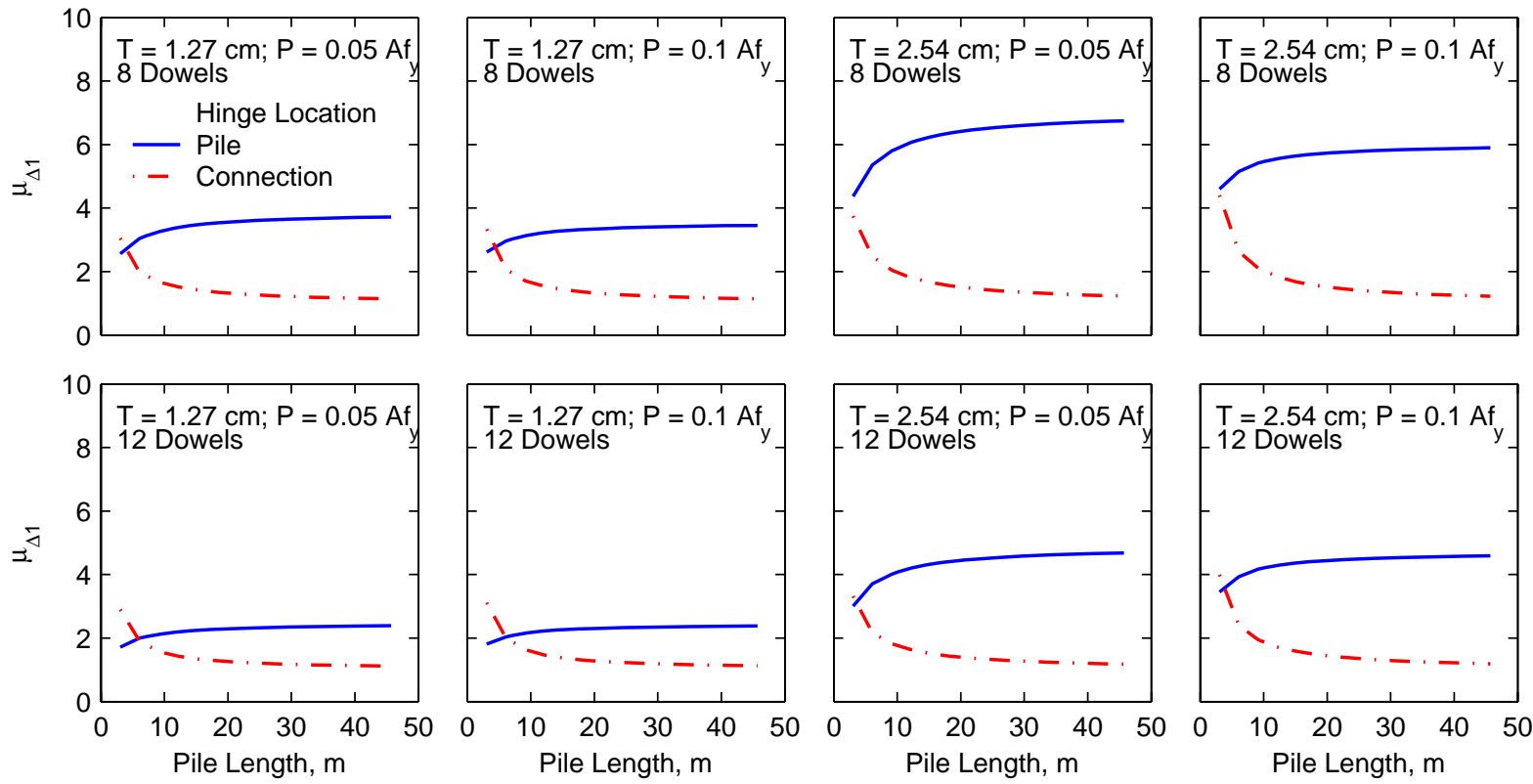

Figure 10.1. Displacement ductility capacity of hollow-steel piles with concrete-plug connections for a design Level 1 earthquake and a $61 \mathrm{~cm}$ pile diameter. Variables include axial load, pile thickness and number of dowels.
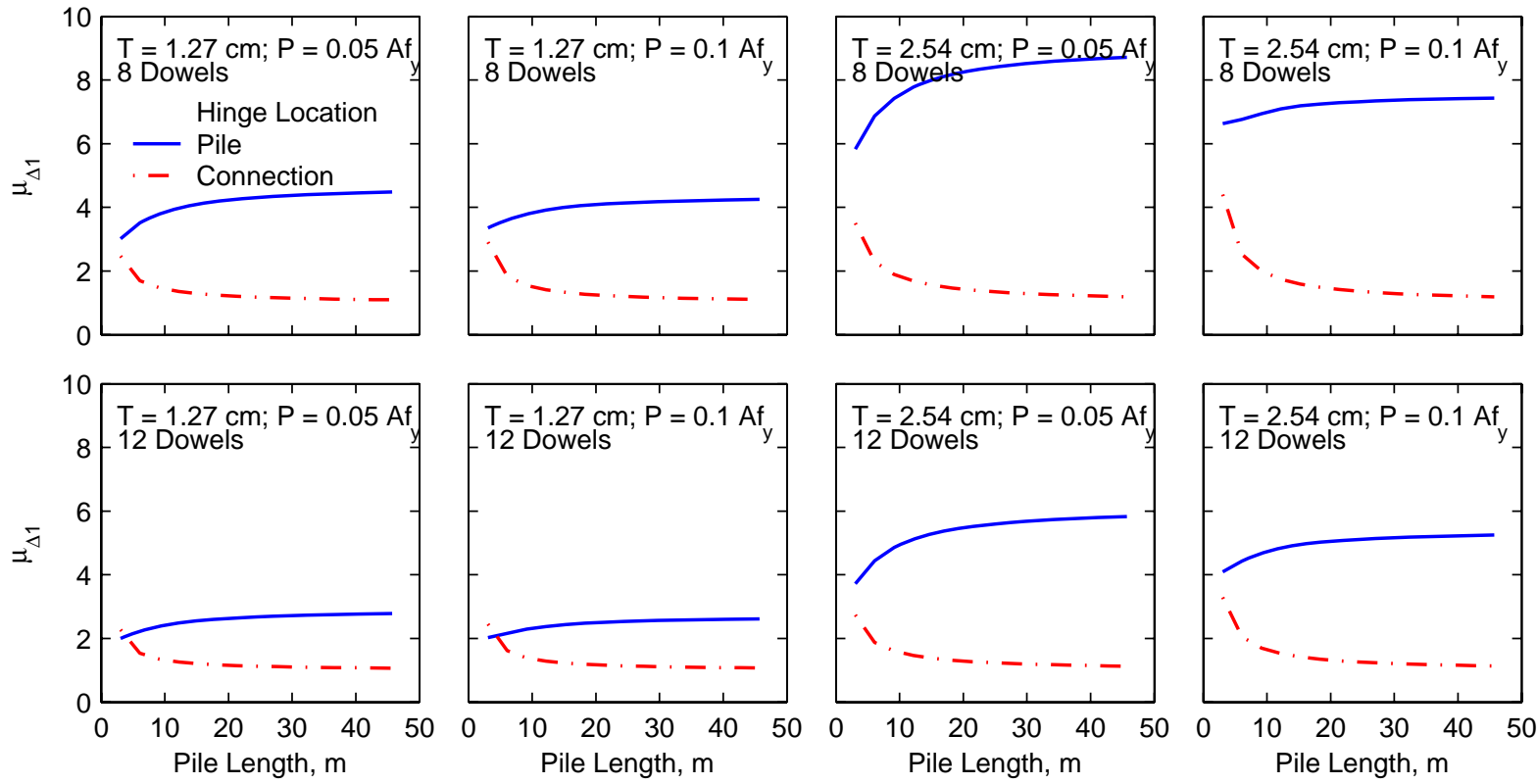

Figure 10.2. Displacement ductility capacity of hollow-steel piles with concrete-plug connections for a design Level 1 earthquake and $91 \mathrm{~cm}$ pile diameter. Variables include axial load, pile thickness and number of dowels. 

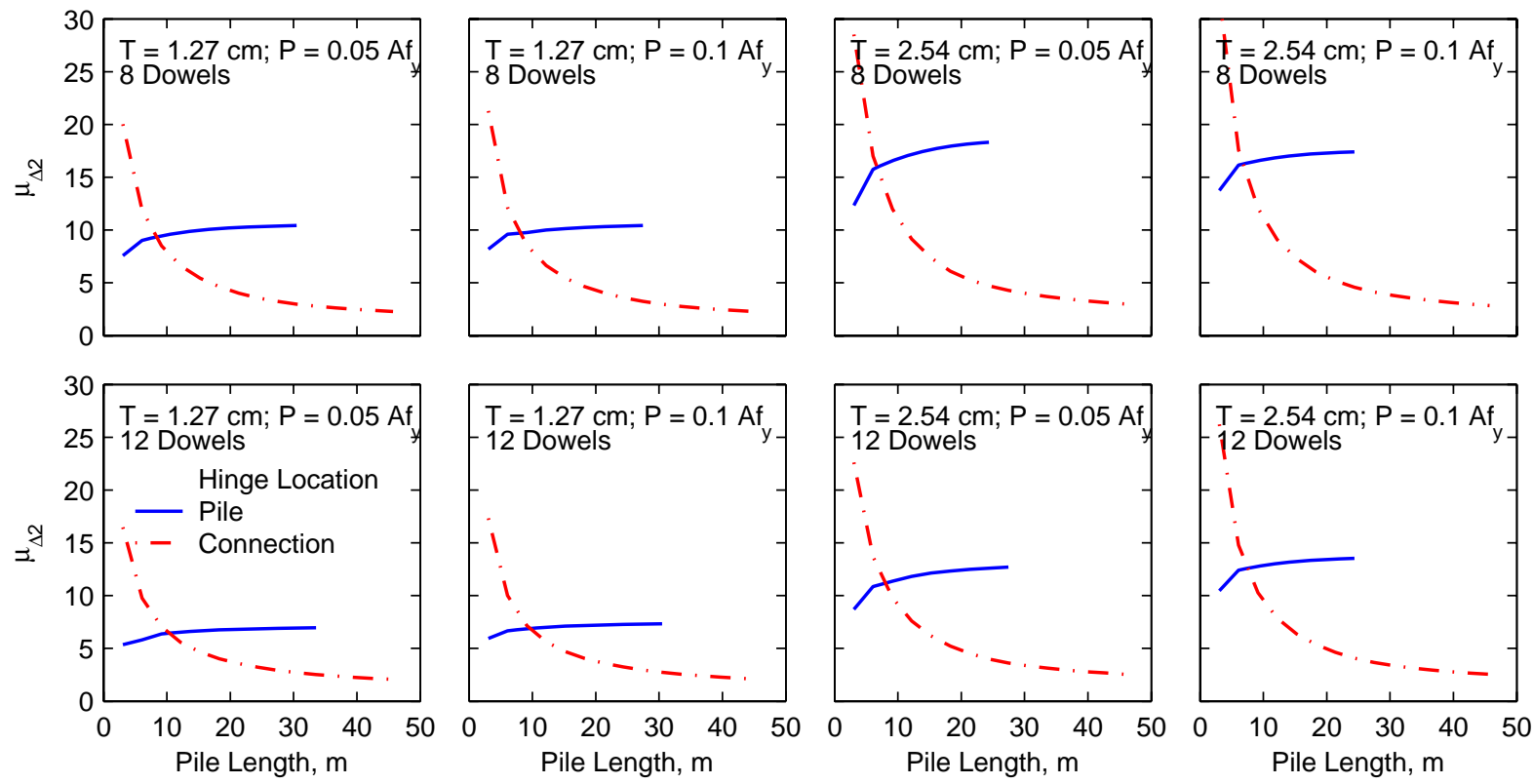

Figure 10.3. Displacement ductility capacity of hollow-steel piles with concrete-plug connections for a design Level 2 earthquake and $61 \mathrm{~cm}$ pile diameter. Variables include axial load, pile thickness and number of dowels.
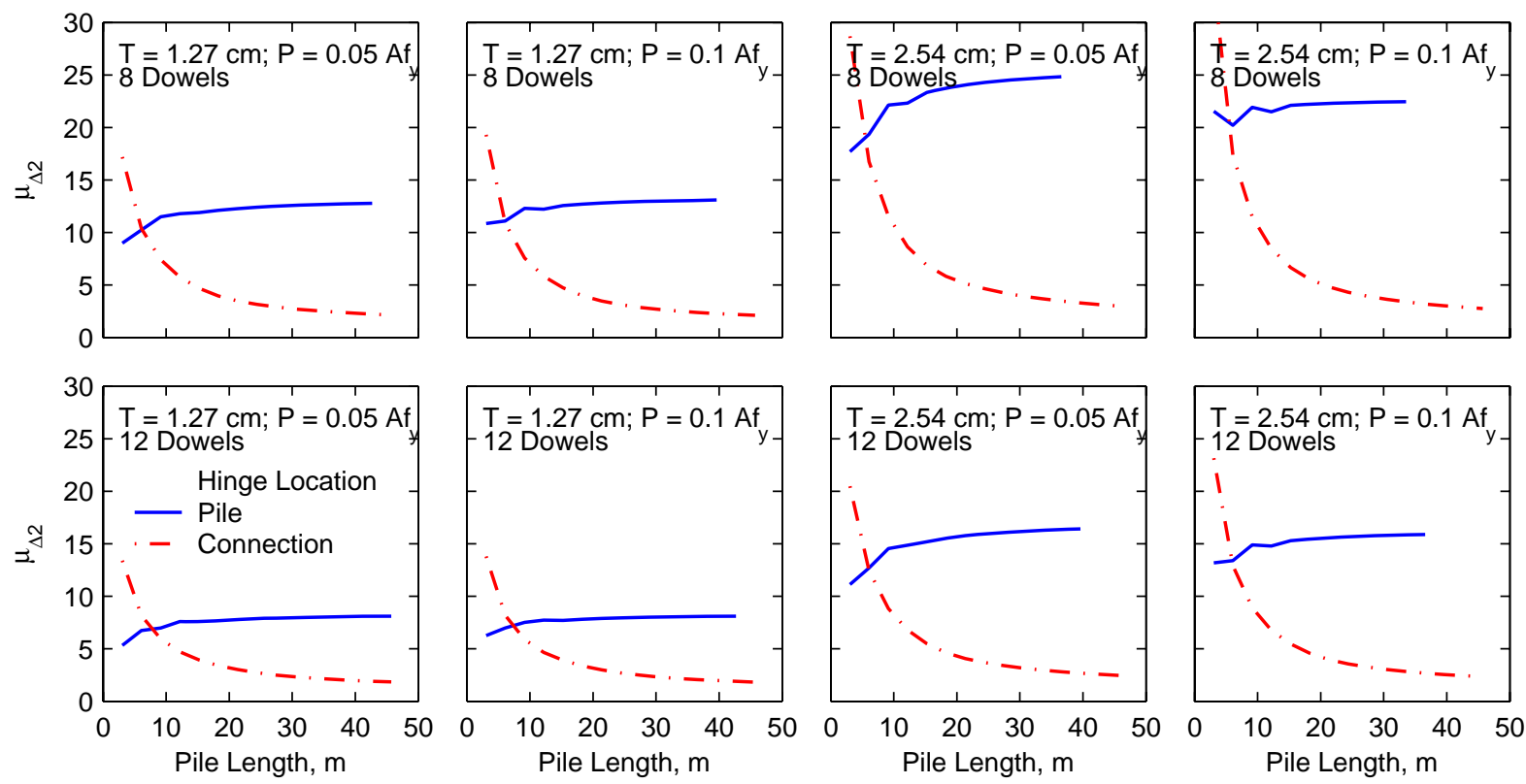

Figure 10.4. Displacement ductility capacity of hollow-steel piles with concrete-plug connections for a design Level 2 earthquake and $91 \mathrm{~cm}$ pile diameter. Variables include axial load, pile thickness and number of dowels.

The accuracy of the formulas developed in Chapter 9 are examined next by comparing design ductility capacity from nonlinear finite element analysis (NFEA) with that from Equations (9.29) and (9.33). Note that the results presented are the higher of the ductility values due to 
hinging in the pile and the connection. The value of $\rho=0.03$ for Level 1 earthquake design and $\rho=0.075$ for Level 2 earthquake design has been selected for hollow steel piles. These values must be used in estimating the ductility capacity from Equation (9.33). The presented results in Figures 10.5 and 10.6 are for a Level 1 earthquake, Figures 10.7 and 10.8 are for a Level 2 earthquake and they indicate that the formulas developed in this investigation provide highly accurate estimates of displacement ductility capacity of hollow steel piles with concrete-plug connection.
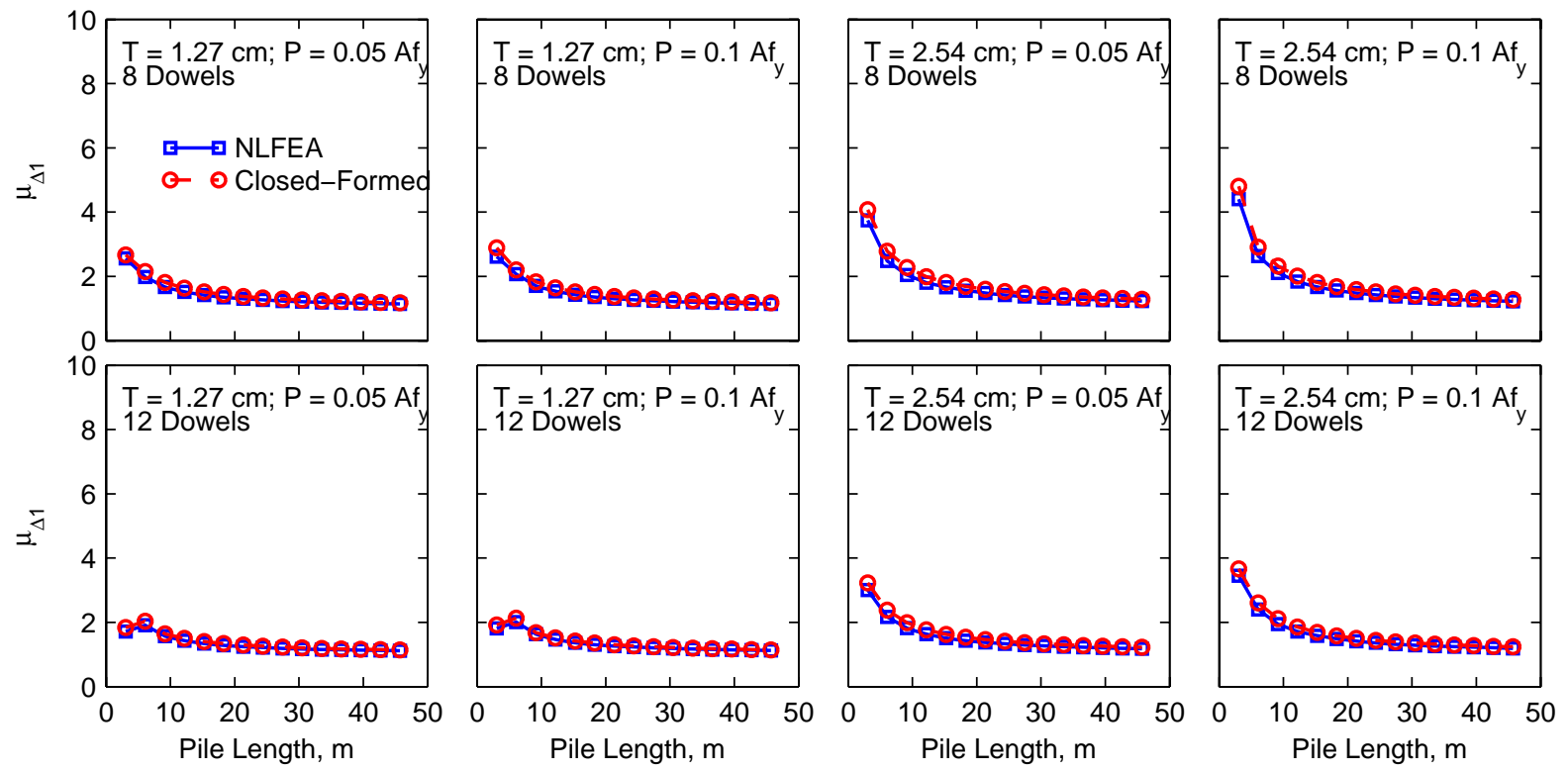

Figure 10.5. Comparison of design displacement ductility capacity of hollow-steel piles with concrete-plug connections from Equations (9.29) and (9.33), and nonlinear finite element analysis (NLFEA); results are for piles with $61 \mathrm{~cm}$ diameter and a design Level 1 earthquake. Variables include axial load, pile thickness and number of dowels. 

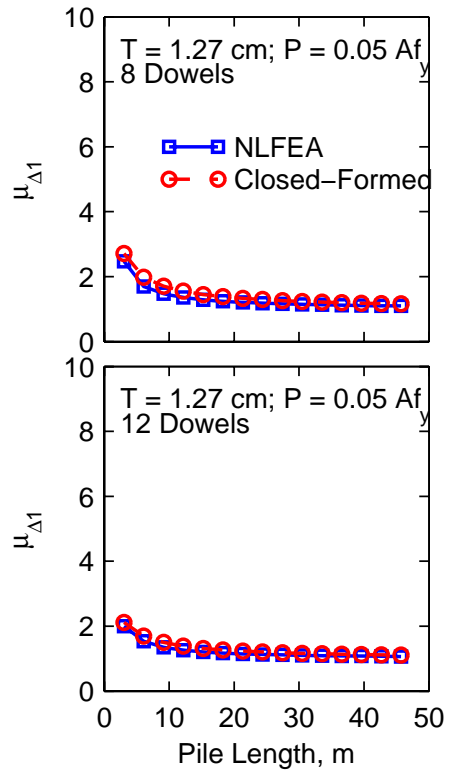
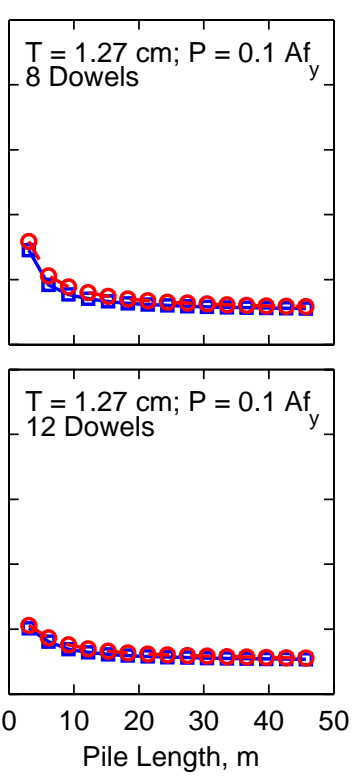
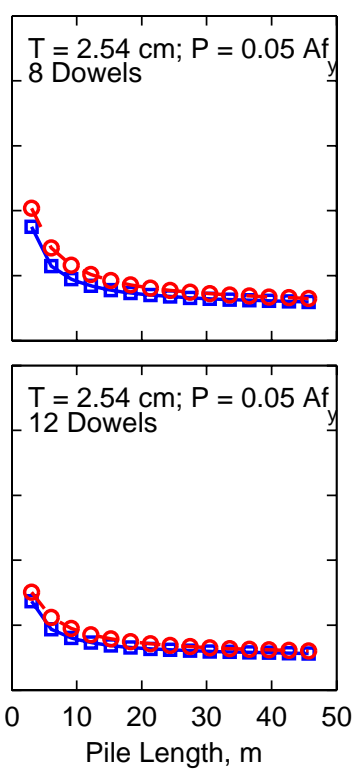
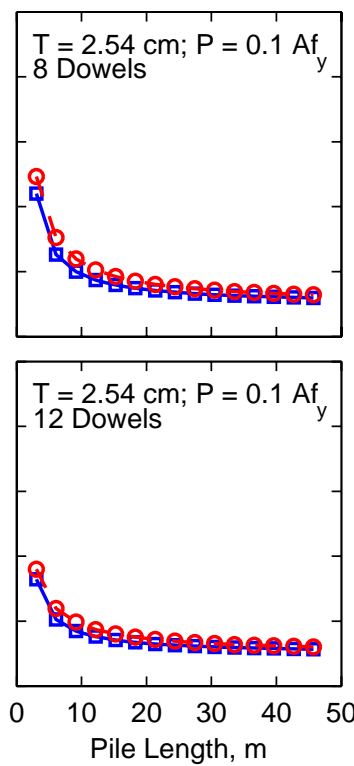

Figure 10.6. Comparison of design displacement ductility capacity of hollow-steel piles with concrete-plug connections from Equations (9.29) and (9.33), and nonlinear finite element analysis (NLFEA); results are for piles with $91 \mathrm{~cm}$ diameter and a design Level 1 earthquake. Variables include axial load, pile thickness and number of dowels.
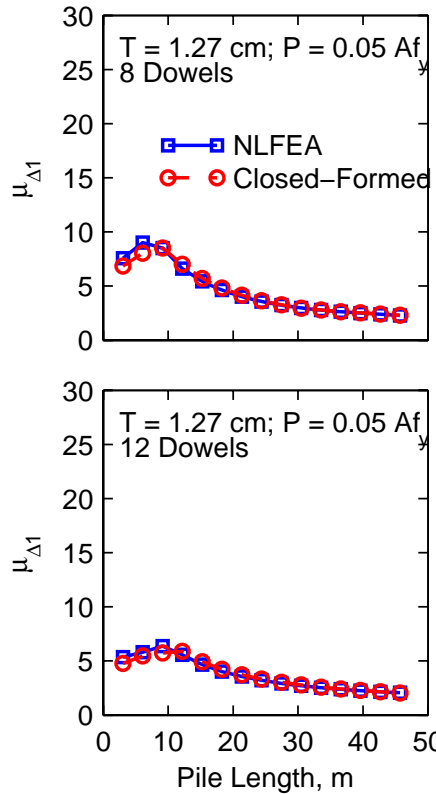
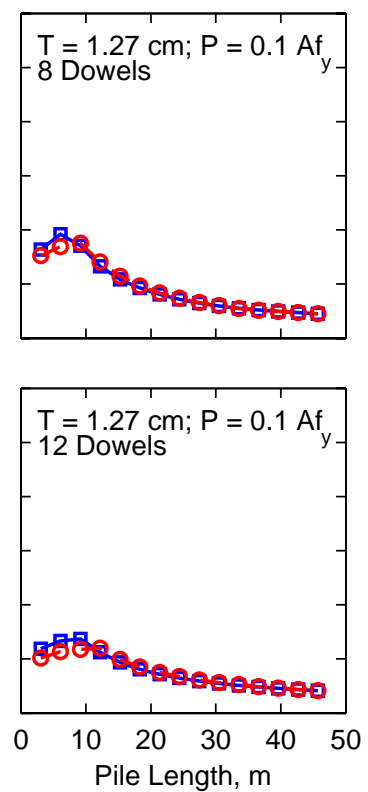
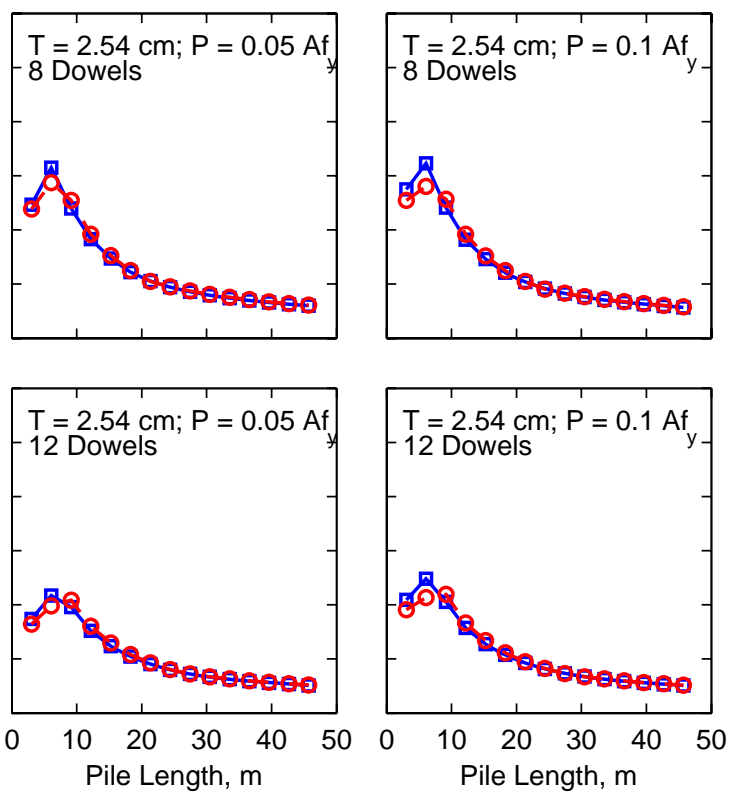

Figure 10.7. Comparison of design displacement ductility capacity of hollow-steel piles with concrete-plug connections from Equations (9.29) and (9.33), and nonlinear finite element analysis (NLFEA); results are for piles with $61 \mathrm{~cm}$ diameter and a design Level 2 earthquake. Variables include axial load, pile thickness and number of dowels. 

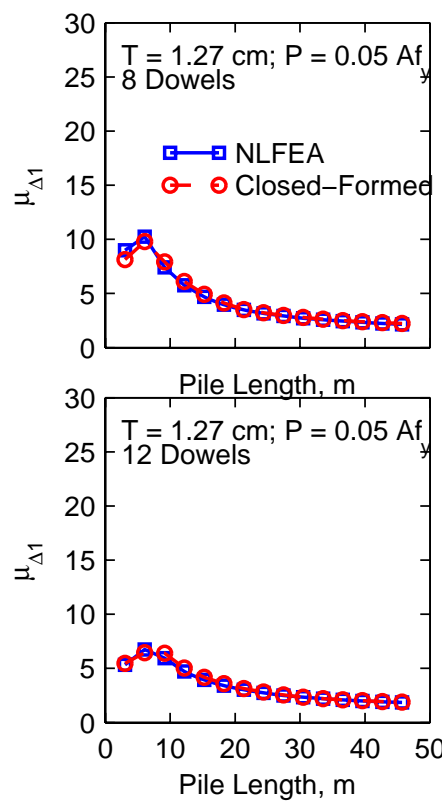

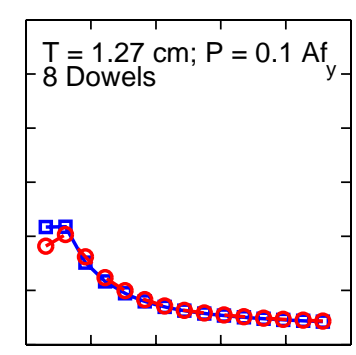

Pile Length, $m$

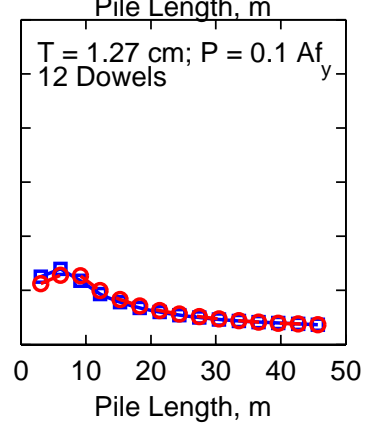

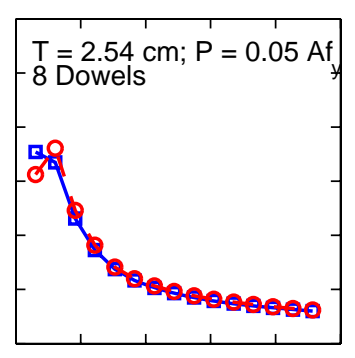

Pile Length, $m$

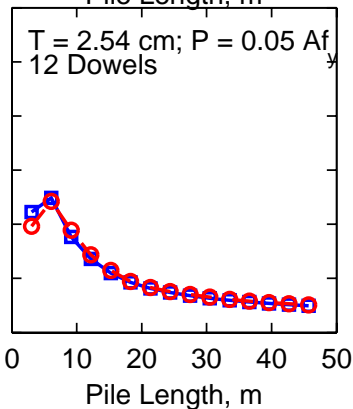

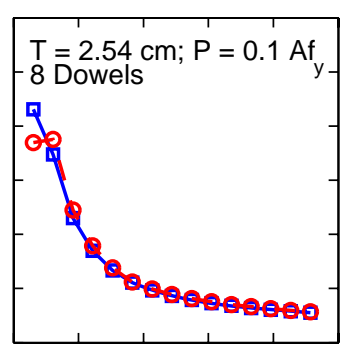

Pile Length, $m$

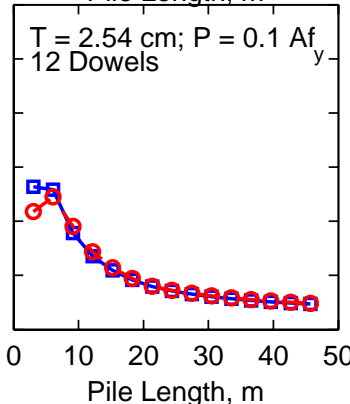

Figure 10.8. Comparison of design displacement ductility capacity of hollow-steel piles with concrete-plug connections from Equations (9.29) and (9.33), and nonlinear finite element analysis (NLFEA); results are for piles with $91 \mathrm{~cm}$ diameter and a design Level 2 earthquake. Variables include axial load, pile thickness and number of dowels.

\section{DUCTILITY CAPACITY OF PRESTRESSED CONCRETE PILES WITH DOWEL- CONNECTION}

The displacement ductility capacity of prestressed concrete piles with dowel connections to the deck is investigated in this chapter. For this purpose, two design levels - Level 1 and Level 2 specified for seismic analysis of Marine Oil and LNG Terminals are considered. The strain limits specified in the MOTEMS for reinforcing steel are 0.01 for Level 1 and 0.05 for Level 2 if the hinge were to form in the connection. If the hinge were to form in the pile, the strain limits in the prestressing strand are 0.005 (total) for Level 1 and 0.015 (incremental) for Level 2. The results are generated for a pile diameter of $61 \mathrm{~cm}$ with 16 prestressing strands. The area of each prestressing strand is equal to $1.4 \mathrm{~cm}^{2}$, strength is $1884 \mathrm{MPa}$, and initial prestress in the strands is equal to $70 \%$ of its strength. The confinement is provided by $\# 11$ spiral wire (area $=0.71 \mathrm{~cm}^{2}$ ) with spacing equal to $6.3 \mathrm{~cm}$. The dowel connection consists of 8 bars, each with an area equal to $3.9 \mathrm{~cm}^{2}$. The piles are considered to be fixed at the bottom to reflect the equivalent-fixity assumption at that point. The axial load on the pile is assumed to be $0.05 A f_{c}^{\prime}$ in which $A$ is the cross-section area of the pile and $f_{c}^{\prime}$ is the compressive strength of concrete. Four values of the 
de-bonded length of the bars in the dowel connection are considered: $0 \mathrm{~cm}, 30 \mathrm{~cm}, 61 \mathrm{~cm}$, and 91 $\mathrm{cm}$. The pile is modeled in computer program OPENSEES (McKenna and Fenves, 2001) using fiber section and nonlinear beam-column elements.

Figures 11.1 and 11.2 compare the ductility of prestressed concrete piles with a dowel connection due to the formation of a hinge in the pile from nonlinear finite element analysis (NLFEA) and from Equation (9.33). Note that a value of $\rho=0.05$ has been used for both design levels. These results show that Equation (9.33) provides results for Level 1 design that are almost identical to those from the NLFEA (Figure 10.1). For Level 2 design, Equation (9.33) provides results that are almost identical to those from the NLFEA for longer piles but provide a lower bound for very short piles (Figure 11.2).

Figures 11.3 and 11.4 compare the ductility of prestressed concrete piles with a dowel connection due to the formation of a hinge in the connection from nonlinear finite element analysis (NLFEA) and from Equation (9.29). These results show that Equation (9.29) provides results that are almost identical to those from the NLFEA.
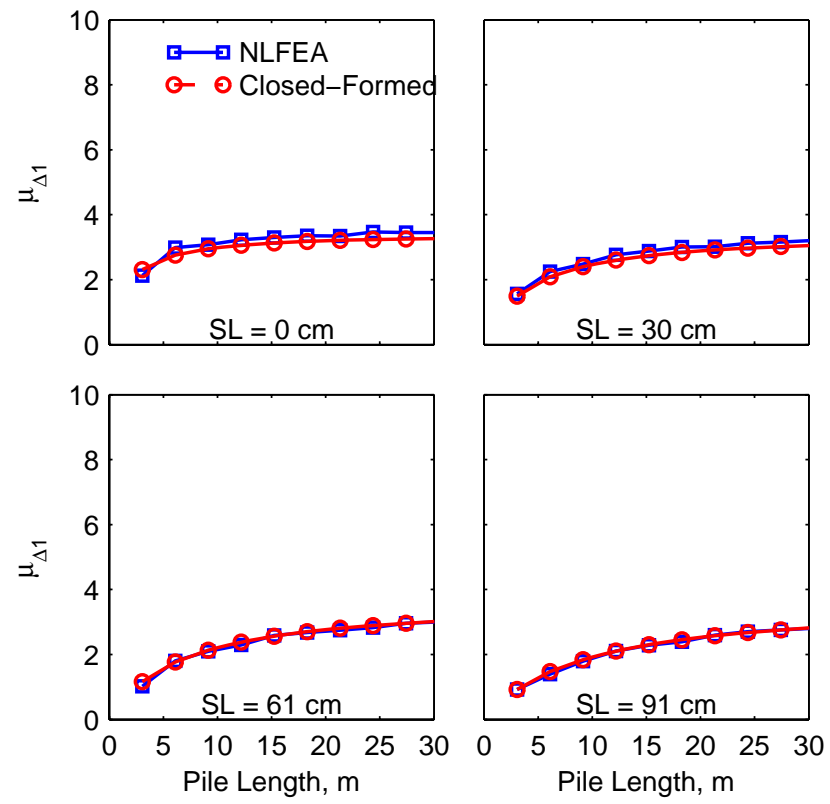

Figure 11.1. Comparison of displacement ductility of prestressed concrete piles with dowel connections due to the formation of a hinge in the piles from nonlinear finite element analysis (NLFEA) and from Equation (9.33). Results are for design Level 1 earthquake. SL = de-bond length. 

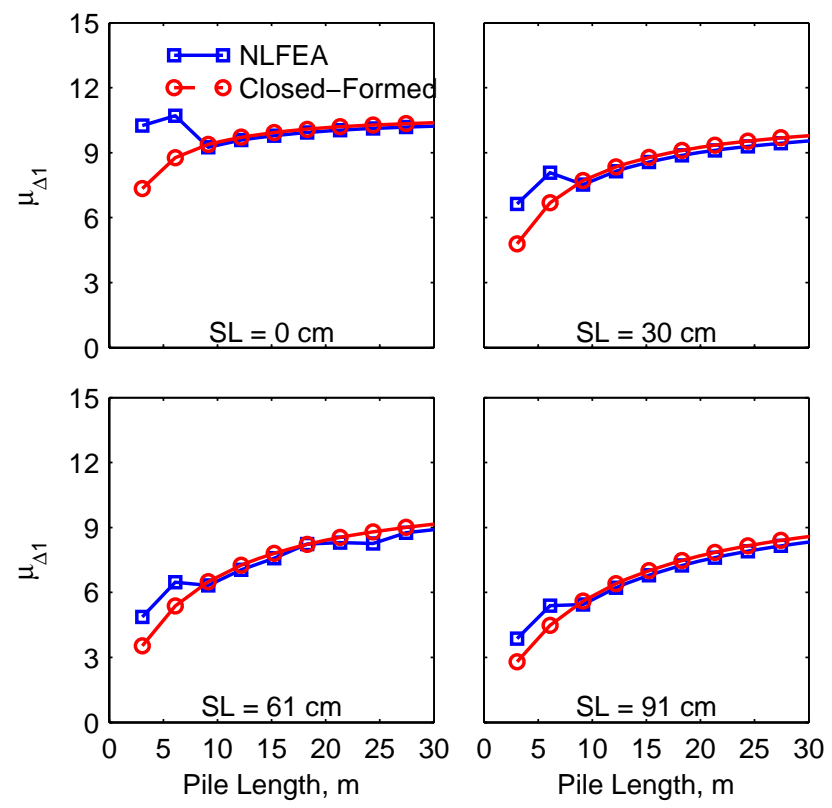

Figure 11.2. Comparison of displacement ductility of prestressed concrete piles with dowel connections due to the formation of a hinge in the piles from nonlinear finite element analysis (NLFEA) and from Equation (9.33): results are for design Level 2 earthquake. SL = de-bond length.
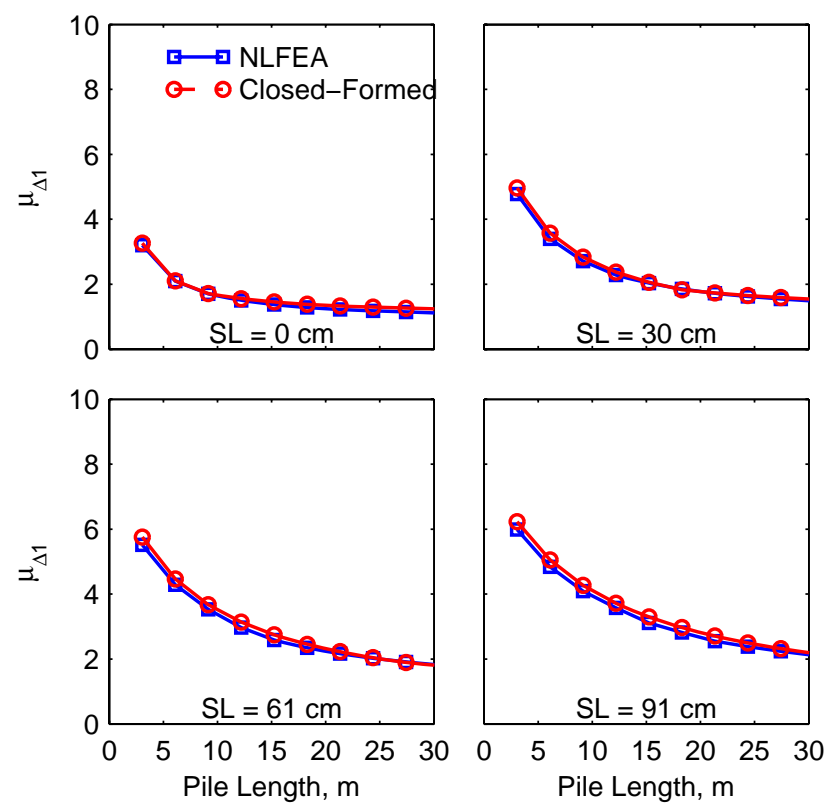

Figure 11.3. Comparison of displacement ductility of prestressed concrete piles with dowel connections due to the formation of a hinge in the connection from nonlinear finite element analysis (NLFEA) and from Equation (9.33). Results are for a design Level 1 earthquake. SL = de-bond length. 

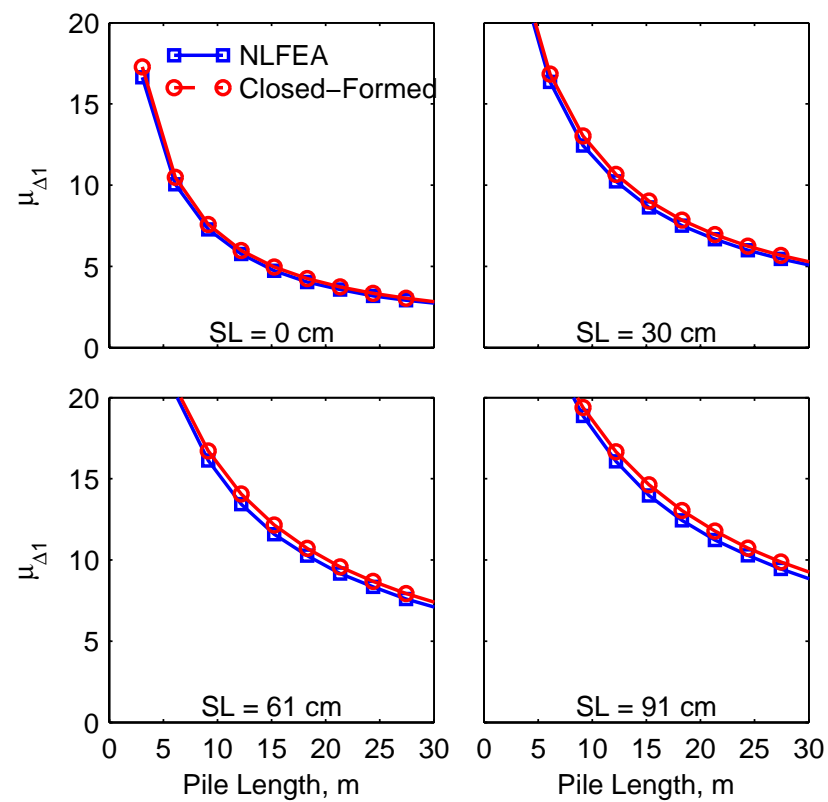

Figure 11.4. Comparison of displacement ductility of prestressed concrete piles with dowel connections due to the formation of a hinge in the connection from nonlinear finite element analysis (NLFEA) and from Equation (9.33). Results are for a design Level 2 earthquake. SL = de-bond length.

Figures 11.5 and 11.6 compare the displacement ductility capacity of prestressed concrete piles with dowel connections, defined as lower of the ductility due to the formation of a hinge in the pile or the formation of a hinge in the connection, from nonlinear finite element analysis (NLFEA) and Equation (9.33). These results show that the formulas developed in this investigation provide results that match well with those from the NLFEA. 

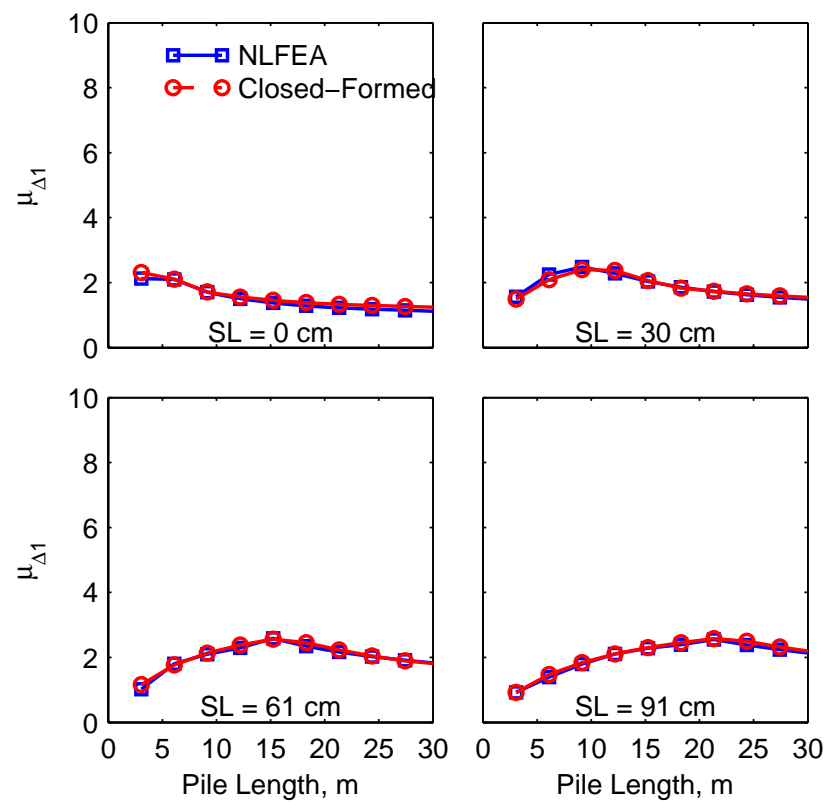

Figure 11.5. Comparison of displacement ductility capacity of prestressed concrete piles with dowel connections, defined as the lower of the ductility due to the formation of a hinge in the pile or the formation of a hinge in the connection, from nonlinear finite element analysis (NLFEA) and from Equation (9.33). Results are for a design Level 1 earthquake. SL = de-bond length.
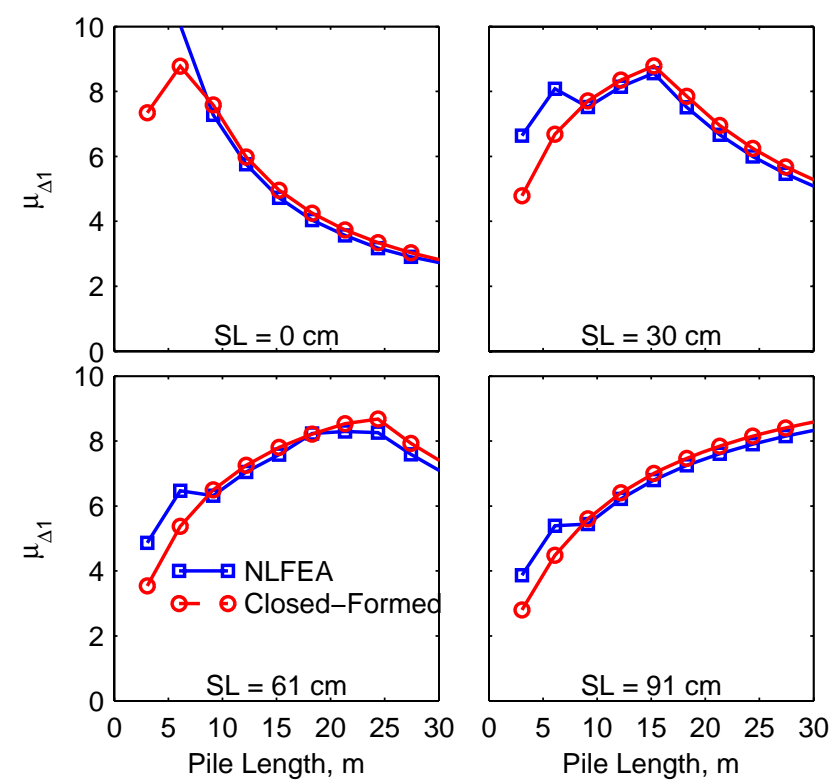

Figure 11.6. Comparison of displacement ductility capacity of prestressed concrete piles with dowel connections, defined as the lower of the ductility due to the formation of a hinge in the pile or the formation of a hinge in the connection, from nonlinear finite element analysis (NLFEA) and from Equation (9.33). Results are for a design Level 2 earthquake. SL= de-bond length. 


\section{RECOMMENDATIONS}

The following simplified procedures are recommended for estimating seismic displacement demand and capacity of pile in Marine Oil and LNG Terminals. The seismic displacement capacity recommended here is consistent with the strain limits specified in the MOTEMS.

\subsection{DISPLACEMENT DEMAND}

\subsubsection{Regular Structures}

It is recommended that the seismic displacement demand in a regular structure (MOTEMS 2007) be estimated from the following procedure that was recently proposed in the ASCE/SEI 41-06 standard:

$$
\Delta_{d}=C_{1} C_{2} S_{A} \frac{T^{2}}{4 \pi^{2}}
$$

in which $S_{A}$ is the spectral acceleration of the linear-elastic system at vibration period, $T$. The coefficient $C_{1}$ is given by

$$
C_{1}=\left\{\begin{array}{lr}
1.0 ; & T>1.0 \mathrm{~s} \\
1.0+\frac{R-1}{a T^{2}} ; & 0.2 \mathrm{~s}<T \leq 1.0 \mathrm{~s} \\
1.0+\frac{R-1}{0.04 a} ; & T \leq 0.2 \mathrm{~s}
\end{array}\right.
$$

in which $a$ is a site dependent constant equal to 130 for Site Class A and B, 90 for Site Class C, and 60 for Site Class D, E, and F (definition of Site Class is available in ASCE/SEI 41-06 standard), and $R$ is the ratio of the elastic and yield strength of the system and is defined as

$$
R=\frac{S_{A}}{g} \frac{W}{V_{y}}
$$

where $W$ is the seismic weight of the system, $V_{y}$ is the yield force (or base shear) of the system, and $g$ is the acceleration due to gravity. The coefficient $\mathrm{C}_{2}$ is given by 


$$
C_{2}= \begin{cases}1.0 ; & T>0.7 \mathrm{~s} \\ 1+\frac{1}{800}\left(\frac{R-1}{T}\right)^{2} ; & T \leq 0.7 \mathrm{~s}\end{cases}
$$

The estimation of displacement demand should be restricted to systems with

$$
R \leq \frac{\bar{\Delta}_{d}}{\Delta_{y}}+\frac{\left|\alpha_{e}\right|^{-t}}{4}
$$

in which $\bar{\Delta}_{d}$ is the smaller of the computed displacement demand, $\Delta_{d}$, or the displacement corresponding to the maximum strength in the pushover curve, $\Delta_{y}$ is the yield displacement of the idealized bilinear force-deformation curve, $t=1+0.15 \ln (T)$, and $\alpha_{e}$ is the effective postelastic stiffness ratio computed from

$$
\alpha_{e}=\alpha_{P-\Delta}+\lambda\left(\alpha_{2}-\alpha_{P-\Delta}\right)
$$

where $\lambda$ is a near-field effect factor equal to 0.8 for sites that are subjected to near-field effects and 0.2 for sites that are not subjected to near field effects. The near field effects may be considered to exist if the 1 second spectral value, $S_{1}$, at the site for the maximum considered earthquake is equal to or exceeds $0.6 \mathrm{~g}$. The P-Delta stiffness ratio, $\alpha_{P-\Delta}$, and the maximum negative post-elastic stiffness ratio, $\alpha_{2}$, are estimated from the idealized force-deformation curve.

\subsubsection{Irregular Structures}

The following modal pushover analysis (MPA) procedure is recommended to estimate displacement demands in irregular Marine Oil and LNG Terminal structures (MOTEMS 2007):

1. Compute the natural frequencies, $\omega_{n}$ and modes, $\phi_{n}$, for linearly elastic vibration of the irregular Marine Oil and LNG Terminal structure.

2. Select a reference point where the displacement, $u_{r n}$, is to be monitored in the selected direction of analysis during the pushover analysis. Ideally, this reference point should be the location on the structure with largest value of $\phi_{r n}$ in the selected direction of analysis. 
3. For the nth-mode, develop the pushover curve, $V_{b n}-u_{r n}$, for the nth modal force distribution, $s_{n}^{*}=\mathbf{M} \phi_{n}$, where $\mathbf{M}$ is the mass matrix of the structure, and $\phi_{n}$ is the nth mode shape. The base shear $V_{b n}$ should be monitored in the same direction as the direction of the selected reference point displacement $u_{r n}$.

4. Convert the $V_{b n}-u_{r n}$ pushover curve to the force-displacement, $F_{s n} / L_{n}-D_{n}$, relation for the nth -"mode" inelastic SDF system by utilizing $F_{s n} / L_{n}=V_{b n} / M_{n}^{*}$ and $D_{n}=u_{r n} / \Gamma_{n} \phi_{r n}$ in which $\phi_{r n}$ is the value of $\phi_{n}$ at the reference point in the direction under consideration, $M_{n}^{*}=\left(\phi_{n}^{T} \mathbf{M} \mathbf{\imath}\right)^{2} / \phi_{n}^{T} \mathbf{M} \phi_{n}$ is the effective modal mass, and $\Gamma_{n}=\phi_{n}^{T} \mathbf{M} \mathbf{l} / \phi_{n}^{T} \mathbf{M} \phi_{n}$ with $\mathbf{\imath}$ equal to the influence vector. The influence vector $\mathbf{l}$ is a vector of size equal to the total number of degrees of freedom. For analysis in the X-direction, the components of $\mathbf{l}$ corresponding to $\mathrm{X}$ degree-of-freedom are equal to one and remaining components equal to zero. Similarly the components of $\mathbf{l}$ corresponding to y-degree-of-freedom are equal to one and remaining components equal to zero for analysis in the y-direction.

5. Idealize the force-displacement, $F_{s n} / L_{n}-D_{n}$, curve as a bilinear curve and compute the yield value $F_{\text {sny }} / L_{n}$.

6. Compute the yield strength reduction factor, $R=S_{A} /\left(F_{\text {sny }} / L_{n}\right)$.

7. Compute the peak deformation $D_{n}=\Delta_{d}$ of the nth-"mode" inelastic SDF system defined by the force-deformation relation developed in Step 4 and damping ratio $\zeta_{n}$, from Equation (1). The elastic vibration period of the system is based on the effective slope of the $F_{s n} / L_{n}-D_{n}$ curve, which for a bilinear curve is given by $T_{n}=2 \pi\left(L_{n} D_{n y} / F_{s n y}\right)^{1 / 2}$.

8. Calculate peak reference point displacement $u_{r n}$ associated with the nth-"mode" inelastic SDF system from $u_{r n}=\Gamma_{n} \phi_{r n} D_{n}$.

9. Push the structure to the reference point displacement equal to $u_{r n}$ and note the values of desired displacement $\delta_{\text {no }}$. 
10. Repeat Steps 3 to 9 for all significant modes identified.

11. Combine the peak modal displacement, $\delta_{\text {no }}$, by an appropriate modal combination rule, e.g., CQC, to obtain the peak dynamic response, $\Delta_{o}$.

\subsection{DISPLACEMENT CAPACITY}

It is recommended that the displacement capacity of piles in Marine Oil and LNG Terminals be estimated from

$$
\Delta_{c}=\mu_{\Delta} \Delta_{y}
$$

where $\Delta_{y}$ is the yield displacement of the pile and $\mu_{\Delta}$ is the displacement ductility capacity of the pile.

The procedure to estimate the displacement capacity is intended to be a simplified procedure for either initial design of piles or for checking results from more complex nonlinear finite element analysis. The recommendations presented here are limited to: (1) piles with long freestanding heights (length/diameter $>20$ ) above the mud line; (2) piles with transverse volumetric ratio greater than $0.5 \%$; and (3) piles in which the displacement demand has been estimated utilizing equivalent-fixity approximation. Results from this investigation should be used with caution for parameters or cases outside of those described above.

\subsubsection{Piles with Full-Moment- or Pin-Connection to the Deck Slab}

The recommended values of displacement ductility capacity of piles with full-momentconnection or pin-connection to the deck slab are

\begin{tabular}{|c|c|c|c|}
\hline $\begin{array}{c}\text { Design Earthquake } \\
\text { Level }\end{array}$ & Hinge Location & $\begin{array}{c}\text { Reinforced- } \\
\text { Concrete Piles }\end{array}$ & $\begin{array}{c}\text { Hollow-Steel } \\
\text { Piles }\end{array}$ \\
\hline \multirow{2}{*}{ Level 1 } & In-Ground & 1.75 & 1.2 \\
\cline { 2 - 4 } & Pile-Deck & 1.75 & 1.2 \\
\hline \multirow{2}{*}{ Level 2 } & In-Ground & 2.5 & 2.75 \\
\cline { 2 - 4 } & Pile-Deck & 5.0 & 2.75 \\
\hline
\end{tabular}


The yield displacement of the pile may be estimated either from idealized pushover curve developed from the nonlinear static pushover analysis or may be estimated from

$$
\Delta_{y}=\left\{\begin{array}{l}
\frac{M_{y} L^{2}}{6 E I_{e}} \text { for full-moment-connection } \\
\frac{M_{y} L^{2}}{3 E I_{e}} \text { for pin-connection }
\end{array}\right.
$$

in which $M_{y}$ is the section yield moment and $E I_{e}$ is the effective value of $E I$. Note that $M_{y}$ is not the section moment at first-yield but the effective yield moment estimated from bilinear idealization of the moment-curvature relationship.

\subsubsection{Piles with Dowel-Connection to the Deck Slab}

The following procedure is recommended for estimating displacement ductility capacity of piles with dowel-connection, such as hollow-steel piles or prestressed concrete piles connected to the deck slab with dowels:

1. Establish the axial load, $P$, on the pile.

2. Estimate the pile length based on equivalent-fixity assumption.

3. Select an appropriate design level - Level 1 or Level 2 - and establish various strain limits for the selected design level.

4. Develop the moment-rotation relationship of the dowel-connection using the procedure described in Chapter 8 of this report.

5. Determine rotational stiffness, $k_{\theta}$, yield moment, $M_{y, \mathrm{C}}$, and yield rotation, $\theta_{y, \mathrm{C}}$ of the dowel-connection from the moment-rotation relationship developed in Step 4.

6. Establish the rotation of the dowel-connection, $\theta_{L}$, and corresponding ductility, $\mu_{\theta}=\theta_{L} / \theta_{y, \mathrm{C}}$, when strain in the outer-most dowel of the connection reaches the strain limit established in Step 3 for the selected design level.

7. Conduct the moment-curvature analysis of the pile section with appropriate axial load and idealize the moment-curvature relationship by a bi-linear curve. 
8. Compute the effective, $E I_{e}$, and effective yield moment, $M_{\mathrm{y}, \mathrm{P}}$, from the pile momentcurvature relationship. Note that $E I_{e}$ is equal to initial elastic slope and $M_{\mathrm{y}, \mathrm{P}}$ is the yield value of the moment of the idealized bi-linear moment-curvature relationship. For steel piles, $E I_{e}$ may be computed from section properties and material modulus, and $M_{\mathrm{y}, \mathrm{P}}$ may be approximated as $M_{\mathrm{y}, \mathrm{P}} \simeq f_{y}\left(d_{o}^{3}-d_{i}^{3}\right) / 6$.

9. Estimate the yield curvature, $\phi_{y, \mathrm{P}}=M_{y, \mathrm{P}} / \mathrm{EI}_{\mathrm{e}}$.

10. Establish the curvature of the steel pile, $\phi_{L}$, and corresponding curvature ductility, $\mu_{\phi}=\phi_{L} / \phi_{y, \mathrm{P}}$, when material strain in the pile section reaches the strain limit established in Step 3 for the selected design level.

11. Select the value of $\rho$ which defines the length of the plastic hinge as a fraction of the "effective" length of the pile. The recommended value for hollow-steel piles with dowelconnection is $\rho=0.03$ for Level 1 design and $\rho=0.075$ for Level 2; and for prestressed concrete pile with dowel-connection for both design levels is $\rho=0.05$.

12. Compute the dimensionless parameters: $\eta=M_{y, \mathrm{P}} / M_{y, \mathrm{C}}$, and $\beta=E I_{e} / k_{\theta} L$.

13. Compute the normalized value of the plastic hinge length: $L_{P}^{*}=(\rho \eta) /(1+\eta)$.

14. Compute the yield displacement which corresponds to first effective yielding in the connection as: $\Delta_{y, \mathrm{C}}=\theta_{y, \mathrm{C}} L(1+4 \beta) / 6 \beta$

15. Compute the displacement ductility for yielding in the connection as $\mu_{\Delta}=\left(1+4 \beta \mu_{\theta}\right) /(1+4 \beta)$ if $\mu_{\theta}$ computed in Step 6 is less than or equal to $(\eta-1) / 2 \beta$ otherwise $\mu_{\Delta}=\left(2-\eta+6 \beta \mu_{\theta}\right) /(1+4 \beta)$.

16. Compute displacement ductility for yielding in the pile as $\mu_{\Delta}=(2 \eta-1) /(1+4 \beta)+\left(6 \eta L_{p}^{*}\right)\left(1-L_{p}^{*} / 2\right)\left(\mu_{\phi}-1\right) /(1+4 \beta)$

17. Establish the displacement ductility capacity as lower of the values computed in Steps 15 and 16. 
18. Compute the displacement capacity of the pile as product of the yield displacement computed in Step14 and the displacement ductility capacity computed in Step 17.

\subsection{RECOMMENDATIONS FOR FUTURE WORK}

The recommendations developed in this report are based on analytical simulations of piles fixed at the base at a depth equal to depth-of-fixity below the mud line. In order to develop further confidence in these results, the following recommendations are provided for future work:

1. Verify the displacement ductility values for various seismic design levels from laboratory experiments conducted at displacement values appropriate for these design levels.

2. Verify the recommended values of plastic hinge lengths for various seismic design levels from laboratory experiments conducted at displacement values appropriate for these design levels.

3. Compare displacement capacity estimated from equivalent fixity model with those estimated from analysis of pile-soil system.

4. The validity of using the same plastic hinge length for all seismic design levels in the concentrated plasticity model of hollow steel piles and possibly for reinforced-concrete piles should be verified. 


\section{REFERENCES}

ASCE (2000). Pre-standard and commentary for the seismic rehabilitation of buildings. FEMA356, Federal Emergency Management Agency, Washington, D.C.

ASCE (2005). Minimum design loads for buildings and other structures, ASCE Standard ASCE/SEI 7-05, American Society of Civil Engineers, Reston, VA.

ASCE (2007). Seismic rehabilitation and evaluation of existing buildings: 2-Book Set, ASCE Standard No. ASCE/SEI 41-06 and ASCE Standard No. ASCE/SEI 31-03, American Society of Civil Engineers, Reston, VA.

ATC (2005). Improvement of nonlinear static seismic analysis procedures. FEMA-440, Federal Emergency Management Agency, Washington, D.C.

BSSC (2003). NEHRP recommended provisions for seismic regulations for new buildings and other structures. FEMA-450, Federal Emergency Management Agency, Washington, D.C.

Budek, A.M., Priestley, M.J.N., and Benzoni, G. (2000). "Inelastic seismic response of bridge drilled-shaft RC pile/columns," Journal of Structural Engineering, 126(4):510-517.

Chai, Y.H. (2002). "Flexural strength and ductility of extended pile-shafts. I: Analytical model," Journal of Structural Engineering, 128(5):586-594.

Chai, Y.H. and Hutchinson, T.C. (2002). "Flexural strength and ductility of extended pile-shafts. II: Experimental study," Journal of Structural Engineering, 128(5):595-602.

Chopra, A.K., and Goel, R.K. (2004). "A modal pushover analysis procedure to estimate seismic demands for unsymmetric-plan buildings," Earthquake Engineering and Structural Dynamics, 33:903-927.

Chopra, A.K. and Chintanapakdee, C. (2004). "Inelastic deformation ratios for design and evaluation of structures: Single-degree-of-freedom bilinear systems." Journal of Structural Engineering, 130(9), 1309-1319.

Department of Defense (2005). Uniform Facilities Criteria - Design: Piers and Wharves, Report No. UFC 4-152-01, July 28.

Eskijian, M. (2007). "Marine Oil Terminal Engineering and Maintenance Standards (MOTEMS)," Proceedings of 2007 Structures Congress, ASCE, Long Beach, CA. 
Ferrito, L. (1997). Design criteria for earthquake hazard mitigation of Navy piers and wharves, Technical Report No. TR-2069-SHR, Naval Facilities Engineering Service Center, Shore Facilities Department, Structures Division, Port Hueneme, CA.

Ferritto, J., Dickenson, S., Priestley, N., Werner, S. and Taylor, C. (1999). Seismic criteria for California marine oil terminals, Technical Report No. TR-2103-SHR, Naval Facilities Engineering Service Center, Shore Facilities Department, Structures Division, Port Hueneme, CA.

Klusmeyer, L. and Harn, R. (2004). "Displacement-based seismic design of large naval pier." Proceedings of PORTS 2004, Houston, TX, May 23-26.

Mander, J.B., Priestly, M.J.N., and Park, R. (1988). "Theoretical stress-strain model for confined concrete.” Journal of Structural Division, ASCE, 114(8) 1804-1826.

McKenna, F. and Fenves, G. (2001). The OpenSees Command Language Manual: version 1.2, Pacific Earthquake Engineering Center, University of California, Berkeley. $<\underline{\text { http://opensees.berkeley.edu }>}$

MOTEMS (2007). Marine Oil Terminal Engineering and Maintenance Standards (informal name), 2007 Title 24, California Code of Regulations, Part 2, California Building Code, Chapter 31F (Marine Oil Terminals), Published by the International Code Council, Washington, D.C.

Nassar, A.A., and Krawinkler, H. (1991). Seismic demands for SDOF and MDOF systems. Report No. 95, John A. Blume Earthquake Engineering Center, Stanford University, Stanford, CA.

Nezamian, A., Al-Mahaidi, R., and Grundy, P. (2006). "Bond strength of concrete plugs embedded in tubular steel piles under cyclic loading." Canadian Journal of Civil Engineering, 33(2):111-125.

Park, R.J.T., Priestly, M.J.N., and Berrill, J.B. (1987). Seismic performance of steel-encased concrete piles. Report No. 87-5, Department of Civil Engineering, University of Canterbury, N.Z.

Priestley, M.J.N. and Park, R. (1984). Strength and ductility of bridge substructures. Report No. 84-20, Department of Civil Engineering, University of Canterbury, N.Z. 
Priestley, M.J.N, Seible, F. and Calvi, G.M. (1996). Seismic Design and Retrofit of Bridges. John Wiley and Sons, Inc. New York.

Raynor, D.J., Lehman, D.E., and Stanton, J.F. (2002). "Bond-slip response of reinforcing bars grouted in ducts." Structural Journal, ACI, 99(5):568-576.

Roeder, C.W., Graff, R., Sonderstrom, J., and Yoo, J.H. (2005). "Seismic performance of pilewharf connections." Journal of Structural Engineering, 131(3):428-437.

Ruiz-Garcia, J, and Miranda, E. (2003). "Inelastic deformation response of SDOF systems subjected to earthquakes." Earthquake Engineering and Structural Dynamics, 32(8), 1237-1258.

Song, S.T., Chai, Y.H., and Hale, T.H. (2004). "Limit state analysis of fixed-head concrete piles under lateral loads." Proceedings of $13^{\text {th }}$ World Conference on Earthquake Engineering, Vancouver, B.C., Canada, August 1-6, Paper No. 971.

Wray, M., Harn, R., and Jacob, J. (2007). "Port of Everett rail/barge transfer facility seismic design Everett, Washington.” Proceedings of PORTS 2007, San Diego, CA, March 25-28. 